\title{
XIII.
}

Aus der Königl. psychiatrischen und Nervenklinik der Universität Halle a. S. (Prof. Dr. Hitzig).

\section{Ueber Exhibitionismus.}

\author{
Von \\ Dr. W. Seiffer, \\ Assistenzarzt der Klinik.
}

\section{Einleitung.}

Die Frage: "Geistesstörung oder Verbrechen?" ist eine der wichtigsten und zugleich schwierigsten Aufgaben, welche die Psychiatrie zu lösen bat. Obwohl noch nicht alt, hat sie doch bereits eine sehr umfangreiche Literatur hervorgerufen. Aber wie fast überall, so trifft es auch hier zu, dass die Menge der auf irgend einem wissensehaftlichen Gebiet gelieferten Producte in umgekehrtem Verhältniss steht zur Klarheit und wissenschaftlichen Sicherheit des betreffenden Gebiets. Man hat bedeutende Fortschritte gemacht, die Frage hat sich präciser gestaltet, aber sie ist noch nicht gelöst. Weit entfernt davon, einen Schlüssel zur Beantwortung obiger Frage gefunden zu haben, musste man vielmehr in fortschreitender Erkenntniss die Wahrnehmung machen, dass ihrer Beantwortung vorläufig in vielen Fällen fast unäberwíndliche Schwierigkeiten entgegenstehen.

Von den den Psychiater interessirenden Verbrechensarten haben die Sittlichkeitsverbrechen wohl am meisten an Zahl zugenommen und unter ihnen sind es besonders die in den Strafgesetzbuchsparagraphen von der Unzucht ( $\$ 175$ ), der Nothzucht ( $\$ 176$ und 177) und dem öffentlichen Aergerniss ( $\$ 183$ ) näher bezeichneten strafbaren Handlungen, welche am häufigsten den Gegenstand forensisch-psychiatrischer Expertise bilden.

Auch auf diesem Gebiete leiden wir keinen Mangel an wissenschaftlichen Arbeiten, die Schriften v. Krafft-Ebing's hauptsächlich haben 
in ärztlichen, juristischen und sogar Laienkreisen eine starke Produetivität angeregt. Am meisten Staub hat bekanntlich die „conträre Sexualempfindung" aufgewirbelt, welche nach dem Str.-G.-B. in den Unzuchtsverhrechen zwischen Personen männlichen Geschlechts ( $\$ 175$ ) zum Ausdruck kommt. Weniger ist dies der Fall bei einer Erscheinungsform jener öfentlich ein Aergerniss erregenden Sittlichkeitsdelicte $(\S 183$ des Str.-G.-B.), mit welcher sich die nachfolgenden Zeilen beschäftigen werden, dem sogenannten "Exhibitionismus".

Trotz unseres Reichthums an Arbeiten über sexuelle Perversitäten und Sittlichkeitsverbrechen ist man auch hier über manche Fragen innerhalb der Wissenschaft selbst noch lange nicht einig. Die Affaire Menesclou in Paris, in der drei Autoritäten wie Brouardel, Las ègue und Motet zu ganz falschen Schlüssen gelangten, zeigt ein bekannter gerrordenes und bedauerliches Beispiel hiervon ${ }^{1}$ ). Wir brauchten indessen örtlich und zeitlich nicht soweit auszuholen, um weitere Beispiele zu finden. Es muss aber auch hervorgehoben werden, dass in sehr vielen Fallen die Frage, ob Krankheit oder Laster, nicht vor dem Forum des Arztes, sondern vor demjenigen des Richters entschieden wird. So kann es dann nicht ausbleiben, dass z. B. nach einer Berechnung ron Monod²) in Frankreich allein ca. 140 Geisteskranke pro Jahr verurtheilt werden, wovon einen erheb]ichen Theil unter Anderen diejenigen mit sexuellen Delicten ausmachen.

Der Exhibitionismus ist nun eine jener straf baren unsittlichen Handlungen, welche einer richtigen practischen Beurtheilung sehr häufig ganz erhebliche Schwierigkeiten entgegensetzen; es dürfte sich daher verIohnen, eine Anzahl weiterer Beobachtungen mitzutheilen und bei dieser Gelegenheit einmal Rückschau und Umschau zu halten, um festzustellen, was bisher darüber bekannt geworden ist. Daraus werden sich dann vielleicht nicht unwichtige Schlüsse und Verhaltungsmaassregeln für die Zukunft ergeben.

Von Exhibitionismus als einer besonderen Form der abnormen Geschlechtsbethätigung spricht man erst seit 20 Jahren, nachdem La sè gue im Jahre 1877 in der "Union médicale" eine Anzahl von Fällen mitgetheilt hatte, in denen Personen mämnlichen Geschlechts (L. kennt nur einen Fall von F. beim Weibe) vor Kindern, Mädchen oder Frauen ihre Genitalien schamlos und öffentlich entblösst hatten; er gab ihnen den Namen "Exhibitionistes" und beschrieb es als wissenschaftliche

1) Annales d'hygiène publ. 1880.

2) Lemesle, Les irrćsponsables devant la loi. Paris 1896. (Citirt nach der Allg. Zeitschr. f. Psych.) 
Merkmale, dass die Exhibition auf eine gewisse Entfernung, wiederholt, am selben Ort und gewöhnlich auch zur selben Zeit stattfinde, und zwar ohne andere unzüchtige Janipulationen und ohne jeglichen Versuch, mit dem ausgesuchten weiblichen Object in intimere Beziehungen zu treten; ausser dieser monotonen Geschlechtsmanifestation seien dem hetreffenden Individuum keinerlei Vorwürfe in sexueller Hinsicht zu machen. Der echte Exhibitionist rerschliesst sich nach vollbrachter That schamhaft in den Ausdruck des Bedauerns, der Reue und Gewissensbisse; jede Antwort scheint ihm (nach Lasègue) compromittirend, je weniger er ron seinen innersten Gefühlen Rechenschaft ablegt, desto mehr glaubt man nach seiner Ansicht an eine entschuldbare, unbewusste Triebhandlung. Diese Handlungen tragen den Stempel des Pathologischen: „leur instantanéité, leur périodicité, leur non-sens reconnu par le malade, l'absence d'antécédents génésiques, l'indifférence aux conséquences qui en résulteront, la limitation de l'appétit à une exhibition qui n'est jamais le point de départ de lubriques aventures, toutes ces donnécs imposent la croyance à la maladie". In der That waren die Delinquenten Lasègue's zumeist Demente vorwiegend seniler oder paralytischer Art.

Es unterliegt keinem Zweifel, dass diese Perversität des Geschlechtstriebs lange vor Lasègue unzäblige Hale zur Beobachtung gekommen ist (z. B. Sander, Arndt, Westphal, Tardieu, Devergie), nur dass die betreffenden Fälle eben nicht als eine besondere Species und unter einem besonderen Namen zusammengefasst wurden, wie er es in verdienstvoller Weise gethan hat.

Im Laufe der nächsten Jahre folgten den Lasègue'schen neue casuistische Mittheilungen, aus denen besonders die Arbeit von La a gier1) hervorzuheben ist, welcher darauf aufmerksam machte, dass gewisse Exhibitionen bei Leuten mit verschiedenen Genitalaffectionen oder chronischen Erkrankungen der Urinwege und des Mastdarms vorkommen. Es sind dies z. B. Greise mit Prostatahypertrophie oder Urethralstenose, welche an irgend einem abgelegenen Ort obscöne Bewegungen oder längere Exhibitionen vornehmen, und zwar infolge körperlicher Beschwerden, wie z. B. des verlangsamten Urinabgangs. Man glaubte so für viele Fälle einer an sich so umbegreiflichen Handlung wie der Exhibition eine natürliche, körperliche Ursache gefunden zu haben. Indessen sind derartige Beobachtungen in der Folgezeit, soweit ich sehe, nicht wieder hervorgetreten, nur Pelanda ${ }^{1}$ ) wollte neuerdings einen

1) Laugier, Annales d'hygiène publique. 1878. No. 106. 
Zusammenhang zwischen Hernien und sexuellen Perversitäten, darunter auch Exhibitionismus, bemerkt haben.

Während man in der ersten Zeit nach der Lasègue'schen Veröfentlichang mit diesem den Begriff des Exhibitionismus sehr eng: fasste und darin offenbar eine Art von Monomanie erblickte, zeigte es sich bald, dass diese Auffassung unrichtig und die Grenze zu eng gezogen war. Nach der alten ursprünglichen Schilderung gehörte es zum Wesen der Exhibition, dass der Demonstrant die deutliche Absicht hatte, von weiblichen Personen gesehen zu werden, dass er also, wenigstens bis zu einem gewissen Grade, bewusst handelte und bei relativ klarem Geiste einem mächtigen Triebe folgte, den er nicht zu überwinden im Stande war. Ausserdem sollte der Exhibitionismus nach L. „un scandale privé plutôt qu'un outrage public" sein. Man sah nun aber Epileptiker und Schwachsinnige jeder Form, welche ohne Rücksicht auf Zeit, Ort und Umgebung, ohne Zweck und ohne Bewusstsein dieselben ungenirten Handlungen begingen wie die "Exhibitionnistes." v. KrafftEbing ging daher einen bedeutsamen Schritt weiter, indem er jede Handlung als Exhibitionismus bezeichnete, welche in schamloser, öffentlicher Entblössung der Genitalien bestand; er unterschied zugleich einen Exhibitionismus durch krankhafte Antriebe, einen solchen bei Epilepsie und den durch angeborene oder erworbene geistige Schwächezustände (Idiotie, Imbecillität, progr. Paralyse, senile Demenz) bedingten Exhibitionismus.

Einen weiteren Fortschritt machte die Kenntniss dieser sexuellen. Perversität durch die werthvollen und interessanten Forschungen Magnan's über das degenerative Irresein.

Er fand, dass die hereditär Entarteten hinsichtlich ihres Geschlechtslebens die verschiedensten Perversitäten darbieten und dass gerade auch die bei ihnen immer wiederkehrenden Exhibitionen eine besondere Aeusserungsweise, ein "syndrome épisodique," ihres krankhaften Zustandes sein können. Nach seiner Darstellung darf aber der Exhibitionismus nur dann als ein psychisches Stigma in diesem Sinne verwerthet werden, wenn audere Zeichen der hereditären Degeneration sicher vorhanden sind und wenn die Handlung den typischen Verlauf eines Entartungs,zufalls" zeigt; dazu gehört bekanntlich eine unwiderstehliche Zwangsvorstellung oder eine impulsive Nöthigung, lebhafte Angst und Unruhe vor der That, Erleichterung und Beruhigung nach

1) Pelanda, Ernie ed anomalie sessuali. Arch. di psicopatie sess. 1896. No. 6. (Ref. Neurol. Centralbl.) 
derselben, sowie Nichtaufhebung des Bewusstseins. Der perverse Geschlechtstrieb drängt anfallsweise und unwiderstehlich zur Befriedigung, indem er sich von dem mässigenden Einfluss der höheren Centren emancipirt. Diese Classe würde somit dem Lasègue'schen Typus sehr nahe kommen.

Wie schon angedentet, war man also sehr bald zu der Ueberzeugung gekommen, dass bei der Beurtheilung des Exhibitionismus die Handlung selbst als ein blosses Symptom zurücktreten muss, während die Quelle, aus der sie entspringt, die Hauptsache ist. So beschrieb Pribat speciell den Exhibitionismus der Epileptiker in einer Pariser These vom Jahre 1894, in der er 8 Fälle aus der Literatur mit 1 eigenen zusammengestellt hat. Die Zahl dieser Quellen nahm aber mit weiteren Beobachtungen noch zu. v. Krafft-Ebing fügte in den späteren Auflagen seiner "Psychopathia sexualis" zu den bisher genannten Gruppen der Exhibitionisten diejenige der Neurastheniker hinzu; sie stehen nach ihm der epileptischen Gruppe sehr nahe, sie haben anfallsweise auftretende Dämmerzustände mit ängstlicher Beklemmung, in denen irgend ein sexueller Drang ganz impulsiv zu exhibitionistischen Acten führen kann. Hier möge auch v. Krafft-Ebing's Aufstellung eines ideellen Exhibitionismus erwähnt sein, welcher in der Production von schmutzigen Bildern, in der Besudelung von öffentlichen Bedürfnissanstalten u. dgl. zum Ausdruck kommen soll. Wir werden im Folgenden nicht weiter darauf zurückkommen.

Eine andere Gruppe, von Lalanne besonders hervorgehoben, sind die auf Grund von Hallucinationen und Wahnvorstellungen oder in Folge sexueller Erregung exhibitionirenden Geisteskranken, Manische: Verrückte, Alkoholiker, welche er als "Délirants" zusammenfasst. Weiterhin dehnte Lalanne den Begriff des Exhibitionismus auch auf die Blossstellung der Glutaealgegend und beim Weibe der Brüste aus; auch diese Art kommt bei Kranken vor. Er sagt: für denjenigen, der eine solche Handlung sehe, sei das Resultat dasselbe, ob dieser oder jener obscöne Körpertheil exhibirt werde, ob es ein Epileptiker oder ein Paralytiker mache; man müsse daher nach seiner Ansicht bei der Classification nicht nur subjective sondern auch objective Gesichtspunkte in's Auge fassen und er schlägt dementsprechend eine Eintheilung in folgende drei Gruppen vor:

1. Exhibitionnistes antérieurs (des organes génitaux),

2. Exhibitionnistes postérieurs (des fesses ou de l'anus),

3. Exhibitionnistes supérieurs (des seins).

Hiermit ist freilich das Schematisiren in lächerlicher Weise auf die Spitze getrieben. Viel wichtiger als solche Spielereien ist die Erfor- 
schung des Bodens, auf dem diese sexuellen Anomalien entstehen, und in dieser Hinsicht bleibt uns noch eine ganz besondere Klasse solcher Delinquenten zu erwähnen, welche der forensischen Beurtbeilung am meisten Schwierigkeiten bietet. Dies sind die "zweckbewussten, gewohnheitsmässigen" Exhibitionisten, wie sie Schäfer nennt, bei denen sich die nicht eigentlich krankhafte Perversität zugleich als eine Frucht und als "ein höheres Mittel zum Zweck der Onanie" darstellt. Sie bilden eine Hauptart der Repräsentanten unseres Gegenstandes; sie stehen auf der Scheide zwischen Krankheit nnd Gesundheit, indem sie bald mehr nach der gesunden, bald mehr nach der kranken Seite gravitiren, sie sind aber nicht krank im Sinne des $\S 51$. Auf sie in neuester Zeit besonders aufmerksam gemacht zu haben, ist ein Verdienst Schäfer's, Hoche's und A. Cramer's.

Ich theile nun 7 Fälle von Exhibitionismus mit, welche während der letzten Jahre in der Klinik des Herrn Geheimrath Hitzig theils von mir, theils von anderen Aerzten beobachtet wurden. Die grössere oder geringere Ausführlichkeit, mit welcher diese Mittheilungen erfolgen, beruht auf dem grösseren oder geringeren lnteresse des einzelnen Falles. Leider war ich nicht inmer in der Lage in allen Punkten so erschöpfende Angaben zu machen, wie es vielleicht wünschenswerth gewesen wäre. Immerhin scheint mir die Mittheilung dessen berechtigt, was uns bekannt geworden ist.

\section{Neue Beobachtungen.}

\section{Eall I.}

In Erledigung eines Beschlusses des Königl. Landgerichts zu Halle a. S. vom 22. Juli 1897 gebe ich ïber den Geisteszustand des in der Königl. psychiatrischen und Nervenklinik hier beobachteten 26 jährigen stud. theol. N. N. aus X. das nachfolgende Gutachten ab.

I.

Im Norember 1896 wurde der stud. theol. N. beschuldigt, er habe um jeno Zeit in Halle von dem Fenster seiner Wohnung aus mehreren unten auf der Strasse vorübergehenden Mädchen zu wiederholten Malen seine entblössten Geschlechtstheile gezeigt; er habe sich offenbar eine zu diesem Zweck günstige Stellung auf einem Stuhle ausgesncht, habe an seinen Genitalien herumgespielt und durch Husten und andere Zeichen die Aufmerksamkeit dor Mädchen auf sich za lenken gewusst. Die letzteren waren im Alter von 11, 13 und 14 Jahren und nahmen an dem Gebahren des $\mathrm{N}$. ein Aeryerniss. 
Des Genaueren ergab sich bei den verschiedenen Vernehmungen und Gerichtsverhandlungen folgender Sachverhalt.

1. Eines Tages gingen die 13jährige Erna F. und die 14jährige Marie W. auf dem Promenadenwege. Der W. war damals bereits rom Hörensagen bekannt, dass in einem näher bezeichneten Hause ein Mann "Unanständigkeiten" treibe, und sie hatte das auch der F. erzählt. Als die beiden Mädchen sich unterhalb des Hauses befanden, hustete ein am geöffneten Fenster der zweiten Etage stehender Mann vernehmlich, die Mädchen sahen hinauf und bemerkten, dass der Mann sein Glied herausgenommen hatte und an demselben spielte. Sein Gesicht war hinter der Fenstergardine versteckt; der Mann stand erhöht, wie es den Zeuginnen vorkam, auf einem Stuhle. Er war mit Rock und Hose bekleidet.

2. Genau derselbe Vorgang wiederholte sich, als die F. mit der 13jährigen Sch. den Weg entlang ging. - Beide Vorfälle trugen sich am hellen Tage zu.

3. Am Busstage ging Nachmittags die W., diesmal in Begleitung der 14 jährigen Alice R., denselben Weg. Wiederum hörten sie von oben ein Räuspern und bemerkten beim Hinaufsehen, wie ein am offenen Fenster des zweiten Stockw'erks stehender, bekleideter Mann, dessen Gesicht auch diesmal hinter der Gardine steclite, an seinem heraushängenden Geschlechtstheile mit dem Finger spielte.

4. Eines Nachmittags nach 4 Uhr passirten die Sch., die 13jährige Hedwig H., die 11 jährige Martha $J$. und die Meta D. aus der Schule kommend den Promenadenweg. Vor dem Hanse des Angeklagten hatten sich mehrere Volksschüler angesammelt, welche laut lachten. Hierdurch aufmerksam gemacht sahen die Mädchen hinauf. Dasselbe Fenster des Angeklagten war wiederum geöffnet. Die Mädchen sahen daran einen etwas erhöht stehenden Mann, der seinen Geschlechtstheil aus der Hose herausgenommen hatte und in der Hand hielt. Das Gesicht steckte hinter der Gardine.

5. Einen am selben offenen Fenster mit dem herausgenommenen Gliede spielenden Mann sah um dieselbe Zeit noch die H., als sie Nachmittags allein am Hause vorbeiging;

6. Ebenso die J., als sie ebenfalls einmal allein gegen 2 Uhr den Promenadenweg entlang zur Schule ging.

7. und 8. Die 14jährige Charlotte 0 . und die 13jährige Hedwig B. sind mindestens $2 \mathrm{Mal}$, als sie gegen 2 Uhr auf dem Promenadenwege zur Schule gingen, und

9. und 10. die 13jährige Anna D., die 14jährige Margarethe L. und die 14jährige Olga B. sind ebenfalls mindestens 2 Mal, einmal nach $12 \mathrm{Uhr}$, einmal nach 4 Uhr beim Passiren des Promenadenweges rom Hause des Angeklagten durch ein "Pst, Pst" angerufen worden. Alle 4 Mal hat an demselben offenen Fenster des zweiten Stockes ein Mann den Mädchen seinen ontblössten Geschlechtstheil hingezeigt; der Mann hatte einen erhöhten Standpunkt eingenommen und hielt sein Gesicht hinter der Gardine verborgen.

Nachdem ein Theil dieser Mädchen hiervon ihrem Lehrer und dieser der 
Polizei Anzeige gemacht hatte, begab sich eines Nachmittags der KriminalSergeant B. auf das Zimmer des Angeklagten, um jhn zu sistiren. Hierbei gab N. an, Fieber zu haben und sich der rauhen Witterung nicht ohne Weiteres aussetzen zu lrönnen. Nach Zählung des Kriminalbeamten hatte er 82 PuIsschläge in der Minute. Er wollte sich den auf der Strasse angesammelten Kindern absolut nicht zeigen, sondern wich beim Oeffnen der Hausthür wiederholt zurück. Er gab an, lieber in einer Droschke sistirt werden zu wollen, und huschte, als davon Abstand genommen wurde, mit hochgeschlagenem Mantelkragen, als wolle er sein Gesicht verbergen, zur Thür hinaus.

Allen diesen aufgeführten Zeugenaussagen gegenüber bestritt N. constant seine Schuld und behauptete, er wisse von alledem gar nichts. Er worde darauf vom Kgl. Schöffengericht hierselbst in der Sitzung rom 29. Jan. 1897 freigesprochen, indem die Aussagen der Mädchen nicht als Beweis seiner Schuld erachtet wurden. Die Kgl. Staatsanwaltschaft legte gegen dieses Urtheil Berufung ein. In der darauf folgenden Strafkammersitzung des Kgl. Landgerichts Halle vom 8. März 1897 ergab sich nichts wesentlich Neues und die Verhandlung wurde zum Zweok neuer Zengenvernehmungen vertagt. Unter Anderen wurde als neuer Zeuge von Seiten des Angeklagten sein Vetter genannt, der ebenfalls in Halle Theologie studirende Y., dieser sollte möglicherweise der Thäter sein. In der zweiten Sitzung der Strafkammer vom 3. Mai 1897 ergab sich jedoch diese Verdächtjgung als falsch, sämmtliche Aussagen der 16 geladenen Zeugen sprachen für die Schuld des N., obwohl dieser immer noch das Gegentheil behauptete; das Gericht kam zu der Ueberzeugung, dass der Angeklagte im November 1896 fortgesetzt durch eine unzüchtige Handlnng öfentliches Aergerniss erregt habe und verurtheilte iln zu 3 Monaten Gefängniss.

Die hiergegen vom Vertreter des N. eingelegte Revision warde vom Kgl. Oberlandesgericht zu Naumburg in der Sitzung vom 28. Juni 1897 verworfen und dem N. ausserdem die Tragung der Rerisionskosten auferlegt.

Am 8. Juli 1897 theilte nun der Vertreter des N. dem Gericht mit, dass Letzterer jetzt eingestehe, das Vergehen begangen zu haben; jedoch sei er sich des Geschehenen nicht hinreicliend bewusst, er müsse dies Alles nach seiner Angabe in Augenblicken gethan haben, in denen ihm das Bewusstsein und die freie Willenskraft gefehlt habe, also in einem Zustande krankhafter Störung der Geistesthätigkeit. Er wisse nicht, ob die Einzelheiten der ihm zur Last gelegten Vergehen richtig seien. Unter Hinweis auf das Gutachten von zwei ärztlichen Sachverständigen, Dr. B. und Dr. H., wird dann von dem Vertreter beantragt, das Gericht möge das Verfahren wieder aufnehmen und beschliessen, den N. auf seine Kosten in einer öffentlichen Irrenanstalt zur Beobachtung seines Geisteszustandes unterzubringen.

Dr. B. spricht sich in seinem Gutachten vom 22. Mai 1897 dahin aus, dass das dem N. zur Last gelegte Vergehen an und für sich schon als eine Verirrung des natürlichen Triebes zu betrachten sei und eine aufmerksame Prüfung des gesammten geistigen Zustandes erfordere. Eine derartige Störung einer einzelnen Function weise gewöhnlich auf Abnormitäten auch auf anderen 
Gebieten des seelischen Lebens hin und stelle dic Zurechnungstähigkeit einer solchen Person mindestens für einen Theil ihrer Handlungen in Frage. Dr. B. fährt fort, dass $\mathrm{N}$. von gesunden Eltern stamme, dass eine Schwester von ihm hysterisch sei. Er ist als Kind sehr viel krank gewesen und hat von verschiedenen Anfällen ron Gelenlrcheumatismus ein schweres. Herzleiden davongetragen. Sein Vater schildert ihn als von Kindheit auf nervös, unruhig und reizbar; er habe sich des Nachts sehr oft vom Bett aufs Sopha gelegt und sei bei der Aufforderung, ins Bett zurückzugehen, unmotivirt heftig geworden. Einmal rief er in verzweifelter Stimmung aus: „Wenn Ihr wüsstet, mit was für Zahlen ich zu rechnen habe! die soll ich nun multipliciren und dividiren und kann doch nicht damit fertig werden!!" Wenn eine solche Aeusserung auch für Wahnideen nicht beweisend sei, so erwecke sie doch dringenden Verdacht auf solche. Jedenfalls weise es auf einen hohen Grad von sogen, reizbarer Schwäche des Nervensystems hin. Eine bestimmte Form der Geistesstörung kann Dr. B. aus dem Dargethanen nicht erkennen, dennoch hat er nach seinen Beobachtungen triftige Gründe, an der geistigen Gesundheit des N. zu zweifeln und hält eine genaue Beobachtung durch ärztliche Sachverständige für dringend geboten.

Dr. H. stellt in seinem Gutachten vom 6. Juli 1897 folgendes fest:

Der Vater, ein Bruder und eine Schwester desselben, sowie die eigene Schwester des N. sind angeblich nervös. Er selbst ist viel krank gewesen und jetzt seit ca. 10 Jahren herzleidend. Seitdem ist er sehr reizbar, geräth nach Streitigkeiten und Aufregungèn in einen Zustand von Herzklopfen und schmerzhaften Empfindungen in der Herzgegend, der 8-10 Tage anhält und 3-4mal im Jahre auftreten kann. In solchen Perioden treten Zustände veränderten Bewusstseins auf, in denen er Handlungen begeht, an die er später keine oder nur eine unklare Erinnerung hat. So findet er sich häufig an einer Stelle des Zimmers oder Hauses, wohin er sich nicht erinnere gegangen zu sein. Morgens findet er sich manchmal vor dem Fenster oder auf dem Sopha, ohne zu wissen, wie er dahin gekommen ist. Beim Anblick eines jungen Mädchens lommt ein unwiderstehlicher Geschlechtstrieb über ihn, er hört und sieht dann nichts mehr und findet sich nach einiger Zeit, wenn er wieder zu sich gekommen ist, mit heruntergezogenen Hosen, woraus er schliesst, dass er exhibitionirt habe. Diese Anfälle werden zuweilen dadurch eingeleitet, dass er pfeifen, seinen Namen rufen hört etc. Auch in gesunden Tagen hört er manchmal Brandsignale, Läuten und Blasen. Er muss manchmal verzweifelt über seinen eigenen Namen nachdenken und sich in quälender Weise mit ungeheuren Zahlen und Berechnungen beschäftigen. - - Die körperliche Untersuchung ergiebt einen Herzklappenfehler und enorme Vergrösserung des Herzens. - Dr. H. ist der Ansicht, dass die strafbaren Handlungen des N. entweder unter dem Einfluss von Zwangsvorstellungen oder auch im Zustande eines unklaren Bewusstseins, im epileptischen Aequivalent begangen sein können, hä]t aber eine genauere Beobachtung in einer öffentlichen Irrenanstalt für angezeigt.

Dem oben genannten Antrag des N.'schen Vertreters zufolge hatte das Gericht bereits einen entsprechenden Beschluss gefasst, als Anfang August 1897 
gegen den Angeliagten neuerdings Anzeige gemacht wurde. Am $\Delta$ bend des 3. Angust theilte das 15 jährige Fräulein S. dem Polizei-Sergeanten P. mit, dass in dem und dem Hause ein nur mit Hemd bekleideter Herr am Fenstor stehe und, als sie vorbeigekommen, das Hemd hochgehoben und ihr seinen Geschlechtstheil gezeigt habe. Als sich der Polizeibeamte sofort mit dem Fräulein dahin begab, stand der Angeklagte N. wiederum am Fenster, zog die Gardinen zurück, sodass das Fenster ordentlich frei wurde, hob das Hemd in die Höhe und zeigte abermals seinen Geschlechtstheil. In dem Angenblick, wo er den Beamten sah, zog er die Gardinen wieder zu.

Bei seiner Vernehmung am 7. August 1897 sagte $\mathrm{N}$. aus, dass ihm von diesem Vorgange, ebenso wie von den früheren ähnlichen ihm zur Last gelegten Ereignissen nichts bekannt sei, er müsse dieselben in krankhafter Störung seines Geisteszustandes begangen haben.

Die erwähnte Zeugin S. bestätigte bei der Vernehmung ihre obige Aussage und fügte hinzu, dass derselbe Herr schon einmal, ca. 14 Tage vor diesem letzten Vorfall, am Fenster gestanden habe, als sie vorbeikam, und zwar sei er damals nicht einmal mit Hemd bekleidet, vielmehr ganz nackt gewesen.

Auf Grund des Gerichtsbeschlusses meldete sich N. am 18. August zur dufnahme in der Königl. psychiatrischen und Nervenklinik und wurde dann zwecks Beobachtung und Begutachtung am 20. September hierselbst aufgenommen.

II.

In der Klinik wurde zur Beurtheilung des N. Folgendes erhoben:

Nach seinen eigenen Angaben war ein Onkel von ihm (Vaters Bruder) stets leicht erregt und nervös, ein Sohn desselben (Vetter von N.) ist ebenfalls nervös. Der Vater hat früher als Kupferschmied sehr angestrengt gearbeitet, war auffallend leicht erregt und jähzornig und hatte manchmal anfallartige Zustände, in denen er auf offener Strasse umfiel und bei Seite getragen werden musste; seit den letzten Jahren leidet er an Schlaflosigkeit und Herzklopfen, und ein öfters ihn plötzlich überfallendes Angstgefühl lässt ihm angeblich keine Kuhe. Ein anderer Bruder des Vaters ist ebenso wie dieser leicht reizbar, hat ein sehr eigenthümliches Wesen und eine auffallende Scheu vor Gesellschaften und belebten Orten. Eine Schwester des Vaters ist sehr nervös, aufgeregter Natur; ein Bruder des N. ist beim Vater in Geschäft, leistet aber nur wenig, fasst so ziemlich Alles verkehrt an, leht einsam und abgeschlossen, ohne jeglichen Umgang mit Anderen; dies soll sich bei ihm in letzter Zeit zu einer übertriebenen Aengstlichkeit gesteigert haben. Eine 20jährige Schwester des Angeklagten ist hochgradig bleichsüchtig und hysterisch; sie weinte und klagte oft im letzten Jahre ganz unmotivirt, hatte auch einmal einen Krampfanfall und war deswegen 4 Wochen im Krankenhause.

N. selbst hatte als Kind Scharlach und Diphtheritis in schwerer Form. Er blieb angeblich von dieser Zeit an sehr schwächlich und zart, besuchte 
aber vom 5. bis zum 14. Lebensjahre die Volksschule mit dem besten Erfolge and bezog dann das Gymnasium. Des weiteren giebt er seine Vorgeschichto selbst folgendermaassen wieder:

„Da mir das Lernen Dank meines vorgerückten Alters und meiner leichten Auffassungsgabe sehr leicht fiel, gelang es mir, die ersten Klassen als Zweiter zu absolviren. Sehr häufig war ich krank. Ich war sehr leicht Erkältungen ausgesetzt, die fast jedesmal in Gelenkrheumatismus ausarteten. So viel mir erinnerlich ist, hatte ich drei schwere Anfälle dieser Krankheit, welche mich mehrere Wochen still ans Bett fesselte. Vom zweiten oder dritten Anfall, d. h. so ziemlich vom 15. Lebensjahre an ist mir ein Herzfehler bekannt; wenn ich nicht irre, hatte ich damals Herzbeutelentzündung, die mir grosse Schmerzen unter dem Herzen verursachte. Ich war von der Zeit an stets yom Turnen dispensirt, da mich jede körperliche Anstrengung heftig schwitzend machte und mir Herzklopfen verursachte; auch rasches oder langes Gehen strengte mich und strengt mich noch heute sehr an. Mein Herz schlägt so stark, dass ich unter den gesundesten Verhältnissen, in denen mir das Essen gut schmeckt, ein angenehmer Schlaf mich erquickt, jeden Pulsschlag sitzend oder stehend oder liegend fühle und höre, ohne die Hand gerade an eine Schlagader zu legen. Jede Kleinigkeit, Erwartung irgend einer Sache, regt mich auf. Das Rauschen der Blätter, das Fallen eines Gegenstandes, die plötzliche Anrede, Zuschlagen von Fenstern oder Thüren erschreckt mich und verursacht Herzklopfen. Häufig glaube ich Abends die in meiner Vaterstadt heimischen Brandsignale, als Blasen und Läuten, zu hören. Schreien und lautes Sprechen und Spielen der Kinder auf der Strasse regt mich, einmal darauf aufmerksam geworden, auf. Besonders in der Nähe von Wasser bin ich stets etwas aufgeregt, was ron der Zeit herrührt, als ich am 20. Juni 1890 einen vierjährigen Knaben vom Tode des Ertrinkens errettete, wofür ich ron Sr. Majestät König Wilhelm II. die Rettungsmedaille erhielt. Seit dieser Zeit -- ich wurde damals selbst ohnmächtig - befinde ich mich in der Nähe von Wasser in steter Aufregung, da ich befürchte, abermals hineinspringen zn müssen, was für mich wegen meines Herzfehlers von grösster Gefahr sein würde.

Bemerken will ich ausdrücklich, dass ich bei oben beschriebenem gewöhnlichem Znstande, in dem ich mich auch augenblicklich befinde, mein volles Bewusstsein sowie volle geistige Kraft und eigene Willenskraft besitze wie jeder Mensch.

Nur kommt es zwei- bis dreimal im Jahre vor, dass sich mein Herzschlag infolge von Erkältung oder Aerger oder Aufregung, auch wohl, wenn ich meinem Körper in Bezug auf Genuss geistiger Getränle im Uebermaass, oder in Bezug auf Touren machen, zuviel zugetraut habe, verstärkt; Fieber stellt sich ein, ich habe alsdann in 4-5 Tagen keinen Stuhlgang, keinen Appetit, bin sehr leicht reizbar, entbehre den Schlaf vollständig oder werde durch wirre Träume geplagt; ich sehe alsdann Angehörige, die ich niesen höre, ohne dass es der Fall ist, oder eine Gestalt, die an meinem Bette steht. Oeffne ich alsdann die Augen, so sehe ich die Gestalt langsam sich fortbewegend. Manch. mal stehe ich alsdann auf und gehe der Gestalt nach. Ferner sehe ich mit 
offenen dugen manchmal Thiere, besonders Hunde oder Ratten. Nach letzteren habe ich öfters geschlagen oder geworfen. Manchmal stehe ich unmotivirt auf, ohne dass ich eine Ahnung davon habe. Ich fand mich manchmal im kalten Zimmer auf dem Sopha liegend oder sitzend, vor dem Fenster stehend, oder, wenn ich mich vorher nicht im Bett befand, sondern angezogen im Sopha lag, so fand ich mich, allerdings nur seit dem vorigen Jahre, mit entblösstem Geschlechtstheil im Sopha, auf einem Stuhl oder sonstwo. Wie oder wann ich dorthin mich begeben hatte, ist mir nachher nicht bewusst. Mein Herz klopft dann stark und der Herzschlag schmerzt in der Umgebung des Herzens, der Unterleib zieht sich ein, und in der Herzgrube sind die Schmerzen manchmal unerträglich. Die bequemste Lage für mich ist alsdann eine gekrümmte, mit hochgezogenen Beinen, am liebsten übe ich durch die Hand oder durch ein Kissen einen gelinden Druck auf Herz und Unterleib aus. Ich habe in diesen Zuständen im Allgemeinen auch volles Bewusstsein und volle Geistesklarheit, sodass ich jede wissenschaftliche Arbeit erledigen liann. Nur wenn ich so allein daliege, die Augen schliesse und eine Zeit lang mir selbst überlassen bleibe, kommen Momente, wo ich nicht weiss, was ich thue oder sage. Wie lange diese Zeiten der Bewusstlosigkeit sind, weiss ich nicht, das hängt von der Heftigkeit der Schmerzen ab und der Höhe des Fiebers. Das Liegen zu Beit ist mir sehr unangenehm, ich befinde mich entschieden wohler und verhalte mich viel ruhiger auf dem Sopha oder im Sessel sitzend. In solchen Zuständen der verstärkten und schmerzhaften Herzthätigkeit habe ich gerne stille, ruhige Gesellschaft, die nicht viel redet, sondern nur auf meine Fragen antwortet und sofort that, worum ich bitte. Widerspruch oder Verzögerung regt mich sehr auf, sodass ich durch heftiges Auffahren und durch Vorwürfe schon manchen meiner Angehörigen oder Freunde, die mich liebevoll pflegten, tief verletzte und ihnen Unrecht gethan habe, was mir jedesmal sofort leid thut.

Während meiner Studienzeit 1894/95 in Basel, 1895/96 in Erlangen, 1896/97 in Halle hat mein Herzleiden mir ebenso wie auf dem Gymnasium viel zu schaffen gemacht und manchmal am Studiren gehindert. Vieles habe ich wegen meines Leidens entbehren müssen, Fusstouren habe ich nie machen dürfen und können, bei Festen, Kneipen u. s. w. habe ich mich sehr zusammengenommen und aufregende Auftritte habe ich stets zu meiden gesucht".

In dieser zur Vorgeschichte wörtlich mitgetheilten Selbstschilderung des N. beanspruchen gewisse Erregungszustände, die angeblich auf körperlichem und geistigem Gebiete zum Ausdruck kommen, für die Zwecke des vorliegenden Gutachtens eine ganz besondere Beachtung. Dieselben werden vom Angeklagten selbst als Anfälle von Compensationsstörung bezeichnet und bei mündlicher Erörterung stets in derselben Weise geschildert. Sie treten also, um ihre Art nochmals zu präcisiren, angeblich 2-3 mal im Jahre auf, ihr Herannahen kündigt sich durch Stärkerwerden des Herzschlages und niedergeschlagene Gemüthsstimmung an, sie dauern 6-10 Tage and sind verbonden mit körperlichen Erscheinungen, wie Temperatursteigerung, erhöhte und sehr frequente Herzaction (der Arzt soll z. B. 180 Schläge in der Minute gezählt 
haben), starken Blutandrang zum Kopf, Ausbleiben des Schlafs, des Appetits und des Stuhlgangs. In psychischer Hinsicht macht sich eine gewisse Cnruhe geltend, N. kann es nicht.im Bett aushalten, er hat grosse Angst, der Angstschweiss läuft ilhm am ganzen Körper herunter. Er sieht oft Feuerschein, hört Brandläuten, erblickt fremde Personen, Angehörige, fürchtet, dass jemand ins Wasser falle, sieht Kinder, die am Ertrinken sind, will hingehen und helfen, lrann aber nicht. Auch sieht er manchmal Löwen und Tiger unter ängstlicher Erregung. Erst sind sie ganz zahm, werden dann wild und gehen schliesslich auf ihn los. Zuweilen erinnert er sich nachher an alles, was er gesehen hat, zuweilen nicht. Diese Zustände von Verwirrung dauern $1 / 4-1 / 2$ Stunde und werden in ihrem Auftreten besonders begünstigt durch Schliessung der Augen. Doch hallucinirte er auch mit offenen Augen, sah z. B. eine weisse Gestalt oder Ratten, nach denen er dann irgend einen Gegendstand warf.

Was das Geschlechtsleben des N. betrifft, so giebt er an, vom 14. bis zum 20. Lebensjalire ziemlich viel onanirt zu haben; er litt an häufigen Pollutionen, hatte in Anfang seiner Studienzeit in Basel wiederholt Geschlechtsverkehr mit einer Puella puhlica nnd acquirirte dabei Gonorrhöe, die in 4 bis 5 Wochen ausheilte. Vom December v. J. bis Ostern d. J. hatte er ein geschlechtliches Verhältniss mit einem Mädchen hier in Halle, obgleich er bereits seit August vorigen Jahres angeblich mit einer Dame aus guter Familie heimlich verlobt war. Diese Verlobung wurde sogar am 20. Mai cr. - nach seiner Verurtheilung - eine öffentliche, trotzdem der Braut Delicte und Verurtheilung bekannt waren; sie wurde aber im August d. J. wieder aufgehoben.

Bezüglich der incriminirten Vorgänge im November v. J. machte er folgerde Angaben:

Um Buss- und Bettag herum (18. November 1896) hatte er wieder einen Aufall von Compensationsstörung und befand sich eben auf dem Wege der Besserung, nachdem der Anfall ca. 5--6 Tage gedauert. hatte. Der Anfall ging gerade so wie die früheren mit grosser Angst einher. Ob er Hallucinationen während dieses Anfalls hatte, weiss er nicht mit Bestimmtheit anzugeben, nimmt es aber an, da er bei jedem derartigen Zustande hallucinirte.

Der näheren Umstände, unter denen er seiner Zeit im November A. J. auf seinem Zimmer von einem Criminal-Sergeanten sistirt wurde, erinnert sich N. ganz genau. Ein besonderer Erregungszustand lag damals nicht vor. Indessen fand er sich im November v. J., in den Tagen, als Anzeige über ihn erstattet, wurde, etwa 5-6 mal wie aus einem Traum erwachend; dabei hatte er Herzklopfen und ein Druckgefühl über den Augen, war sexuell erregt, hatte bald den entblössten Geschlechtstheil in der Hand, bald die Beinkleider heruntergelassen und das Hemd in die Höhe gezogen, bald fand er sich auf einem Stuhl am Fenster, bald auf dem Sopha. Dasselbe will er auch schon früher, vor dieser Zeit an sich beobachtet haben. - Die Ereignisse im August y. J. erzählt er folgendermaassen:

An einem Augusttage litt er wieder an der Störung von Seiten des Herzens, welche durch vorangegangene Alloholexcesse hervorgerufen war; schon in der Nacht war er sehr unruhig gewesen, phantasirte von seiner Braut,

Arehiv f. Psychiatrie. Bd. 31. Heft 1 und 2. 
sprach riol von Zahlen, ging mehrmals aus dem Bett, wollte auf den Schrank steigen u. dgl., so dass sein Vetter und zwei $\Delta$ ndere bei ihm wachen nussten. Am Nachmittage nun rief ihn zufällig sein Vetter, der neben ihm wohnte; dadurch erwachte er und fand sich am Fenster auf einem Stuhle stehend, die Hose heruntergelassen, den erigirten Penis in der Hand. Er sah unten anf der Strasse ein Mädchen mit einem Polizisten stehen, die beide zu seiner Wohnung binaufschauten. Fr trat dann vom Fenster zurück, zog sich an und ging zu seinem Vetter hinüber. Er war sexuell äusserst erregt, empfand starkes Herzklopfen und hatte einen sehr rothen Kopf.

Auch damals befand er sich in einer Krankheitsperiode, welche noch etwa 3 Tage anlielt und wegen deren er sich zn Herrn Dr. H. hier in Behandlnng begeben hatte.

Ueber diese Punkte wurden nun seitens der Klinik noch einige Zeugen gehört. Der zu dem Behufe vorgeladene Zimmernachbar des N., Apothelrer G., giebt an, er sei einmal Nachts etwa um 12 Uhr nach Hause gekommen und habe von N.'s Vetter gehört, dass es N. schlechter gehe; N. lag im Bett, hatte cine Eisb]ase auf der Brust, erkannte den G. nicht, sprach zusammenhangslos, rief seine Verwandten, seine Brant, behauptete, es kämen Ratten, sie gingen an der Wand hoch, auf den Schrank; er sagte: ,jetzt kommt's auf mich zu" und hatte eine starke Herzthätigkeit. Dies dauerte etwa 20 Hinuten, dann kam N. zu sich und G. ging weg. Am anderen Tage wusste N. nichts von dem Vorfall oder von irgend einer Person, die dabei war. Zu welcher Zeit dies war, weiss G. nicht, jedenfalls aber nach der Verurtheilung. Ein zweiter Anfall war einige Wochen später: G. und der Vetter hörten N. auf seinem Zimmer sprechen und fanden ihn in der Sophaecke zusammengekauert; er war ganz ausgezogen und schien zu schlafen. Dies war Nachts um 12 oder 1 Uhr. N. habe im Allgemeinen Bier schlecht vertragen, doch habe er nur vor dem ersten Anfall Bier getrunken gehabt; er sei geschlechtlich sehr aufgercgt.

Der Hauswirth des N., Hermann D., gleichfalls vorgeladen, sagt aus:

Ungefähr im Juli đ. J. war $\mathbb{N}$. ca. 3 Tage lang lirank, litt an Kopfschmerzen und Herzheschwerden. Er war zeitweilig sehr aufgeregt, warf einmal einen Einmachtopf mit Kartoffelschalen zum Fenster hinaus. Er wusste am nächsten Tage, dass er es gethan hatte, lachte darüber. An welchem Tage des Aufregungszustandes dies sich ereignete, weiss Ref. nicht.

Anfang August d. J. hatte N. einen Erregungszustand von stärkerer Intensität als der vorige. Nachdem er schon einige Tage lang über Kopfschmerzen und Ferzbeschwerden geklagt hatte, erbrach er eines Abends zum Fenster hinaus. Ich war durch Zufall eben im Zimmer gewesen und hatte ihn aufgefordert, sich ins Bett zu legen; dies that $\mathrm{N}$. nicht, sondern wollte erst eine Pfeife rauchen; nach einigen Zügen trat das Erbrechen (ca. 9 Uhr Abends) auf. N. sohwitzte stark dabei. Er ỵar so schwach, dass ich ihn ins Bett tragen musste und ihn auszog. Als er im Bett war, wollte er nicht liegen bleiben und sprang immer wieder auf, während sein Herz sehr stark arbeitete, so dass man das Sehlagen aussen an der Brust sah. Die Brust wurde etwa fausthoch gehoben. Er griff nach der Wand, rief: „Da kommt der Mann, da 
kommt er!"; einmal verkroch er sich unter die Bettdecke, dann wieder machte er häufig eine Bewegung, als ob er eine Fliege fangen wollte. Dreimal wollto er auf den am Fussende seines Bettes stehenden Schrank steigen, stand schon aufrecht auf dem Bettrande nnd wurde dann stets ron mir und seinem nebenan wohnenden Vetter, der gleich um 9 Uhr herübergekommen war, heruntergeholt und ins Bett gelegt. Er hatte sich krampflaft an den Schrank angeklammert. Während N. hinaufsteigen wollte, rief er den Namen „Alma“" (seiner Braut), sonst sagte er nichts. Der Aufregungszustand dauerte bis etwa 5 Uhr Morgens; wälirend dieser Zeit rief N. 3-500mal den Namen Alma. Ferner rief er nach seinem Vater nd seiner Mutter einige Male. Gleich im Anfange der Nacht sagte er einmal, dass er das Bett voll Mäuse hätte; von sonstigen Gesichtstäuschungen, speciell von Frauenzimmern, ist mir nichts bekannt, ebensowenig daron, ob N. geschlechtlich dabei aufgeregt war.

Gleich am Abend legten wir $\mathrm{N}$. einen Eisbentel aufs Herz auf Anordnung eines herbeigeholten Arztes. Dessen Name ist mir nicht belaannt.

Einige Zeit nachher, ob nach Tagen oder Wochen, weiss ich nicht. fand ein Strassenauflauf statt, weil N. mit aufgehobenem Hemde am Fenster gestanden haben soll. Gesehen habe ich es selbst nicht, bloss davon gehört. Bei der Gelegenheit, als darüber gesprochen wurde, sagte ein Kellner der benachbarten Wirthschaft, dass er früher schon einmal so etwas gesehen hätte.

Ich blieb bis um 1/26 Uhr Morgens in der fraglichen Nacht bei $\mathrm{N}$., während der Vetter sich um 2 Uhr hinlegte. N. hatte sich gegen $1 / 25$ Uhr beruhigt, war bei Besinnung; vorher war er nicht bei Besinnung gewesen. Er hatte vorher nur verkehrte Antworten gegeben, wusste anscheinend nicht, wo er war. Er erwähnte, als ich am nächsten Tage wieder mit ihm sprach, nichts von den Vorgängen der Nacht, er erwähnte auch nichts davon, dass ich bei ihm war, bedankte sich auch nicht bei mir. Ich nehme an, dass er von den Vorgängen in der Nacht nichts mehr wusste, da er gar nichts davon erwähnte.

Einige Tage nachler lilagte N. noch über Kopfschmerzen und Herzheschwerden; eine besondere Aufregung in geschlechtlicher Beziehung habe ich nicht bemerkt.

N. war dem Zeugen ausser bei den zwei Aufregungszuständein niemals irgendwie anffällig gewesen, hatte ihm gleich offen alles erzählt, dass er verurtheilt sei, aber nichts von den Strafthaten wisse; er war betrübt darüber.

Der Zeuge ist bereit, seine Aussagen vor Gericht zu wiederholen.

In ähnlicher Weise hat der mehrfach erwähnte Vetter des N. zweifellose Anfälle gesehen, die mit Bewusstlosigkeit verbunden waren, über deren zeitliche Verhältnisse aber nichts Sicheres zu" erlangen war. Was den Lebenswandel des $\mathrm{N}$. betrifft, so soll dieser nach des Vetters Urtheil etwas locker gewosen sein; indessen werden die diesbezüglichen Anssagen von N. bestritten.

Soweit die Vorgeschichte, die Zeugenaussagen und die eigenen Angaben des Angeklagten.

Die klinische Untersuchung and Beobachtung ergab folgenden Befund : 
$\mathrm{N}$. ist bei klarem Bewusstsein, zeitlich und örtlich wohl orientirt; seine Intelligenz ist ungestört und sein Verhalten im Allgemeinen correct. Er erscheint leicht deprimirt und es fällt ihm ausserordentlich schwer, seino Gewohnheiten des Rauchens und Biertrinkens auf das hier angeordnete Maass einzuschränken, obwohl er behauptet, in diesen Punkten draussen keinen Missbrauch getrieben zu haben. Er vorurtheilt seine Handlungsweise als Vorlobter selbst und äussert, er habe sich jedes Mal Vorwürfe gemacht, wenn er mit dem andern Mädchen verkehrt hatte; indessen sei er stets sexuell leicht erregbar gewesen und jedesmal seien seine von Hause aus streng moralischen und kirchlichen Grundsätze der Leidenschaftlichkeit des betreffenden Mädchens unterlegen. Ebenso bedauert er seine Delicte und macht dabei den Eindruck der Aufrichtiglieit. Mit medicinischer und speciell psychiatrischer Lektüre über sexuelle Abnormitäten will er sich nicht belasst haben.

Die liörperliche Untersuchung ergiebt eine mittelkräftige Constitution, einen ziemlichen Grad ron Kurzsichtigkeit und einen ausgesprochenen Herzfehler, welcher sich schon bei oberflächlicher Betrachtung durch eine starke Pulsation fast der ganzen linken vorderen Brustfäche bemerkbar macht. Ueber dem ganzen Herzen ist oin schwaches systolisches und namentlich über der Aorta ein lautes, blasendes diastolisches Geräusch zu hören; die Herzdämpfung ist nach links 2 Querfinger-breit über die Mammillarlinie hinaus und nach reclsts ebenfalls etwas verbreitert; die grösseren Arterien des Körpers pulsiren sichtbar; der Puls ist hoch und schnellend; seine Frequenz gesteigert und leicht veränderlich, sie schwankt während der Untersuchung zwischen 120 und 140 Schlägen in der Minute. - Sonst finden sich von Seiten der inneren Organe, des Nervensystems oder der äusseren Formen keine besonderen Abnormitäten.

Während der weiteren Beobachtung bot das gowöhnliche Verhalten des N. zunächst durchaus nichts aufälliges, er selbst sprach die Befürchtung aus, cr werde vielleicht hjer keinen jener Zustände von Compensationsstörung bekommen und es lasse sich dann kein definitives Gutachten über ibn ersta ten. - In liörperlicher Hinsicht ist nur zu erwähnen, dass er immer eine sehr gesteigerte Herzaction, eine abnorme Pulsbeschaffenheit und eine erhöhte und sehr labile (gewöhnlich ca. $108-120$ p. M.) Pulsfrequenz hatte, auch litt er hin und wieder an Schmerzen in der Herzgegend und im Zusamnenhang mit seinem früheren Gelenkrheumatismus an Schmerzen in den Schulter- und Hüftgelenken.

Nachdem er nun derartige leichtere Klagen schon rom 6 . bis 10 . October cr. geäussert hatte, gab er am Abend des 11. October an, er fühle sich sehr erregrt, habe Nachmittags läuten hören, sei gedrückter Stimmung, habe Schmerzen in der Herzgegend und die ahnende Befürchtung, dass einer jener Anlälle von Compensationsstörung eintrete, die er wiederholt geschildert hat. Er sah thatsächlich congestionirt aus, hatte eine noch lebhaftere Herzaction als sonst und eine Temperatur von $38,90 \mathrm{C}$. In der Nacht schlief er schlecht, träumte angeblich viel, sehr schwer und unangenehm. - Am anderen Morgen (12. X.) hatie er $38^{\circ} \mathrm{C}$. und 166 Pulse, im Uebrigen war der Zustand wie gestern 
Abend und es wurde ihm Bettruhe angeordnet. - Am Abend desselben Tages (12. X.) hörte ein zufällig im Saal anwesender Arzt, wie N. ängstlich Zahlen vor sich hinmurmelte; zugleich bemerkte er den starr nach der Decke gerichteten Blick desselben. Dies dauerte fort, während er einen anderen Arzt holte. N. lag jetzt ausgestreckt zu Bett, der ganze Brustkorb wogte durch die enorm lräftigen Erschütterungen von Seiten des Herzens, auch das Abdomer, die ganze vordere Hälfte des Halses und die Temporalarterien pulsirten auf's lebhafteste, der stark verhreiterte Spitzenstoss war in der Höhe der 6. Rippe bis in die mittlere Axillarlinie sichtbar, der Puls altus und celer, unregelmässig, seine Frequenz ca. 160 p. M., das Gesicht stark geröthet und mit Schweiss bedeckt, der: Gesichtsausdruck starr und ängstlich, der Blick an die Decke, manchmal auch ängstlich in den Saal gerichtet. Während dessen presste N. die Hände hin und wieder auf die Herzgegend und murmelte theils unverständliche, theils abgerissene Worte: "Ich kann's nicht", theils Zahlen: „67, 66, 67", alles in ängstlich erregtem Tone. Auf die Berührung beim Pulszählen reagirte er nicht besonders.

Nach etwa 5 Minuten Dauer (in toto) ging dieser Zustand allmählich in einen normalen iiber; zugleich fiel die Pulsfrequenz damit über 144 anf 128, während die übrigen körperlichen Errscheinungen sich zunächst wenig veränderten. Die am Ende des Zustandes geprüfte Lichtreaction der Pupillen war deutlich vorhanden. N. gab nun auf Anrufen Antwort und prompte richtige Auskunft auf alles. Er berichtete auf specielle Fragen über das eben Erlebte folgendes: Das Herantreten des Arztes und das Pulsfühlen habe er nicht bemerkt. Es seien ganze Klumpen von Zahlen millonenweise auf ihn zugekommen, es sei ihm gewesen, als ob er diese Zahlenklumpen verschlucken, resp. habe zählen müssen, ohne dessen fähig zu sein. Er habe dadurch die grösste Angst ausgestanden. Der Befehl, die ungeheuren Zahlen zu zählen, sei ihm von einem Manne mit langem Bart und weissen Kleid gegebon worden, welchen er an der Decke sab und der ihm von den früheren ähnlichen $\mathrm{Zu}$ ständen her bekannt sei. Ausserdem habe er gesehen, wie der Patient S. (in demselben Saale liegend) zur Thüre hereinkam und sich aufbängte. Auch dies habe ihm grosse Angst eingeflösst. - - Während dieses Zustandes bestanden keine Zuckungen, keine Erectio, kein Urinabgang etc. Nachher fühite sich Patient sehr matt und klagte über starke Schmerzen in der Herzgegend. Dio Temperatur betrug an diesem Abend $39,2^{\circ} \mathrm{C}$.

13. October. Hat Nachts nicht geschlafen. Klagt über Schmerzen in der Magengrube. Kein Appetit. Seit 11. October kein Stuhlgang. Puls 120, sehr stürmische Herzaction, Temperatur $38,3^{\circ} \mathrm{C}$.

Er weiss, dass der Arzt gestern bei ibm war, wie lange, ist ihm unbekannt. Dieser habe ihn untersucht. Er hat Erinnerung daran, dass er habe rechnen müssen. Er sei in der Nacht sehr aufgeregt gewesen, seine Gedanlien seien von einem zum andern gegangen, namentlich habe er sich wit seinem Process beschäftigt, habe sicher geglaubt, er ginge verloren. Deutlich habe er seinen Vater und seine Schwester gesehen. Er sei zeitweilig so versunken ge- 
wesen, dass er die Aussenwelt vergass. Während der Nacht habe er viel Läuten gehört.

N. wird beim Gehen schwindlig. Der Urin hat jetat geringen Eiweissgehalt (früher nicht) und wird spärlich abgesondert (700 ccm in 24 Stunden). - Am Abend giebt N. noch weitere Auskunft über seine gestrigen Hallucinationen: Er sah einen Mann, klein und gross, an der Decke hängen; ein anderer Patient hing sich an der Thür auf; eine Ratte fiel von der Decke herunter. Auch heute Nachmittag habe er eine Ratte gesehen. Er habe alles dies zunächst für wirklich normal gehalten; erst als er nnormal" geworden sei, babe er gewusst, dass es "Unsinn" war. Wie sein Erregungszustand gestern Abend anfing, weiss er nicht mehr; das erste, dessen er sich wioder entsinnen kann, ist ein Anruf von Seiten des Arztes.

Die Temperatur ist Abends 39,20, der Puls 136 p. M., die Herzaction ausserordentlich stürmisch. N. klagt über Schmerzen in der Herzgegend, hat einen sehr congestionirten Kopf, liegt mit nach oben gewandtem Gesicht $7 u$ Bett, zuclit zuweilen mit den Händen, ist nicht verwirrt und giebt geordnete Auskunft.

14. October. Hat schlecht geschlafen; Morgens Puls 112, 'Temperatur $38^{\circ} \mathrm{C}$.; Abends Puls 108, Temperatur $38,7^{\circ} \mathrm{C}$. Klagt über Schulterschmerzen, sonst Wohlbefinden. Seit 11. October immer noch Stuhlverstopfung.

15. October. Spontane Wiederkehr des Stuhlgangs. Temperatur 37,80. Wohlbefinden ausser den noch mehrere Tage anhaltenden Schulterschmerzen. Steht auf. Psychisch wie gewöhnlich.

Dioser relativ normale Zustand hielt bis zur Entlassung des N. am 30. October an; irgend welche Beobachtungen von Belang wurden nicht mehr gemacht und os sind für die Beurtheilung des Falles nur noch die Protocollo der folgenden Explorationen von Interesse:

\section{Exploration am 9. October 1897.}

\section{Fragen.}

1. Es ist doch sohr auffällig, dass Sic als Stud. theol. soviel mit sexuellen Dingen zu thun gehabt haben?

2. Nach Ihren Aenserungen zu Herrn Dr. L. war jenes Mädchen so leidenschaftlich, dass os lhnen nicht möglich war, sich von ibr zu trennen?

3. Sie ist auf JhrZimmer gekommen?

4. Davon komten Sie sie nicht abhalten?
Antworten.

1. Ich war mir des Unrechts bewusst, konnte mir aber darin nicht helfen.

2. Ich habe ein Zusammentreffen wiederholt vermieden, aber sie suchte mich immer wieder zu treffèn. Meine Freundo haben mir gesagt und ich wusste es auch, dass das zu einem faulen Ende führen werde.

3. Ja.

4. Wir trafen uns Abends auf der Strasse. Ich habe sie reinweg mit 
Fragen.

5. Thre sexuellen Neigungen werden aber aul den Richter einen üblen Eindruck machen.

6. Können Sie zur Zeit der Herzerregung sich selbst weniger beherrschen?

7. Sind Sie überhaupt sexuell sebr aufgeregt oder könnten Sie sich beherrschen, wenn keine Herzerregung vorliegt?

8. War das immer schon so?

9. Auch damals schon Coitus ausgefiuhnt?

10. Onanirt?

11. Auch mit anderen Jungen in der Schule?

12. Päderastie?

13. Wie hängen die Herzzustände mit den Strafthaten zusammen? Konnten Sie bei letzteren auch nicht widerstehen?

14. Haben Sic in diesen Zuständen Gestalten gesehen?

15. Wenn Mädchen auf der Strasse waren, hatten Sie dann Lust, Ihre Geschlechtstheile zu zeigen?

16. Wenn sic letzteres doch thaten, versuchten sie rorher zu widerstehen?
Antworten.

Füssen getreten, aber immer wieder kam sie zu mir. Sie wollte alles mögliche thun zu meinen Gunsten, wollte meiner Brautgegenüber widerrufen, es sei alles nicht wahr, bloss um mich zufesseln.

5. Was das Geschlechtliche anbetrifft, wenn ich mit meinem Herzen zu thun habe, dann bin ich so aufgeregt u. kann mir nicht helfen.

6. Ja. Auch mit dem Jähzorn ist es so.

7. Auch für gewöhnlich bin ich sexuell sehraufgeregt. Aberwenn mix die Gelegenheit so geboten wird...

8. Immer schon, schon als Schüler.

9. Nein.

10. Ja.

11. Nein.

12. Nein.

13. Ich wusste, wenn ich krank war, dass mein Herz in fürchterlicher Aufregung und ich in grosser Angst war. Ich fand mich zuweilen mit heruntergelassener Hose am Fenster, war geschlechtlich sehr erregt, hatte auch zuweilen eine Pollution.

14. Nackte Frauen und Mädchen mit weissen Kleidern.

15. Nein.

16. Nein. Ich wusste vorher nicht, dass das passiren würde. Ich konnte z. B. im Bett liegen und wurde ausser Bett angetroffen; dann wusste ich gleich die Möglichkeit, es könnte so etwas passirt sein. 
Fragen.

17. Wurden Sie von Freunden in ähnlichen Situationen gefunden?

18. Hahen Sie das vor Gericht angeführt?
Antworten.

17. Eines Nachmittags hatte ich dio Erregung, meine Herzgeschichte. Da traf mich mein Hauswirth, mein Stubennachbar and Vetter. Ich lag auf dem Sopha, schwatzte dummes Zeug.

18. Nein. Es ist nachler passirt.

\section{October 1897.}

1. Wie kamen Sie zu solchen Handlungen, wie die Ihnen zur Last gelegten?

2. Sio wissen also von den Umstïnden während des Vorganges gar nichts?

3. Warum haben Sie denn von Ihren derartigen Zuständen dem Gericht oder dem Anwalt lieine Angaben gemacht?

4. Wie fing ein solcher Zustand denn an?

5. Wie wirkt auf der Strasse der Anblick yon Mädchen auf Sie?

6. Sind Sie dabei bewusstlos?
1. Ich wusste nicht, wie ich es that; dass ich es gethan hatte, schloss ich daraus nachträglirh, dass ich mich in der bewussten Situation befand, am Fenster, in der Sophaecke, oder nackend, obwohl ich vorher angezogen war.

2. Ich weiss, dass ich geschlechtlich erregt war.

3. Dersagte, das hätte keinen Nutzen, höchstens bei Wiederaufnahme des Verfahrens.

4. Es kam ganz allmälig; wenn ich mich bestimmten Gedanken oder Vorstellungen hingab, salh ich allmälig Gestalten, einen Mann in weissen Kleidern, der von der Decke kam etc., Löwen und Tiger, erhängte Menschen, denen ich nicht helfen konnte.

5. Je nach meiner Stimmung und der Gestalt des Mädchens, jedoch nicht immer lrommen mir dann sexuelle Gedanken und Anwandlungen. - Unter Umständen aber kann jch auch fürchterlich erregt werden und beliomme dann grosse Hitze im Kopf, Herzklopfen, IKreuzschmerzen.

6. Nein, ich werde auf der Strasse abgelenkt und kann es dadurch bekämpfen, mich zusammenneh- 
Fragen.

7. Diese Anfälle sind also etwas ananderes, als die grossen, vorhin geschilderten?
Antworten.

nehmen, so lange ich körperlich relativ wohl bin. In meiner , Anfallszeit" aber bin ich dazu nicht im Stande und lomme in einen Zustand von Bewusstlosigkeit.

7. Ja, sie sind weniger schwer, ich habe keine Sinnestäuschungen dabei.

III.

Es ist durch die Beweisaufnahme erwiesen, dass N. zu wiederholten Malen rom Fenster seines Zimmers aus, gegen die Strasse gerichtet, ror jungen Mädchen seine Geschlechtstheile entblösst und dadurch öffentlich ein Aergerniss gegeben hat.

Man bezeichnet derartige Handlungen, die in einem Zurschanstellen der Genitalien bestehen und meist eine besondere Form des perversen Gesehlechtstriebs repräsentiren, ganz allgemein als „Exhibitionismus". Diese Perversität braucht an sich durchaus nicht krankhaft zu sein; sie kommt oft genug bei Gesunden als raffinirtes Mittel zur Befriedigung des für rormale Reize geschwächten Geschlechstriebs vor und ist dann nichts weiter als ein schamloser und strafwürdiger Verstoss wider die Sittlichkeit. In anderen Fällen jedoch und. sehr oft ist sie die Aeusserung eines krankhaften Geisteszustandes. Besonders häufig beobachtet man sie bei geistigen Schwächẹzuständen angeborener oder erworbener Art, sowie bei Epileptikern. Es entsteht daher die Frage, ob einer dieser krankhaften Zustände bei dem Angeklagten N. vorliegt oder nicht.

Thatsächlich wurde seitens des von N. gewäblten Rechtsanwalts vermuthet und von Seiten des Vorgutachters Dr. B. als wahrscheinlich hingestellt, dass der Angeklagte sich zur Zeit der strafbaren Handlungen in einem krankhaften Geisteszustande befand, der mit einem Fehlen des Bewusstseins und der freien Willenskraft verbunden gewesen sein sollte.

Eine der gewöhnlicheren, hier in Frage lommenden Formen der Geistesstörung, z. B. Paralyse der Irren oder Schwachsinn, liegt jedenfalls bei N. nicht vor; dies bedarf keines weiteren Beweises. Indessen mussten seine eigenen und andere Angaben den Sachverständigen von vornherein nach einer anderen Richtung hin aufmerksam machen, insofern diese auf gewisse psychische Anomalien hinweisen, denen einige Aehnlichkeit mit manchen Erscheinungen der Epilepsie nicht abzusprechen war.

Diese Erwägung drängte sich schon bei Beginn der klinischen Beobachtung ganz von selbst auf. Sie ist zugleich in den Ausführungen der beiden Herrn Vorgutachter angedeutet, denen eine genauere Beobachtung nicht zu Grunde lag. Sie war aber auch ganz unabhängig von einer Erfahrungsthatsache, welche an dieser Stelle hervorgehoben werden muss. Nach der wissenschaftlichen Erfahrung nämlich werden die hier in Rede stehenden Sittlich- 
leitsverbrechen ausserordentlich häufig gerade von Epileptikern begangen und zwar besonders in Zuständen der sogenannten epileptischen Aequivalente. Dieselben bestehen in einer krankhaften Veränderung des Bewusstseins mit triebartigen, oft schwer gemeingefährlichen Handlungen, wie Brandstiftung, Mord und Gewaltthätigkeiten jeder Art; sie treten an Stelle der gewöhnlichen epileptischen Krampfanfälle auf, letztere können sogar während des ganzen Lebeus fehlen, so dass die Epilepsie sich nur in den Aequivalenten äussert. Nach Ablauf des anfallartigen Zustandes hat der Kranke gewöhnlich nur eine partielle, oberflächliche oder gar keine Erinnerung von dem bei krankhaft verändertem Bewusstsein Vorgefallenen.

N. hat nun von solchenZuständen borichtet(cf. TheillI), die er mit seinen ihm unbewussten. Delikten in Verbindung bringt, und seine Beschreibung derselben erscheint äusserst charaliteristisch und in vollem Umfange glaubwiirdig. Es wäre aber doch möglich, dass er sich selbst üher dio Art solcher Zustände unterrichtet hätte oder von anderen instruirt worden wäre, dass also seine Berichto erfunden wären, um den Richter und den Sachverständigen zu täuschen.

Dieser Verdacht wurde indessen durch den sechswöchentlichen Aufenthalt in der KThinik beseitigt, indem $\mathbf{N}$. nicht den Eindruck eines Betrügers oder eincs solchen machte, der durch medicinisch-specialistische Lektüre beeinflusst worden wäre. Die Beobachtung in der Klinik war aber insbesondere in der Lage, einen Anfall genau zu constatiren, der sicherlich nicht von N. gemacht, d. h. willkürlich hervorgerufen oder vorgetäuscht sein konnte; dies wäre bei so starken mit einhergehenden körperlichen Erscheinungen, wie jene stürmische Herzaction, jene abnorme Pulsfrequenz, Temperatursteigerung und Stuhlvorhaltung, jene gesteigerte Schweiss- und verminderte UTrinsecretion es sind, ganz unmöglich. Es war ein zeitweise mit Trübung des Bewusstseins combinirter Anfall ron Compensationsstörung des Herzens, der mit den Vorläufersymptomen otwa 9, in seinem Hauptstadium 4 Tage dauerte; der Höheprnklt war am Abend des 7. Tages, dem 12. October cr. erreicht, wo N. bei starlier Bewusstseinstriibung und in hochgradigster Angst schrechiaft hallucinirte. Das innerhalb dieses Zustandes Erlebte, das in seinem äusseren Verhalten zum Ausdruck kam, ist so charakteristisch, seine Schilderung hiervon wie von seinen früheren Anfüllen so typisch, dass an der Echtheit derselben kein Zweifel bestehen kann.

Diese Beobachtung hat also für die Beurtheilnng N.'s die grösste Wichtigkeit; denn da solche schweren Anfälle im Jahre nur 2-3 Mal auftreten sollen, so wäre es leicht möglich gewesen, dass ein nur sechswöchentlicher Aufenthalt in der Klinik resultatlos geblieben wäre.

Es kommt aber noch hinzu die Bestätigung der N.'schen Aussagen und unserer Beobachtungen durch Zeugen, die solche Zustände bei N. in viel höhercm Grade gesehen haben. Das ist, wie in Theil II angegeben, der Apotbeker G., der Hauswirth und der Vetter des Angeliagten.

Endlich werden diese Mittheilungen noch erhärtet durch die im Gutachten des Herrn Dr. B. wiedergegebenen Angaben des Vaters.

Es muss nun darauf hingewiesen werden, dass $\mathrm{N}$. nach wiederholten Aussagen ausser diesen schweren psychischen Anfällen auch solche leichteren 
Grades bekommt, in denen er zwar keine Sinnestäuschungen, aber ein mindestens getrübtes Bewusstsein hat und durch den Anblick eines Mädchens ausserordentJich stark sexuell orregt wird; er schliesst das aus seinen nachherigen Befunden an seiner Kleidung.

Ich habe lieinen Grund, an dieser Angabe zu zweifeln und es handelt sich nach meiner Ansicht in beiden Fällen um epileptoide Znstände, jeweils hervorgerufen durch Compensationsstörungen bei einem sehr schweren schon Jahre lang bestehenden Herzfehler. Man kann diesen Zusammenhang sehr wohl so erklären, dass die Ernährung des Gehirns und speciell der Gehirnrinde, welche man gemeinhin als den Sitz der epileptischen Errirankungen ansieht, nicht nur durch die chronisch veränderten Circulationsverbältnisse in hohem Grade gelitten haben muss, sondem auch ducch die zahlreichen "Anfällo", in denen die Circulationsstörung sicher eine noch stärkere war. Das anf solche Weise lirankhaft vorbereitete Gehirn reagirte dann offenbar auf jede neue Insufficienz-Periode des-Herzens und den damit verbundenen Reiz in der geschilderten Weise.

In dieser Auffassung der Anfälle wird man noch bestärkt durch die Annahme einer hochgradigen neuropathischen Disposition, d. h, einer theils ererbten, theils erworbenen Veranlagung zu psychischen oder nervösen Störungen. Nicht nur, dass N. aus einer im allgemeinen enorm belasteten Familie stammt, sein auch sonst sehr nervöser Vater hat - wenn man den Angaben Glauben schenkt - ebenfalls Anfälle offenbar epileptoider Natur, wenn auch anderer Art, gehabt. N. selbst war ausserdem sehr sexuell angelegt, beschäftigte sich sehr riel mit sexuellen Dingen, trieb Jahre lang Onanie und hat ron Jugend auf sehr schwere Krankheiten durchgemacht. Dies alles konnte nicht olne Einfluss auf sein Centralnervensystem bleiben und dass es thatsächlich psychopathisch disponirt ist, zeigt sich in seiner verminderten Widerstandsfähigkeit gegen Alkohol and vielleicht auch in der Disharmonie zwischen der Art seines Studiums und seinem Lebenswandel.

Dass jene Zustände epileptoider Yatur sind, dafür sprioht ausser dem charaliteristischen Verlauf mit Bewusstseinsverlust resp. -trübung auch ihre nach allen Sehilderungen offenbar vorhandene Stereotypie. Für die Annahme irgend einer anderen, z. B. hysterischen Form der Geistesstörung existiren keine Anhaltspunkte.

Es entsteht nun schliesslich die Frage: hat $\mathrm{N}$, auch die Delikte in einem solchen epileptoiden Zustande begangen?

Diese Frage ist zwar nicht absolut sicher zu entscheiden, aber in Erwägung des ganzen Sachverhalts mit grosser Wahrscheinlichkeit zu bejahen. Freilich dürfte er die Delicte nicht in einem jener schweren mit Hallucinationen verbundenen Anfälle begangen haben, denn es wäre auffallend, dass gerade hierbei immer die Tageszeiten um 1, 2 oder 4 Uhr eingehalten wurden, wo die Exhibitionen, wenigstens im November 1896, meistens stattgefunden haben. Wohl aber hat sich $\mathrm{N}$. damals höclstwahrscheinlich in einer jener Perioden von Compensationsstörung befunden, in denen er nach seiner Angabe schon durch den Anblick eines Mädchens die schwerste sexuelle Erregung mit unan- 
genehmen körperlichen Empfindungen und Bewusstseinstrübung erfuhr. Seine diesbezüglichen Mittheilungen entbehren durchaus nicht der: inneren Wahrscheinlichkeit. Damit würde es auch stimmen, dass die Delicte im November 1896 alle innerhalb weniger Tage, um die Zeit des Busstages herum, begangen wurden. Die Anklageschrift benennt hierfür die Zeit vom 18. bis 24. November 1896 .

Es lönnte hior fom Standpunkte des Laien aus als höchst verdächtig bezeichnet werden, dass $\mathrm{N}$. sich zu seinen Zwecken auf einen Stuhl am geöffneten Fenster stellte, dass er immer nur vor Mädchen manipulirte, dass er das Gesicht hinter der Gardine versteckte und sich vor dem Schutzmann zurückzog. Es fehlt also hierbei jene Planlosigkeit und Ungenirtheit, die man bei gewöhnlichen Geisteskrankien beobachtet, wenn sie exhibitioniren, z. B. vor Personen gleichen Geschlechts, jedes Alters, jedes Standes und an jedem Orte. - In gleichem Sinne liönnte angeführt werden, dass N. einen höchst anfechtbaren Lebenswandel geführt, dass er während seiner Verlobung ein regelmässiges Geschlechtsverhältniss mit einer dritten weiblichen Person unterhalten hat und sexuell offenbar stets sehr erregt war.

Demgegenüber ist indessen zu betonen, dass eine solche Planmässigkeit gerade den epileptoiden Handlungen oft in einem Umfange anhaftet, der für den Laien das Vorhandensein einer krankhaften Geistesrerfassung als ganz unmöglich erscheinen lässt. In diesen Zuständen der Bewusstseinstrübung rufen aber dio normalen Sinnesreize auf gewöhnlichem Wege in dem krankhaft veränderten Centralorgan eine Summe von Associationen hervor, welche sich nach aussen bin so projiciren, dass die Effecte völlig überlegt und beabsichtigt aussehen können. Man kennt diese Thatsachen aus Erfahrungen, die man häufig genug in Fällen macht, bei denen gar kein forensisches Interesse nitspielt, und ist daher berechtigt, sie auch auf den concreten, wie auf andere forensische Fälle anzuwenden. Wemn also N. z. B. im August d. J. mitten in seinen Exhibitionen aufhörte, sobald er jenen Schutzmann bemerkte, so ist dies wohl so zu erklären, dass sich in dem, wenn auch zur Zeit hochgradig getrübten, Bewusstsein doch dunkle Vorstellungsmassen abspielten, welche plötzlich getrennt order auf ein anderes Gebiet geleitet wurden durch den neuen Sinnesreiz, den der Anblick des uniformirten Polizisten auslöste, resp. durch die hiermit nergebildeten Associationen. - Aehuliche Erklärungen gelten für die übrigen auffälligen Nebenumstände bei den Delicten des Angeklagten.

Dass übrigens bei einem so stark sexuell veranlagten Menschen wie $\mathrm{N}$. die triebartigen epileptoiden Handlungen auf dem sexuellen Gebieto liegen, ist nicht weiter verwunderlich. Ungekehrt muss auch daran erinnert werden, dass erfahrungsgemäss bei Epileptikern der Geschlechtstrieb im Allgemoinen sehr stark ausgeprägt ist.

Wenn N. ferner innerhalb der Klinik niemals sexuelle Erregung oder Neigang zum Exhibitionismus gezeigt hat, so ist hierza zu bemerken, dass er wälhrend der Anfallszeit im Bett gehalten wurde und keine Gelegenhat hatte, weibliche Personen zu sehen, dass überhaupt der hier beobachtete Anfall 
offenbar weniger schwer war, weil der Patient zu einer geordneten und in jeder Hinsicht mässigen Lebensführung genöthigt war.

Ich gebe also schliesslich mein Gutachten zusammenfassend dahin ab, dass N. an transitorischen Geistesstörungen epileptoider Natur leidet und die ihm zur Last gelegten Strafthaten mit grösster Wahrscheinlichkeit in einem hierdurch bedingten Zustande von Bewusstlosigkeit begangen hat.

Auf Grund dieses Gutachtens wurde N. in der mündlichen Verhandlung freigesprochen.

\section{Fall Ir.}

Der 30jährige Eisenbahnarbeiter, frühere Kellner W. W., überfiel am 20. Februar 1891 auf dem Bahnhof ein 7jähriges Mädehen, griff ihr an die Genitalien, machte ihr einen unsittlichen Antrag und fing an, seine eigenen Gesehlechtstheile zu entblössen. Bereits vorher hatte er mehreren Frauen unter obscönen Aufforderungen sein Glied gezeigt. Die eine derselben hatte ihn im Sommer 1890 mehrfach an einer bestimmten Stelle der Promenade getroffen, als er ihr mit entblössten Genitalien ontgegentrat und daran manipulirte. Sie hatte bei ihm Aehnliches kleinen Mädchen gegenüber beobachtet. Eine andere Fran sah ihn September 1890 im Herrenpissoir an seinen entblössten Geschlechtstheilen spielend stehen, so dass ihn Vorübergehende sehen mussten. Anderen Frauen hatte er Februar 1891 in der Damen-Retirade des Bahnhofs sein erigirtes Glied unter obscönen Redensarten gezeigt.

Bei seiner Vernehmung hierüber vor dem Criminal-Conmissar am 2. März 1891 bestritt W. diese Angaben zum Theil, zum Theil wollte er sich ihrer nicht entsinnen können. Später sagte er, er habe in einigen dieser Fälle einen Scherz machen wollen, indem er seinen Finger mit einer rothen Kittmasse beschmiert und vor die Hosenklappe gehalten habe.

Nachträglich kam noch eine ganze Anzahl gleichartiger Handlungen des W. zur Kenntniss. 12 Mädchen im Alter von 11 bis 20 Jahren sagten aus, er habe ihnen oft sein erigirtes Glied unter Manipulationen und obscönen Reden gezeigt, andere Male sie auch drastisch zum Coitus aufgefordert. Die Mehrzahl dieser Fälle ereignete sich im Sommer 1890, meist an einer bestimmten Stelle, welche die Mädchen passiren mussten. Aber auch aus dem Herbst und Winter 1890-91 wurde über Aehnliches berichtet.

Nachdem Verwandte des W. dem Gericht mitgetheilt hatten, dass er bereits mehrfach an Geistesstörungen gelitten habe, gab Herr Medicinalrath X. ein Gatachten ab, das sich auf eine ,allerdings nicht zu Ende geführte Untersuchung" stïtzte; danach sollte W. bei Begehung der That nicht geistesgestört, sondern überhaupt ein sinnlicher, frivoler Mensch sein, dem es einen Sinnenkitzel bereite, mit Hintansetzung alles Schamgefühls seiner Geschlechtsbefriedigung auf wahrbaft hündische Weise nachzugehen.

W. wollte nach wie vor von seinen Delicten nichts wissen und gab an, er leide von Zoit zu Zeit an einer geistigen Störung; in einer solchen habe er bereits 1887 ähnliche unsittliche Handlungen begangen, sei im Krankenhaus behandelt und freigesprochen worden. Die angestellten Recherchen ergaben 
thatsächlich ganz ähnliche und mehtrache exhibitionistische Jandhungen auf Kircbböten und Promenaden, ror Kindern und Franen aus dem Jahre 1887. Auch damals will er von nichts gewusst haben und gab an, dass er sich oft wachend in einem sch]afähnlichen Zustand befincle und dann nicht wisse, was er thue; auf diese Weise habe er sich z. B. aus einem traumähnlichen Zustande erwachend mit entblössten Geschlechtstheilen oder an Orten vorgefunden, wo er gar nicht hingewollt habe. Ausserden sei er immer etwas schwach im Kopfe gewesen und man habe ihm damals als Kellner gekündigt, weil er nicht genügt habe. - Das in dieser Sache damals (1887) erforderte Gutachten eines Kreisphysikus führte unter Anderem an, dass die Zellengenossen dos W. an diesem oft bemerkt haben, wie er im Schlafe unverständliches Zeug sprach, mehrfach Nachts aufstand, im Zimmer umherging und dann plötzlich um Hïlfo rief oder mit einem Schrei zu Boden sank, ohne am anderen Morgen etwas davon zu wissen. Das Gutachten nimmt bei W. Melancholie und in Folge derselben vorübergehende Zustände der Beraubung des freien Willens an, welche wahrscheinlich auch für die Delicte heranzuziehen seien. Daraufhin Freisprechung.

Zwischen 1887 und 1891 sind keine weiteren Vergehen belannt geworden.

Auf Antrag des Herrn Medjcinalrath X. erfolgte jetzt die Aufnahme zwecks Beobachtung in die Klinik.

Die Frau des W., mit welcher er seit 1889 verheirathet ist, giebt an, dass er, seit sie ihn kenne, vergesslich sei, über Schwindel und Kopfschmerz lilage, einmal auch auf der Strasse umgefallen und bewasstlos gewesen sei. Er habe von Zeit zu Zeit Zustände excessiver Reizbarkeit, durch Kleinigkeiten hervorgerufene Zornausbrüche; dabei Unruhe, Zerstreutheit, zweckloses Herumliramen. Er schlief sehr unruhig, rief laut aus dem Schlafe, lief Nachts öfters im Hemde auf den Hof und wusste am andern Horgen nichts mehr davon. In dieseu Zeiten ausserordentliche Steigerung des Geschlechtstriebes: ausser dem normalen Coitus entblösste er gelegentlich anch am Tage seine Geschlechtstheile vor ihr und forderte sie zu Obscönitäten auf. Dauer dieser Zustände 2-3 Tage, während deren er seiner Fran so zusetzte, dass sie in einem anderen Zimmer schlafen musste. Sie merkt das Eintreten einer solchen Periode immer an seinen lebhafteren Klagen über Kopfschmerzen und an der beschriebenen Veränderung seines ganzen Wesens. Nachher war er sehr matt, geschlecbtlich viel zurückhaltender und wollte von diesen Excessen nichts wissen.

Die Intervalle zwischen diesen Zuständen dauerten manchmal mehrere Wochen. Eigentliche Krampfanfälle wurden nie beobachtet. W. hatte stets ein ganz auffallendes Schlafbedürfniss, schlief z. B. Mittags anstatt zu essen. - Der Vater des W. ist Potator, die Mutter soll einen "Nervenschlag'“ mit nachileibender Lähmung einer Hand gehabt haben, ein Bruder ist sehr heftig und reizbar. W. hat ein gesundes Kind.

Der Angeklagte selbst theilt über sein Vorleben noch mit, dass er als Kellner ziemlich früh zum Alkoholgenuss und geschlechtlichen Verkehr gekommen sei, vom 18.-23. Jahre stark masturbirt habe und dies auch in der Elhe nicht lassen könne. Exhibitionistische Neigungen bestehen 
angeblich erst seit 1885 oder 1886 . Berichtet über seine anlallsartigen Zustände wie schon beschrieben. Dieselben gehen angeblich mit Berrusstlosigkeit einher, vorher empfinde er heftige geschlechtliche Begierde, Boklommenheit and Schwindel, nachher Mattigkeit und Abspannung. "Allerhand Gemeinbeiten", die er während dieser Zeit begehe, seien ihm nachher nicht erinnerlich, unerklärlich. Diese Angaben wendet er auch auf seine letzten Delicte an und giebt jetzt zu, dass die Geschichte mit dem rothen Kitt otc. eine Ausrede gewesen sei, um aus der schwierigen Lage herauszukonmen.

Die körperlicbe Untersuchung ergiebt nichts Besonderes, ebenso nicht die geistige; er war für gewönlich etwas deprimirt, empfand cin tiefes Schamgefühl und änsserte gelegentlich zum Arzte, dass er wohl ,in der Achtung unter dem Thier stehen müsse". Kein nachweisbarer Intelligenzdefect. Während der Beobachtungszeit hatte er mehrfach des Tachts Verwirrungsauzustände mit Hallucinationen, nachheriger Amnesie und Kopfschmerzen, manchmal auch Schwindel, Unruhe, Uebelleit u. dergl.

Das Gutachten führt aus, dass eine der gewöhnlielieren Formen continuirlicher Geistesstörung nicht vorliege. Seine eigenen und die Angaben der Frau erscheinen unter den vorhandenen Umständen durchaus glaubwürdig und sprechen in ganz charakteristischer Weise für Epilepsie. Die Annabme einer solchen wird noch weiter gestützt durch die hereditäre Belastung und sein ausschweifendes Leben, während das Fehlen von Krämpfen nicht dagegen spricht. Es ist dies die Form der psychischen epileptischen Aquivalente, welche unter anderem auch durch die von seinen Gefängnissgenossen im Jahre 1887, sowie während seines Aufenthaltes in der Kklinik beobachteten Erscheinungen bestätigt wird. In einem derartigen geistesgestörten oder mit Bewusstlosigkeit verbundenen Zustande $(\S 51)$ hat sich W. jedenfalls auch zur Zeit seiner strafbaren Handlungen befunden. Darauthin Freisprechung.

Bald nach seiner Entlassung beging $W$. in einer anderen Stadt dieselbon Handlungen wieder, wurde dann wieder in die Klinik und von hier nach der Irren-Austalt gebracht, wo er mehrfach entlassen und wieder aufgenommen wurde. - Am 6. Juli 1894 wurde er von der Polizei der hiesigen Klinik zum dritten Male zugeführt, nachdem er kurz vorher wiederum vor Kindern, und äteren weiblichen Personen exhibitionirt hatte. Auch hiervon will or lieine Erinnerung haben. Vor der That Genuss von 3 Glas Bier. Vorboten und Folgeerscheinungen wie früher. Keine gerichtliche Verfolgung. Wird nach oinigen Wochen klinischer Behandlung nach Hause entlassen.

\section{Fall.}

Der 44jährige Gärtner A. M. ist angeklagt, am 28., 29. und 30. Mai 1895 in einem Glacis drei Mädchen im Alter von 10 bis 11 Jahren zu sich ins Gebüsch gerufen, seinen Geschlechtstheil vor ihnen entblösst und sie aufgefordert zu haben, einmal daran zu greifen. Bei seiner polizeilichen Vernehmung am 30. Mai hat er dies auch eingestanden und hinzugefügt, er habe bereits mehrfach ähnliche Handlungen vorgenommen, so z. B. im Jabre 1894, wo er im Glacis mit entblössten Goschlechtstheilen herumgelaufen sei, damit 
die frauen diese sehen sollten. Er habe so einen sinnlichen Reiz für sich erzielen wollen. Später hielt er dies Geständniss nur für die That vom 28. Mai aufrecht, wollte aber von den Thaten am 29. und 30. Nai und depjenigen aus früherer Zeit nichts wissen und behauptete, in einem krankhaften Zustande gehandelt zu haben.

Im Vorverfabren gab ein Arzt sejn Gutachten dahin ab, dass sich bei dem nervös veranlagten Manne in Folge von sexuoller Abstinenz (die Frau ist unterleibskrank, nachdem sie 8 Schwangerschaften durchgemacht hat) eine gesteigerte Erregbarkeit und eine Hyperästhesia sexualis ausgebildet habe, und dass er durch den Anblick ron Mädchen oder nackten Theilen weiblicher Personen periodisch in den Zustand höchsten Geschlechtstriebes versetzt werde.

Aufnabme in die Klinik am 21. October 1895 zwecks Beobachtung seines Geisteszustandes. Nach Angabe der Frau ist an ihm eine gewisse Gedankenschwäche und ein vorübergehendes Insichversunkensein, ein traumhafter Zustand seit mehreren Jahren aufgefallen. Er nejge zu Depressionszuständen. Weiter theilte die Frau mit, M. sei unehelich geboren, sein Vater sei im Gefängniss gesessen, weil ex seine eigene Stiefmutter geschwängert habe. Kein Alkoholmissbrauch des M. Die seit einigen Jahren bestehende Vergesslichkeit und Gedankenschwäche habe seit 1895 zugenommen; seine Arbeiter haben die Köpfe äber ibn geschüttelt, weil er widersprechende Anordnungen getroffen habe. Zu Hause sei er sehr müde gewesen und bei drr Arbeit oft eingeschlafen. Er habe über Augenschwäche, Zittern des ganzen Körpers und ein eigenthümliches Gefühl im Kopfe geklagt. Im Schlafe habe sie oft Zucliungen, Zusammenfahren, Stöhnen, Aufschreien und eiu lautes Träumen bemerkt.

Körperlich bot M, ein etwas blasser, mässig gut genährter Mann, nichts besonderes, ausser leichtem Zittern der Augenlider und der rechten Hand, sowie etwas gesteigerter Pulsfrequenz. In geistiger Hinsicht war er bei klarem Bewusstsein, nicht schwachsinnig, aber deutlich gedrückter Stimmung. Er erzählt, dass er seit drei bis vier Jahren gleichgiltiger geworden sei, weiss von der That nur, dass er die Genitalien der kleinen Mädchen gesehen habe, dadurch aufgeregt geworden sei und seinen eignen Geschlechtstheil herausgeholt habe; er könne aber nicht unterscheiden, ob er dies ans eigener Erinnerung oder durch die Vernehmungen wisse. Während der weiteren klinischen Beobachtung behauptete M., sehr häufig nicht zu wissen, wo er sei. Einmal stand er Nachts auf und sagte, es sei Feuer; es stürme draussen; er hielt die Hand an die Stirn, ging zum Fenster und horchte; als ihm der Wärter sagte, es sei nichts, legte er sich wieder hin; einen veränderten Eindruck soll er nicht gemacht haben. Nach einer halben Stunde erhob er sich wieder im Bette und änsserte, es läute draussen, er höre es doch. Später erklärte er auf Befragen hierüber, es sei ihm so eigenthümlich, so übel im Kopfe gevesen; seine Frau sei dagewesen und habe gerufen, er habe läuten gehört und sei sich nicht recht klar geweren, wo er sich befinde; dass er aufgestanden sei, wisse er nicht; es sei ihm sonst noch Verschiedenes, „dummes Zeug" durch den Kopf gegangen, worüber er sich nicht äussern könne. Zur Zeit dieser Angaben betrug die Pulsfrequenz 124 p. M., ausserdem wurde wieder 
Zittern der rechten Hand beobachtet, welches sich steigerte, als der Arzt den Puls zählte. (Diese Beobachtung wurde noch wiederholt gemacht.) Er klagte weiterhin noch oft über Kopfschmerz und Schwindel, aber immer nur auf Befragen, ferner über Ohrensausen und Taubheitsgefühle in den oberen Extremitäten. Der Schlaf war öfters unruhig, einmal sprach er Nachts lant im Schlafe und stiess mit den Fäusten. Am Morgen gab er an, er habe einen aufregenden Traum gehabt, in dem er sich habe wehren müssen. Pulsfrequenz dauernd über normal. Weitere Irrankhafte Beobachtungen wurden an M. nicht gemacht.

Das Gutachten führt aus, dass zwar ein absolut sicheres Urtheil nicht möglich sei, dass aber die anamnestischen Angaben und die klinischen Beobachtungen auf eine reizbare Schwäche des Centralnervensystems, d. h. auf eine Neurasthenie, hinweisen; anf diese allein hin wäre $\$ 51$ nicht anwendbar; möglicherweise sei aber auch Epilepsie in Form transitorischer psychischer Störungen mit im Spiele; es sei nicht ausgeschlossen, dass die Delicte in einem derartigen Zustande begangen worden seien. - In der HauptverhandIung: Freisprechung.

\section{Fall.}

Am 16. März 1898 wird der 32jährige Maler R. B. ron der Polizei in die Klinik eingeliefert, nachdem er angeblich seine Frau mit dem Messer bedroht hat. Er selbst gab bei der polizeilichen Vernehmung zu, betrunken gewesen zu sein und mit seiner Frau Streit gehabt zu haben; mit dem Messer aber habe er sie nicht bedroht. Uebrigens wisse er oft nicht mehr was er thue, wenn er angetrunken sei. Dem Polizeiarzt war es bekannt, dass er an Epilepsie gelitten hat und er vermuthete bei ihm Geistesstörung.

B. selbst gab nach seiner Aufnahme Folgendes zur Anamnese: Der Vater war Potator und erhängte sich; ein Stiefbruder starb mit 16 Jahren an einer Rückenmarkskrankheit. B: nässte bis zum 17. Jahre jede Nacht das Bett, kam in der Schule ziemlich gat mit, war dann zuerst Laufbursche, dann Schuhmacher, konnte aber das Sitzen nicht vertragen und wurde Bäcker. Als solcher litt er viel unter der Hitze und den Dünsten, er bekam häufig Uebelkeit und Erbrechen. Seit 1891 ist er Maler und leidet seitdem an Kopfschmerzen. Im Alter von ca. 10 Jahren fiel er eine Bodentreppe herunter auf den Kopf, war etwa $1 / 4$ Stunde lang bewustlos und weiss davon nichts mehr, als dass er den Arm in einer Binde trug. Seit dieser Zeit belram er fast jede Woche einmal "Krämpfe"; er fällt um, hat Zuckungen und verunreinigt sich zuweilen mit dem Urin. Dies dauert nur kurz; vorher wird es ihm immer "dumm im Kopfe", nachher füllt er sich matt und hat keine Erinnerung von dem Vorgefallenen. 1890 traten die Anfälle heftiger und besonders bei Aerger auf, z. B. als er sich darüber ärgerte, dass seine Brant mit einem Anderen tanzte. Es sei ihm gesagt worden, 10 Mann hätten ihn nicht halten können, es sei Blut aus dem Munde gekiommen und unwillkürlich Urin abgegangen. Er merkte das Auftreten der Anfälle daran, dass ihm heiss im Kopf wurde. Behandlung mit "Salzwasser", (Brom). Bald nach seiner Verheirathung 1891 sollen die eigentlichen Krampfanfälle aufgehört haben. Indessen hatte er seit 1890 angeblich auch Zustände, in 
denen er durch den $\Delta$ bblick von Frauenzimmern auf der Strasse, besonter's wenn sio boi schmutzigem Wetter ihre Kleider in die Höhe nebmen, sexuell stark erregt werde; er bekomme dann Erection und verliere das Bewusstsein; erst nach beendeter Ejaculation, oder wenn er von Jemand angeredet werde, lomme er wieder zu sich. Er habe anch öfter, wie ihm gesagt wurde, dabei Manipulationen an seinen Gliede vorgenommen. Häufig habe er sich nach stattcehabter Ejaculation in einer Nebenstrasse mit heruntergelassener Hose wiedergefunden. Nachlier habe er immer Angst gehabt, dass es Jemand gesehen hätte. Er habo stets vorher getrunken gehabt. Derartige Zustände seien in der Woche oft 2 bis $3 \mathrm{Mal}$ aufgetreten, namentlich, wenn er keine Arbeit hatte und in den Strassen herumlief.

Bereits im Jahre 1887 sei er rechtmässigerweise wegen Beihilfe zur Nothzucht bestraft worden. Der Andere habe seine Begleiterin auf offener Strasse vergewaltigt, er selbst habe sie festgehalten. Er sei etwas angetrunken gewesen, wisse sich aber an Alles gut zu erinnern. - 1895 vier Monate Gefängniss wegen Erregung öfentlichen Aergernisses. Er solle sich laut Zeugenaussage auf einer Wiese mit heruntergelassenen Beinkleidern herumgetrieben haben. Er sei angetrunken gewesen und wisse ron dem Vorfall nichts. - 1897 vier Monate Gefängniss aus demselben Grunde: Erregung eines öflentlichen Aergernisses in der gleichen Weise wie 1895. -

Zur Zeit sei er wegen zwei neuen derartigen Delikten angeklagt. Er solle sich am 1. März cr. Abends 9 Jhr in stark betrunkenem Zustande vor 3 weiblichen Personen entblösst haben. Er wisse daxon nichts, sei erst zu sich gelommen, als ihn seine Frau zu Hause zur Rede stellte. Das zweite Mal sei er am 5. März cr., wiederum betrunken, in einer borïchtigten Strasse von ebenso berüchtigten Frauenzimmern aufgefordert worden, sein Glied zu zeigen; er habe dies gethan, nachdem er sich auf die andere Seite der Strasse gestellt hatte. Der hinzugekommene Polizist habe ihn aufgefordert, seine Kleider zu ordnen. Das Bew usstsein habe er nicht verloren gehabt.

Nach Alkoholmissbrauch befragt, giebt er an, dass er seit 1890 täglich für $5 \mathrm{Pgg}$. Schnaps, manchmal auch mehr trinke. Tach seiner Entlassung aus dem. Gefängniss, December 1897, sei cr in's „Blane Kreuz" eingetreten, er sei aber von anderen wieder verführt worden und habe manchmal ziemlich riel (für 25 Pfg. Schnaps) getrunken. Dass er eine verminderte Resistenz gegen Alkohol habe, lässt sich aus seinen ungenauen Angaben nicht mit Sicherbeit schliessen.' Er ist Vater von 3 gesunden Kindern.

Seine Fran theilt mit, dass sie vor dor Verhoirathung bei B. selbst einmal einen seiner Krampfanfälle gesehen lrabe; auch nach ihrer Schilderung scheint es sich um Epilepsio gehandelt zu haben. Seit der Verbeirathung aber seien dieselben nie wieder aufgetreten. 1892 habe er eine Zeit lang so heftige Kopfschmerzen gehabt, dass er den Kopf immer gegen die Wand gestossen habe. Er kann nach ihrer Ansicht nicht viel Alkohol vertragen, ist z. B. von 3-4 Glas Bier und 1 Schnaps betrunken. Er weint beim geringsten Affect und lacht bei jeder Gelegenheit, unmotivirt. Zu Hause sitzt er immer stumm da, starrt vor sich hin, "wie ein Tränmer"; "er kann sich nicht mit den Leuten 
unterhalten". Die Angaben über seine Exhibitionen und Bestrafungen werden von der Frau bestätigt; dass erste Mal entblösste er sich vor Kindern, das zweite Mal vor 3 Dienstmädchen und zuletzt vor 2 ledigen Mädchen und 1 Frau. Ausser diesen Delikten habe er auch einmal in nüchternem Zustande, vor etwa 3 Jahren, im Hofe seiner Mutter vor Kindern die Genitalgegend entblösst, seine Verwandten hätten aber eine Anzeige zu verhindern gewusst. Der Geschlechtstrieb in der Ehe soll nur gering sein; andere sexuelle Abnormitäten hat er nicht gezeigt. Die Frau hält ihn übrigens jetzt nicht für krank, hat keine Gedächtnisabnahme und dergl. bei ihm bemerkt; sie ist sehr animos gegen ihn und will sich gänzlich von ihm trennen, nie wieder etwas mit ihm zu thun haben; sie seien beide schon 4 Mal ziemlich lange auseinander gewesen. Er sei ein Taugenichts, arbeite nichts, mache überall Schulden, lüge und bettle, und sei deshalb schon einmal eingesteckt gewesen. In der Betrunkenheit ist or sehr grob und misshandelt seine Frau. Nachdem er zum letzten Male wegen seiner Exbibitionen zur Anzeige gebracht worden war, sprach er davon, sich und seine Frau vergiften zu wollen, weil er jetzt Strafe fürchtet; andererseits wünschte er, man müsste ihn mit 3 Jahren bestrafen, weil er diese Unsittlichkeiten nicht lasse.

Die Untersuchung des B. in der Klinik ergiebt keine körperlichen Abnormitäten, speciell keine besonderen Stigmata der Degeneration, ebensowenig Zeichen von Epilepsie oder einer gewölnnlichen Geistesstörung.

Sein Verhalten ist gewöhnlich nicht gerade das èines, ,Träumers". Er ist entschieden geistig etwas beschränkt, indessen im Verhältniss zu seinem niedrigen Bildungsgrade nicht in einem irgendwie verwerthbaren Maasse. Seine Stimmung ist meist eine muntere, aber sehr labile: er weint leicht und verfällt schnell und ebenso leicht ins andere Extrem. Er ist sehr erregbar, droht, als ihm die Angaben seiner Frau vorgehalten werden, sie umzubringen und weigert sich, dem Arzt weiter Antwort zu geben, wenn er so etwas glaube. Er brüstet sich mit dem, was er für seine Frau gethan habe und wirft ihr ausserehelichen Coitus vor. Was seine nicht zur Anzeige gelkommene Exhibition betrifft, so bestreitet er nicht, bei Bewusstsein gewesen zu sein; er wisse aber nicht, wie er dazu geliommen sei; er habe übrigens nur die Beinkleider aufgemacht, die Genitalien bätten die Kinder nicht gesehen, sie seien weggelaufen. Er habe gedacht, dies mache den Kindern Vergnügen, seinetwegen habe er es weniger gethan; es hätte ihn aber doch gefrent, wenn sie dageblieben wären und an seine Geschlechtstheile gefasst hätten. Weitere Erlklärungen hierüber sind ron ihm nicht zu erlangen. Er stellt es energisch in Abrede, dies in bewusstem Zustande andere Male wiederholt oder andere Perversitäten getrieben zu haben. - Weitere Beobachtungen wurden an ihm nicht gemacht. Von den früher über ihn geführten Gerichtsakten konnte bisher keine Kenntniss genommen werden.

\section{Fall.}

A. B., 42 Jahre alt, Photograph, wird beschuldigt, am 19. und 21. August 1896 auf einem öffentlichen Platze, wenn Kinder des Weges kamen, seine Geschlechtstheile herausgenommen und an denselben herumgespielt zu haben. 
Weiter wird er beschuldigt, er habe am 20. August 1896 an cinem anderen Platze ebenfalls vorbeigehenden Mädchen seine Genitalien gezeigt; endlich sei er an einem weiteren Orte in ein Haus hineingetreten, um dieselben Handlungen zu begehen, wenn kleine Nädchen vorbeilramen. Wenn erwachsene Leute kamen, habe er seine Kleider in Ordnung gebracht, vor den Kindern aber habe er die Beinkleider theilweise bis zu den Knien heruntergelassen.

B. wurde sistirt, wollte bei der Vernehmung von dem Vorgefallenen nichts wissen, als dass er "Wolf" gehabt und diesen im Gebüsch gekühlt habe; seine Geschlechtstheile habe er weder gezeigt, noch daran herumgespielt. Die Kinder seien ihm nachgelaufen. Der Polizeiarzt konnte am 22. August ein Wundsein nicht feststellen und empfahl seine Verbringung nach der Klinik. B. wurde daher am 22. Angust 1896 in der Klinik aufgenommen.

Die Untersuchung ergab bei B. einen etwas herabgekommenen Ernährungszustand, blasse Hantfarbo, Tremor der Zunge, der Lider, sowie beim Fixiren auch des Kopfes; lebhafte Sehnen- und Periost-Reflexe der oberen und unteren Extremitäten. Psychisch völlig orientirt und klar, von gewöhnlicher Intelligenz, aber deprimirter Stimmung. Er fängt bei der Erzählung seiner widrigen Lebenschicksale an zu weinen. Vor 2 Jahren sei er durch Unglück genöthigt gewesen, sogar seinen Apparat zu versetzen und sei nun seitdem nicht mehr selbstständig. Er befinde sich schon längere Zeit auf Reisen, habe seit 1. August 1896 in Halle eine Stelle als Gehilfe. Frau und 3 Kinder befinden sich in Stettin. Von Here dität nichts bekannt. Seit seinem Unglück habe er viel vor sich hingebrütet, er sei vergesslich geworden, es steige ihm oft heiss und dann wieder kalt in den Kopf. Vor Jahren habe er mehrere Mal Ohnmachtsanfälle gehabt, bei denen er umgefallen und bewusstlos gewesen sei. Er habe manchmal Zustände, bei denen er etwas Unrechtes mache, was ihm nachher leid thue. Krämpfe habe er nie gehabt. Angeblich keine Onanie, geringes geschlechtliches Bedürfniss. Bei den wiederholten Explorationen wollte er von den Exhibitionen absolut keine Erinnerung haben, er könne sich die Vorfälle nicht erklären, könne es nicht glauben. Er wisse nur, dass er seinen "Wolf" mit Talg gekühlt habe. Weitere Beobachtnngen wurden in der Klinik an ihm nicht gemacht. Sein Allgemeinzustand besserte sich etwas und er wurde am 13. October 1896 entlassen.

Bei einer später stattfindenden Gerichtssitzung wurde von dem Sachverständigen mündlich ausgeführt, dass sich durch die klinische Beobachtung Zeichen einer habituellen Geistesstörung nicht ergeben haben. Es bestanden nur leichte neurasthenische Symptome. Andere Angaben, als seine eignen, haben nicht erhoben werden können. Diese allerdings deuten darauf hin, dass er in den letzten Jahren Bewusstseinstrübungen, vielleicht epileptischer Art, unterworfen war. Inwieweit diese Angaben begrïndet seien, könne man zwar nicht sicher beurtheilen, indessen scheinen dieselben doch der innern Wahrscheinlichkeit nicht zu entbehren. Es wäre dann nicht unmöglich, dass B. die betr. Handlungen in einem solchen epileptoiden, krankhaft gestörten Geisteszustande begingen bätte. Dies lasse sich aber nicht sicher beweisen. - Daraufhin Freisprechung. 


\section{Fall.}

Am 23. Juli 1894 wurde der 37 Jahre alte Kaufmann E. H. durch die Polizei der Klinik zugeführt mit der Angabe, er sei vor etwa 4 Wochen dadurch auffällig geworden, dass er gegen Abend auf einer der belebtesten Strassen einer Frau sein erigirtes Glied zeigte und sie zum Coitus aufforderte. Einige Zeit später habe er wiederum zwei junge Mädchen auf derselben Strasse belästigt, indem er ihnen unter die Röcke griff, angeblich ohne zu exhibitioniren. Vor 8 Tagen endlich fiel er zum dritten Male auf, als er auf der Strasse an die zwei Töchter gutsituirter Eltern, welche vor ihnen hergingen, herantrat und sie aufforderte, mit auf sein Zimmer zu kommen, er habe dort ein Bott für sie. Er machte bei der sogleich exfolgenden polizeilichen Vernehmung den Eindruck eines entweder Betrunkenen oder Geisteskranken.

Aus den Acten ist zu entnehmen, dass er bereits am 14. Oct. 1893 in Berlin wegen Erregung öffentlichen Aergernisses zu $50 \mathrm{Mk}$. Geldstrafe verurtheilt worden ist.

H. giebt zar Anamnese an, sein Vater sei Gastwirth und Trinker gewesen; eine Schwester der Mutter war geisteskrank und einige Zeit in einer Anstalt. Ein Bruder von ihm habe noch im Alter von 20 Jahren das Bett genässt. Er selbst habe nie an Krämpfen u. dergl, gelitten, habe aber in der Schule schlecht gelernt und sei geschlechtlich immer sebr aufgeregt gewesen. Von sonst bei ihm vorhandenen sexuellen Perversitäten wollte er nichts wissen. Die Bestrafung in Berlin sei erfolgt, weil er in der Friedrichstrasse sein Glied herausgenommen haben soll. Er selbst wisse nichts davon. Vor 8 Jahren Ulcus durum mit Secundärerscheinungen. Er sei einmal von einem Lehrling mit einer Flasche vor den Kopf geschlagen worden. Durch geringen Alkoholgenuss steigere sich seine sexuelle Erregung, er könne überhaupt nicht viel vertragen und wisse, wenn er etwas mehr trinke, nicht mehr was er thue. Er habe Nachts öfters anfgeschrien und sei seit mehreren Jahren vergesslich geworden.

In der Klinik war H. zunächst etwas deprimirt durch die Sorgen wegen der begangenen Handlungen, bot aber im Uebrigen keine geistigen Störungen. Er weiss von dem Vorgefallenen andauernd nichts, und bemerkt dazu nur, dass er eben sehr wenig Alkohol vertragen lönne und jedesmal, wenn er einige Glas Bier mehr trinke als er gewohnt sei (z. B. beim Genuss von 4--6 Gläsern), plötzlich "abfalle" und geschlechtlich sehr erregt werde; was weiter passire, entziehe sich seiner Erinnerung. In körperlicher Hinsicht fanden sich nur secundär-luetische Erscheinungen, sonst nichts Besonderes.

Da ein Strafantrag gegen H. zunächst nicht vorlag, wurde er am 19. Oct. 1894 aus der Ḱlinik entlassen. Auf eine spätere Anfrage der Staatsanwaltschaft, ob H. geisteskrank sei resp. war, wurde erwidert, dass er sich zur Zeit der Begehung der That jedenfalls in einem sogenannten pathologischen Rausch, d. h. in einem geistesgestörten Zustand befunden habe, durch welchen seine freie Willensbestimmung aufgehoben war. Es sei aber zu bemerken, dass er 
seine geringe Widerstandsfähigkeit gegen Alkohol kenne und sehr wohl wisse, dass er durch den Genuss geringer Mengen unzurechnungsfähig werde. $\mathrm{Ob}$ demnach das Vorhandensein einer strafbaren Handlung auszuschliessen sei, bleibe richterlichem Ermessen überlassen. Weitere Folgen nicht bekannt.

\section{VIT. FaII.}

Der 56jährige Privatmann, frühere Kanfmann, 0. L. wird am 29. Juni 1896 durch die Kriminalpolizei zur Klinik gebracht, nachdem er am vorhergegangenen Abend an einem öffentlichen Platze auf einer Bank sitzend, angeblich seinen Geschlechtstheil hat heraushängen lassen, was den dort spielenden Kindern aufgefallen ist. Er machte 1 ach der Sistirung den Eindruck eines Geisteskranken. Auf dem Transport hat er sich ruhig verhalten, nur bisweilen mit den Achseln gezuckt und geseufzt.

L. war bereits rom 3. Aug. bis 31 . Oct. 1895 in der hiesigen Klinik wegcn einer hypochondrisch-melancholischen Geistesstörung behandelt worden.

In seiner Vorgeschichte ist nichts von sexuellen Delieten enthalten. En ist unverheirathet. Ein Onkel von ihm war "nervenkrank", von auffallendem Charakter, ein anderer Onkel, Bruder von diesem, ist verlrommen, war dispositionsunfähig. L. selbst war von Jugend auf kränklich, litt angeblich an nervösem Herzklopfen, lebte sehr ängstlich und solide; Neigung zu Hypochondrie. Fürchtete einen Herzschlag zu bekommen. Durch geringe Vermögensverluste in den letzten Jahren wurde er noch mehr erregt, machte sich selbst Vorwürfe, hatte unbegründete Angst vor kommender Noth, sprach von Selbstmord, war ganz ruhelos, zerpflückte Holz- und Papiẹrstückchen zu kleinsten Partikelchen, redete immer vor sich hin und gestikulirte, ass wenig und schlief gar nicht. Genau dasselbe Verhalten zeigte er damals auch in der Klinik, besserte sich aber ganz erheblich and konnte so gut wie genesen entlassen werden.

Bei seiner jetzigen Wiederaufnahme giebt er an, er sei nach kurzem Aufenthalte bei Verwandten und in seinem früheren Wohnort nach Halle zurückgelehrt. Er habe sich ohne Gepäck in den Gasthöfen herumgetrieben, habe jede Nacht in einem anderen Hôtel gewohnt: "weil ihn sonst die Wirthe für cinen Faullenzer gehalten hätten". Er that dies, obwohl ih w seine Verwandten ein Zimmer gemiethet hatten. Letzteres hielt er aber für zu theuer, über seine Verhältnisse gehend. Auf den Einwurf, dass er so ja doppelt habe bezahleon müssen, für Privat- und Hôtelzimner, weiss er nichts zu erwidern. Er habe sich von einer Kneipe zur anderen herumgetrieben, um die Zeit hinzubringen, nicht des Bieres wegen. Letzteres habe er sehr wenig getrunken, Schnaps gar nicht. Am Abend des Delicts sei er an Thatorte spazieren gegangen, habe sich auf eine Bank gesetzt und sich mit einem Manne unterhalten. Da sei ein Polizist auf ibn zugekommen, habe ihn gefragt, was er hier mache und ihn aufgefordert, mitzuliommen. Von der Exhibition weiss er nichts; es soi möglich, dass or nach dem Verlassen des Pissoirs seine Kleidung nicht ganz in Ordnung gebracht habe. Als man ihm auf der Polizei von dem Delict Mittheiluug machte, sei er sehr erschrocken; er könne ja an der Richtigkeit der dussagen 
nicht zweifeln, wisse aber nichts dałon. Er sei doch ein anständiger Mann und habe immer solche Sachen verabscheut. Hierbei fängt er an zu weinen. Nachträglich fügt er noch hinzu, er have schon längere Zeit bemerkt, dass es geistig mit ihm nicht richtig sei; vor etwa $\mathbf{4}$ Wochen habe er in der Irrenanstalt Nietleben vergeblich um seine $A$ ufnahme gebeten. - Dies entspricht der Wahrheit, wie überhaupt sämmtliche Angaben L.'s durchaus glaubwürdig erscheinen.

Körperlich ist L. für seine Jahre sehr gealtert, hat weisses Haupthaar, macht einen reducirten Eindruck, bietet aber sonst keine Abnormitäten. In geistiger Hinsicht ist er deprimirt, denkt fortwährend über seine Lage nach, seufzt und jammert; er ist dabei klar und orientirt, hat gute allgemeine Kenntnisse; Gedächtnissdefecte nicht bemerkbar. Im weiteren Verlauf der Beobachtung schloss er sich von den anderen Kranken ab, klagte über ein dumples Gefühl im Kopfe, grübelte über seinen Zustand, brïtete immer vor sich hin, zorkleinerte fortwährend Streichhölzer u. dergl. Von letzterer Gewohnheit sagt er selbst, dass sie sinnlos sei, er lönne sie jedoch nicht lassen. Er machte einen ganz rathlosen Eindruck, wirkte dadurch auf die anderen komisch, wollto das Zimmer nicht verlassen, weil er sich Vorwürfo üter seine That machte. Während eines vierwöchentlichen Aufenthaltes in der Klinik änderte sich sein Zustand nicht und er wurde so nach der IrrenanstaIt Alt-Scherbitz überführt.

Es wurde bei dem Kranken ein depressives Irresein auf der Basis des etwas frühzeitjg beginnenden Seniums angenommen. Die an die Klinik gerichtete Anfrage der Staatsanwaltschaft, ob L.'s Behauptung. seiner Bewusstlosigkeit oder Geistesgestörtheit möglich bezw. wahrscheinlich sei, wurde bejaht. Der weitere Verlauf ist diesseits nicht belrannt geworden.

Die mitgetheilten Fälle bieten in mehrfacher Hinsicht ein klinisches und forensisches Interesse. In Anbetracht dessen möchte ich kurz auf einige Punkte hinweisen.

Bei einer Gesammtbetrachtung fällt es zunächst in die Augen, dass bei 5 von 7 Fällen die Epilepsie in irgend einer Weise mitspielt, während ausgesprochener Schwachsinn in keinem der Fälle vorhanden war. Als solchen kann man auch den zuletzt berichteten Fall VII nicht auffassen, obwohl der Kranke körperlich sehr gealtert und seine Psychose von etwas senilem Charakter war, die Annahme einer senilen Demenz also nahe lag; er hatte aber noch einen guten Fond geistiger Kräfte, sein Sittlichkeitsgefühl war ganz intact. Natürlich wäre es ein Leichtes gewesen, eine ganze Anzahl von Exhibitionen auf Grund von paralytischem Schwachsinn mit aufzuführen. Derartige Beobachtungen sind wohl in jeder Irrenanstalt nicht selten; indessen erlangen sie, einmal in der Anstalt und bei deutlicher Demenz, meist keine forensische Bedentung mehr. Ihre Mitheilung wäre daher nur von geringem praktischen Werthe.

Nun sind freilich diese Spuren der Epilepsie in allen 5 Fällen 
weder gauz rein noch ganz sicher. .Krämpfe hat keiner von ihnen gehabt ausser B. in Fall IV; auch bei diesem sollen die eigentlichen Krampfanfälle seit mehreren Jahre cessirt haben und kurz vorber epileptoide Zustände mit Bewusstseinsverlust eingetreten sein. Diesen letzteren begegnen wir nun wieder in Fall I, II, III and V, also in jedem der 5 ersten Fälle. Während sie aber nur im II. Falle ganz rein, gewissermaassen idiopathisch sind, erscheinen sie im I. Fall als der Ausdruck einer schweren Circulationsstörung im Gehirn auf Grund einer Herzerkrankung. Im III. und V. Falle sind sie verbunden mit gewissen Erscheinungen der Neurasthenie, ausserdem sind sie hier nicht ganz sicher festgestellt und in Fall IV sollen sie angeblich nur nach Alkoholgenuss auftreten. Dadurch bildet der letztere einen Uebergang zu Fall VI, bei welchem epileptische oder epileptoide Elemente nicht nachweisbar waren; der Betreffende gerieth aber ebenfalls durch Alkoholgenuss und zwar schon geringer Quantitäten, in einen pathologischen Erregungszustand mit krankhaft veründertem Bewusstsein und nachherigem Erinnerungsdefect. Die Verbindung epileptoider und neurasthenischer Symptome erscheint mir bemerkenswerth; sie ist ein nicht seltenes Vorkommiss und erschwert die Beurtheilung des betreffenden Falles oft sehr. Eine Entscheidung war in diesen beiden Fällen noch um so schwieriger, als die epileptoiden Störungen sich nicht auf sichere Beobachtungen stützen konnten.

Eine mit Ausnahme des Falles VII allen gemeinsame Eigenthïmlichkeit sind die Wiederholungen der exhibitionistischen Handlungen; dieselben geschahen theilweise selbst nach der Entlassung aus dem Gefängniss, nach der Verurtheilung, oder nach der Entlassung aus der Irrenanstalt. Man darf wohl mit Recht annehmen, dass die zu unserer oder zur Kenntniss des Gerichts gelangten Exhibitionen bei Weitem nicht die einzigen waren und dass diese Individuen die öfentliche Sittlichkeit in viel häufigeren Fällen werden verletzt haben, als in den durch reinen Zufall bekannt gewordenen.

Was den Geschlechtstrieb betrifft, so war derselbe in Fall I und VI offenbar von jeher ziemlich stark ausgeprägt, in Fall II und III ist von einer besonderen sexuellen Veranlagung nichts bemerkt, dagegen hatten die Betreffenden zeitweilige geschlechtliche Erregungszustände, die bei dem einen, zwar nicht rein periodisch, aber in verschieden langen Zwischenräumen immer wieder spontan auftraten, bei dem anderen augenscheinlich durch eheliche Abstinenz in Folge Krankheit seiner Frau bedingt waren. In Fall IV bestand offenbar ein sehr excitabler Sexualtrieb, andererseits aber eine der Frau auffallende Kälte im ehelichen Verkehr. Der Photograph B. (V) wollte nur geringe geschlecht- 
liche Bedürfnisse haben; auf diese Angabe möchte ich indessen nicht viel Gewicht legen. Masturbation wurde in 3 Fällen (I, II und IV) zugegeben.

Bezüglich der sonstigen Moralität unserer Exhibitionisten konnte ich bloss in 3 Fällen zuverlässige Anhaltspunkte gewinnen. Darnach würde nur dem Privatier L. (VII) ein gutes, dem stud. theol. N. (I) und dem Maler B. (IV) dagegen ein ungünstiges Prädicat zukommen. Besonders der Letztere scheint nach dem persönlichen Eindruck und nach den Schilderungen seiner Frau moralisch ziemlich tief gesunken oder auf einer niedrigen Stufe stehen geblieben zu sein.

Von anderen Perversitäten sind uns nur unzüchtige Betastungen von kleinen Mädchen in Fall II und VI bekaunt geworden, während die Repräsentanten der Fälle III und IV schon durch den Anblick weiblicher Waden sexuell stark erregt wurden.

Alle waren bereditür belastet, abgesehen von dem Photographen B., bei dem von Belastung nichts bekannt war. Zwei von ihnen (II und IV) hatten mehrfach ihre Berufsarten gewechselt. - Sie befanden sich sämmtlich im Mannesalter, auf der Höhe der Geschlechtsreife, zwischen dem 25. und 44. Jahre, mit Ausnahme des Privatier L., der im 566. Lebensalter stand und sich in so manchen anderen Punkten von den Uebrigen unterschied.

In 6 von den 7 Fällen wurde von dem Gericht die Frage aufgeworfen, ob der Delinquent im Zustande der Geistesstörung gehandelt habe oder nicht und in allen 6 wurde darüber ein SachverständigenUrtheil eingefordert (bei dem restirenden Fall IV wird dies voraussichtlich bald ebenfalls geschehen). Es war aber nur in 2 Fällen (II und VI) mit einiger Sicherheit möglich gewesen, die unsittliche That auf eine krankhafte Geistesthätigkeit im Sinne des $\S 51$ des St.-G.-B. zurückzuführen; in einem (I) konnte dies als sehr wahrscheinlich und in dreien (III, V und VII) als möglich, jedoch nicht beweisbar, ausgesprochen werden. Das Unbestimmte dieser gutachtlichen Aeusserungen war zum Theil in der Eigenart der betreffenden Fälle, zum Theil in der Unzulänglichkeit der uns zur Verfügung stehenden Angaben begründet. Bei 6 Delinquenten fehlte angeblich das Bewusstsein der That, was bei vieren von diesen (I, II, VI und VII) auch durchaus glaubwürdig erscheint, bei zweien davon (IV und V) ist mir diese Angabe nicht über jeden Zweifel erhaben, und bei einem (III) war das Bewusstsein angeblich nur theilweise vorhanden. In 5 Fällen erfolgte Freisprechung, bei einem (VII) ist mir das Resultat nicht bekannt geworden.

Betrachten wir nimmehr unsere Beobachtungen im Einzelnen und 
suchen sie in irgend ein Verhältniss zu den in der Einleitung beschriebenen Gesichtspunkten zu bringen, so müssen wir schon bei dieser relativ kleinen Zahl von Fällen alsbald erkenmen, dass sich die Praxis nicht in vorgeschriebene Schemata zwängen lässt, und dass es unter Umständen kaum möglich ist, vom psychiatrischen Standpunkte aus, ein entscheidendes Urtheil zu fällen.

Schon der Fall I scheint mir in dieser wie in anderer Hinsicht besonders lehrreich zu sein. Der betreffende Delinquent, ein Student der Theologie, hatte in sexuellen und allgemein moralischen Dingen keinen sehr vortheilhaften Leumund. Von Jugend auf Onanist, unterhielt er hier mit einem. Mädchen des Bürgerstandes ein dauerndes sexuelles Verhältniss, nachdem er sich bereits mit einer Dame aus guter Familie erst heimlich und dann offentlich verlobt hatte. Kurz vorher war er erst hierhergezogen und hatte jene wiederholten, raffinirten Exhibitionen begangen. Er lengnete vor dem Schöffen- und vor dem Landgericht und erst als seine Revision vom Oberlandesgericht verworfen war, trat er mit der Angabe hervor, dass er die Thaten in einem geistesgestörten Zustande begangen haben müsse. Was liegt hier näher, als an einen sexuell überreizten, "zweckbewussten und gewohnheitsmässigen" Exhibitionisten zu denken, der in dieser Perversitat eine nene Form der Onanie suchte. Zwar erfuhr man von ibm und von Anderen, dass er thatsächliche vorübergehende Zustände von Geistesstörung habe, aber niemand hatte einen positiven Zusammenhang zwischen diesen und den Exhibitionen bemerkt; erstere waren überhaupt nicht sachgemäss beobachtet und ihrer Natur nach nicht klargestellt, ihr Werth für die Beurtheilung des ganzen Falles war daher sehr zweifelhaft. Auch die 6 wöehentliche Beobachtung in der Klinik wäre — $z a$ Ungunstea des Angeklagten - ganz resultatlos gewesen, wenn N. nicht zufällig gerade hier eijen jener von ihm ebenso geschilderten Anfälle von Geistesstörung bekommen hätte, welche sonst nur selten im Jahre auftreten sollen. Dies verschob doch die ganze Auffassung um ein Wesentliches, wenn auch hier ein directer Zusammenhang mit den Delicten nicht stricte nachzuweisen war. Nach der ganzen Constellation der Thatsachen und der zeitlichen Verhältnisse musste man nunmehr die Wahrscheinlichkeit des erwähnten Zusammenhangs anerkennen, aber boweisen liess er sich nicht. Allerdings erscheint es verdächtig, dass N. ̈̈hnlich, wie ein Theil der Lasègue'schen Exhibitionisten, seine Handlungen fast stets am selben Orte, in derselben Situation und zu ganz bestimmten Stunden begangen hat. Hierzu gebört entschieden ein gewisser Grad von Bewusstsein, auch hierin liegt etwas "Gewohnheitsmüssiges und Zweckbowusstes." Alloin dies schliesst die Krankhaftig- 
keit eines Bewusstseinszustandes nicht aus, wie man ihn bei Epileptikern z. B. so häufig im Zusammenhang mit einem Anfall oder im Aequivalent findet. Bemerkenswerth ist noch die Angabe N.'s, dass er' zweierlei Anfälle bekomme; die eine Art derselben ist die im obigen Gutachten geschilderte, mit schweren Hallucinationen u. s. w. verlaufende, die andere geht nur mit einer Bewusstseinsstörung einher und soll durch den Anblick von Mädchen, aber ebenfalls nur innerbalb der Periode der Compensationsstörung ausgelöst werden. So skeptisch man anch gegen diese Angabe sein mag, so muss man sich doch andererseits vergegenwärtigen, dass erfahrungsgemäss bei den dazu disponirten Individuen sehr häufig die Exhibitionen erst erfolgen, wenn durch den Anblick von Mädchen oder Frauen oder bestimmter Körpertheile dem übererregten Centrum ein geschlechtlicher Reiz zugegangen ist. Dies war um so leichter möglich, als sich bei N. zu einer chronischen eine ganz acute Ernährungsstörung des Gehirns schwerster Art hinzugesellte. N. war ausserdem nicht nur sehr sexuell veranlagt, sondern auch stark hereditär belastet, er war von Jugend auf schwächlich, hat schwere Krankheiten durchgemacht und davon ein ernstes Herzleiden zurückbehalten. Letzteres beansprucht in diesem Falle ein hervorragendes klinisches Interesse, da es in dem psychopathisch vorbereiteten Gehirm jene transitorischen Geistesstörungen ausgelöst hat. Ich gedenke diesen Punkt bei einer anderen Gelegenheit specieller zu erörtern und lasse ihn daher an dieser Stelle zunächst unberücksichtigt.

Der Fall II stellt ein interessantes Beispiel der epileptoiden transitorischen Geistesstörungen dar. W. war bereits von einem Sachverständigen als das denkbar verworfenste Subject dem Riehter preisgegeben, als ähnliche Delicte und Krankheitserscheinungen aus früherer Zeit bekannt wurden, we]che Verdacht auf Epilepsie hervorrufen mussten. Das damalige ärztliche Gutachten führt aber die den exhibitionistischen Handlungen zu Grunde gelegten transitorischen Zustände der Willensberaubung auf Melancholie zurück. Erst hier in der Klinik beobachtete man mehrere Nächte hintereinander epileptoide Delirien, welche mit den anamnestischen Angaben und der ganzen Vorgeschichte W.'s zum Bilde der Epilepsie vorzüglich zusammenpassten. Er hatte in 2-bis 3 tägigen Perioden ausser den Zeichen üusserster allgemeiner Excitation einen sehr gesteigerten Geschlechtstrieb mit nachherigem Erinnerungsdefect für das Vorgefallene. Dies erinnert vielleicht an die von v. Krafft-Ebing aufgestellte Psychopathia sexualis periodica, eine Form des "periodischen Irreseins mit krankhaften Trieben." Indessen sprechen die typischen epileptischen Antecedentien und der Bewusstseinsverlust für eine epileptische Grundlage. Von Wichtigkeit ist u. A. 
auch die Angabe, dass W. vor seiner Frau am Tage ebenfalls die Genitalien entblösste, ohne nachher etwas davon zu wissen. Endlich möchte ich noch auf die Thatsache aufmerksam machen, dasss W., ebenso wie $\mathrm{N}$. in Fall I, seine Delicte zunächst leugnete und erst später sie mit der Möglichkeit einer Geistesstörung in Verbindung brachte; ja er versuchte sogar eine läppische Ausrede, indem er so theil weise eine Erinnerung an das Vorgefallene vermuthen liess. Dadurch war Vorsicht seiner Glanbwürdigkeit gegenüber geboten. Es hat sich aber herausgestellt und es darf in beiden Fällen (I und II) als ziemlich sicher angesehen werden, dass es den Delinquenten einerseits peinlich war, solche Schamlosigkeiten einzugestehen, dass sie andererseits von denselben kein Bewusstsein, oder doch nur ein sehr fragmentäres, besessen haben. Unbestimmte Ahnungen oder leise Erinnerungen an früher Erlebtes, auch Mittheilungen anderer Personen über ähnliche Vorfälle mussten ihnen aber den Gedanken an die Möglichkeit der Delicte doch nahe legen. - Dieses Leugnen ist natürlich sehr häufig auch eine Ausflucht derjenigen Exhibitionisten, welche volles Bewusstsein der That haben. Die psychologische Erklärung hierfür ist nicht schwer. Ich erinnere hier an die vorne citirte Auslegung von Lasègue.

In Fall III sprach die Anamnese für eine Neurasthenie mit vielleicht epileptoiden Elementen; ähnlich fielen die klinischen Beobachtungen aus. Beides zusammen gestattete aber doch kein sicheres Urtheil darüber, ob zur Zeit der Begehung der That die Bedingungen des $\S \check{1} 1$ zutrafen oder nicht. Nicht einmal die Frage, ob wirklich etwas Epileptisches mit im Spiele sei, konnte zur Entscheidung gebracht werden; jedenfalls standen neurasthenische Symptome in Vordergrunde. Vielleicht könnte man daher diesen Fall der v. KrafftKibing'schen Gruppe der neurasthenischen Exhibitionisten zurechnen. Damit bliebe aber die Frage der Zurechnungsfähigkeit ebenso in suspenso wie vorher. Mit dem Einreihen in eine Krankheitscategorie ist bezüglich des $\$ 51$ nichts präjudicirt, die ganz individuelle Analyse des betreffenden Falles ist allein entscheidend.

In den nächsten beiden Fällen sind die Angaben, nach denen wir uns eine Anschauung zu bilden haben, nicht unter allen Umständen zuverlüssig. Ich selbst weiss nicht, in wie weit man denselben trauen darf. Soviel scheint sicher zu sein, dass Fall IV einen dureh langjährige Krampfanfälle und Alkoholmissbrauch moralisch defecten Menschen betrifft, der besonders in seinen Rauschzuständen exhibitionirt. Er selbst spricht von einem unwiderstehlichen Trieb und nachheriger Bewusstlosigkeit. Seine Geistesfähigkeiten befinden sich vielleicht, angeboren oder erworben, unter dem gewöhnlichen Durchschnittsmaass, 
jedoch nicht in einem Grade, der eventuell forensisch verwerthbar wäre. Nicht unerwähnt möge der Umstand bleiben, dass die Exhibitionen und die alkoholischen Bewusstlosigkeitszustände erst zu einer Zeit aufgetreten sein sollen, wo die Krampfanfälle zu verschwinden begannen (Verheirathung). Wir werden später in der Litteratur (Fall Freyer) ein ähnliches vicariirendes Verhältniss zwischen Krampfanfällen und Exhibitionen wiederfinden.

Fall $V$ entspricht etwa dem Fall III, insofern er ebenfalls neurasthenische Symptome mit Angaben über epileptoide Erscheinungen vereinigte, ein bestimmtes Urtheil aber nicht zuliess. Auch hier suchte der Exhibitionist eine Ausrede in der Pflege seines vorgeblichen "Wolfes".

Fall VI stellt einen gewöhnlichen "pathologischen Rauschzustand" als Grundlage der Exhibition wie anch der übrigen Sittlichkeitsdelicte dar. Herr H. wurde bereits zum 2. Mal wegen Entblössung der Genitalien sistirt; er ist gegen Alkohol sehr wenig widerstandsfähig und wird schon durch geringe Hengen sexuell erregt.

Am wenigsten klar liegt der Fall VII, bei dem zwar deutliche Senescenzerscheinungen vorbanden waren, aber eine irgendwie erhebliche Demenz mit sittlichen oder intellectuellen Defecten fehlte. Er war schon von früher her in der Klinik bekannt und hatte damals ein depressives Irresein leichter Art. Von Störungen des Bewusstseins war nie etwas bemerkt worden, er war streng sittlich veranlagt und geschlechtlich in keiner Weise erregt. Seine Versicherung, von dem ihm zur Last. gelegten Vergehen nichts zu wissen, erschien glaubwürdig. Er machte sich die schwersten Vorwürfe darüber, versuchte nicht einfach zu leugnen, sondern sagte sich ganz richtig, wenn er deshalb verhaftet worden sei, müsse es doch wahr sein. Wie früher litt er auch jetzt wieder an einer depressiven Irreseinsform. Mit dieser lässt sich die einmalige Exhibition nicht ohne Weiteres in einen causalen $\mathrm{Zn-}$ sammenhang bringen. Wenn es auch Autoren giebt, welche über Exhibitionismus bei Hypochondrie und Melancholie berichten, so sind diese Auffassungen doch nicht unanfechtbar, worauf ich später noch eingehen werde. Immerhin wäre es denkbar, dass der deprimirte, $\check{6} 6$ jährige Yann durch irgend welche krankhafte körperliche Empfindungen nach Art eines Hypochonders so sehr in Anspruch genommen war, dass sich seine Aufmerksamkeit fïr kurze Zeit von der Aussenwelt abwandte, dass sein ganzer Bewusstseinsinhalt nur auf einen Punkt gerichtet war und dass es so zur vorübergehenden Exhibition kam. Er könnte auch, analog den Fällen Laugier's, durch organisch bedingte Empfindungen an den Genitalien dazu getrieben worden sein. Dafür haben sich aber keinerlei Anhaltspunkte ergeben. Es ist daher unwahrscheinlich und 
dieser krankhaften Zustände machte freilich schon für die Zwecke dieser groben Gruppirung einige Schwierigkeiten; ich konnte mich nicht immer an die Diagnose der betreffenden Autoren halten, sondern musste mehrfach, besonder's in älteren Fällen nach Gutdünken rubriciren. Oefter macht man dabei die auch sonst bekannte Erfahrung; dass die That das Resultat verschiedener zusammenwirkender Krankheitszustände ist. In einigen Fällen blieb die Art der pathologischen Grundlage unaufgeklärt. Soweit ich beurtheilen konnte, schien es- mir am vortheilhaftesten, sämmtliche männlichen Exhibitionisten in 6 Gruppen zu verweisen, wobei ich indessen wiederholt und ausdrücklich bemerke, dass diese Gruppirung keine andere Bedeutung haben soll als diejenige eines Hilfsmittels zur besseren Debersicht.

Diese Gruppen sind nun:

1. die Epileptiker (Fall 1-18),

2. die Dementen (angeborener und erworbener Schwachsinn) (Fall 19-35),

3. die Degenerirten (Magnan) (Fall $36-48$ ),

4. die Neurasthenischen (Fall 49-56),

5. die Alkoholiker und die Psychosen im engeren Sinne (Paranoia etc.) (Fall 57-64),

6. die Gewohnheitsmässigen (Fall 65-75).

Die Fälle von Exhibitionismus bei Franen (76-86) sind am Schluss besonders zusammengestellt.

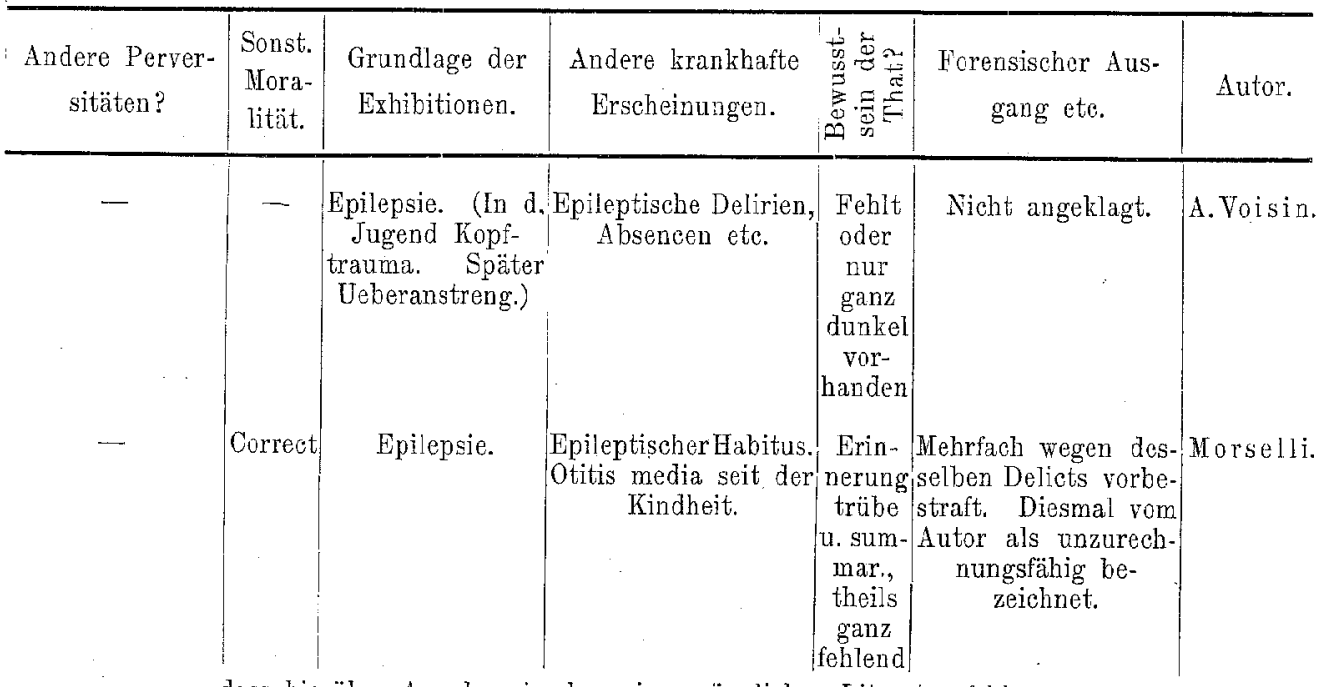

dass hierüber Angaben in der mir zugänglichen Literatur fehlen. 


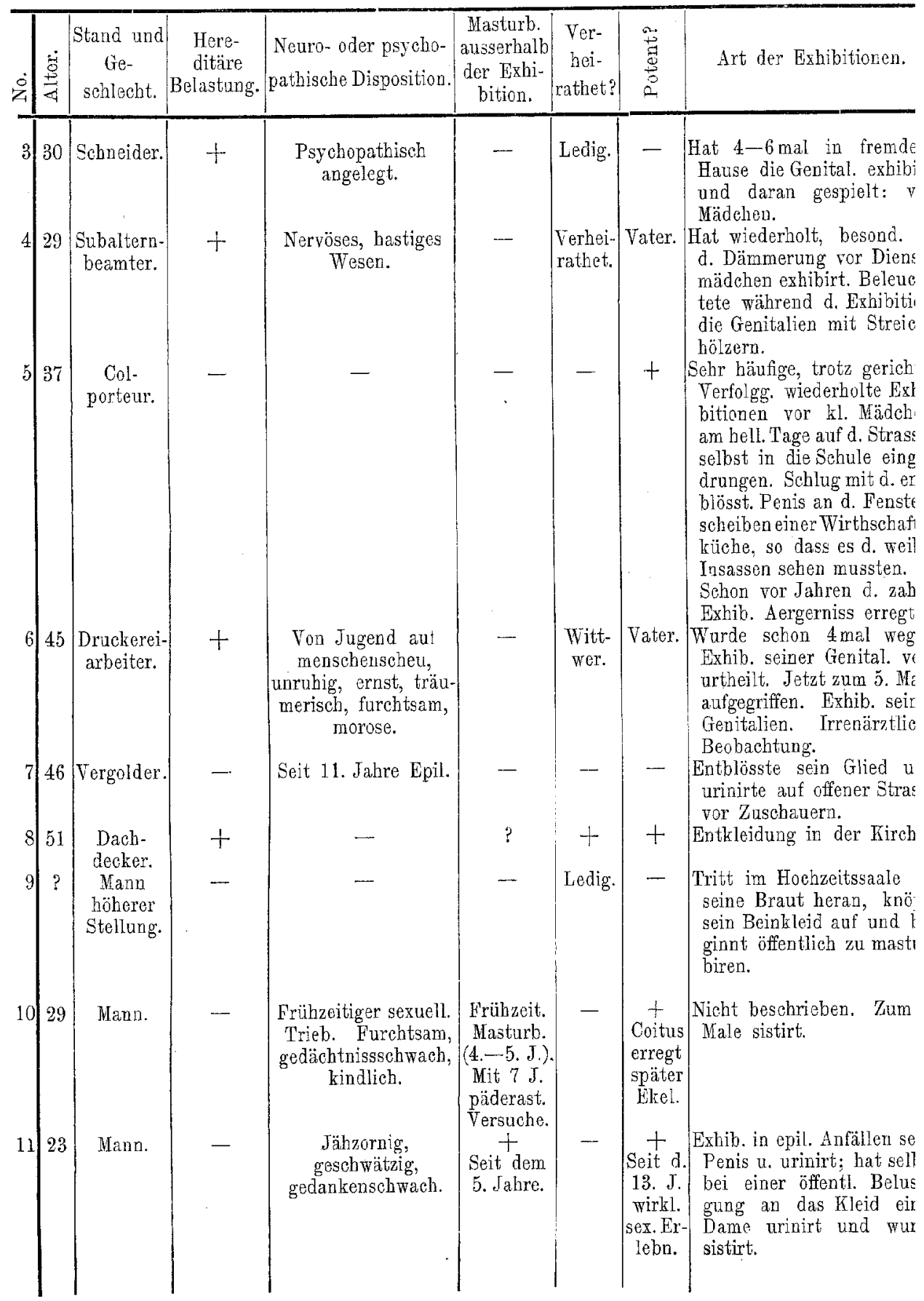




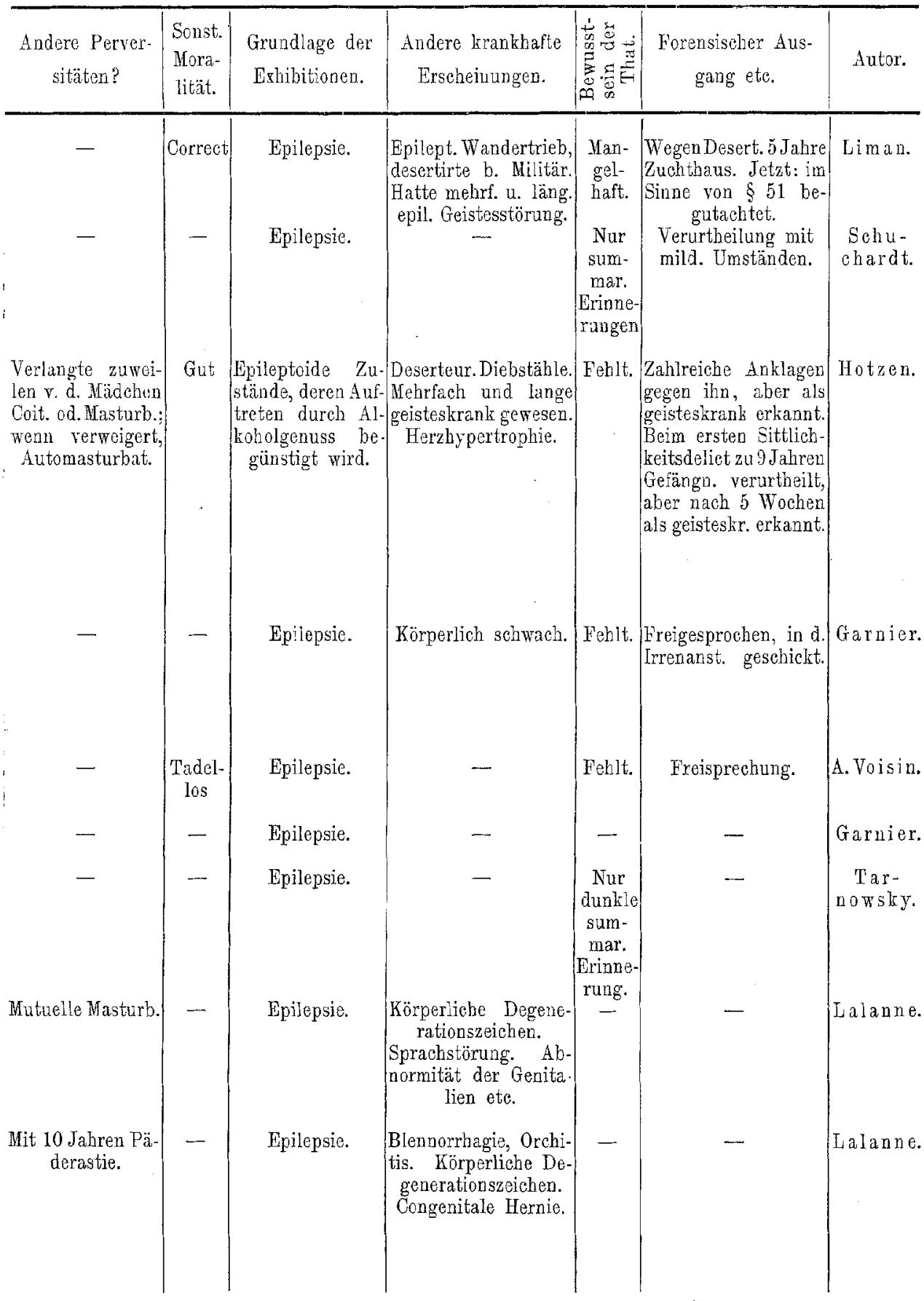




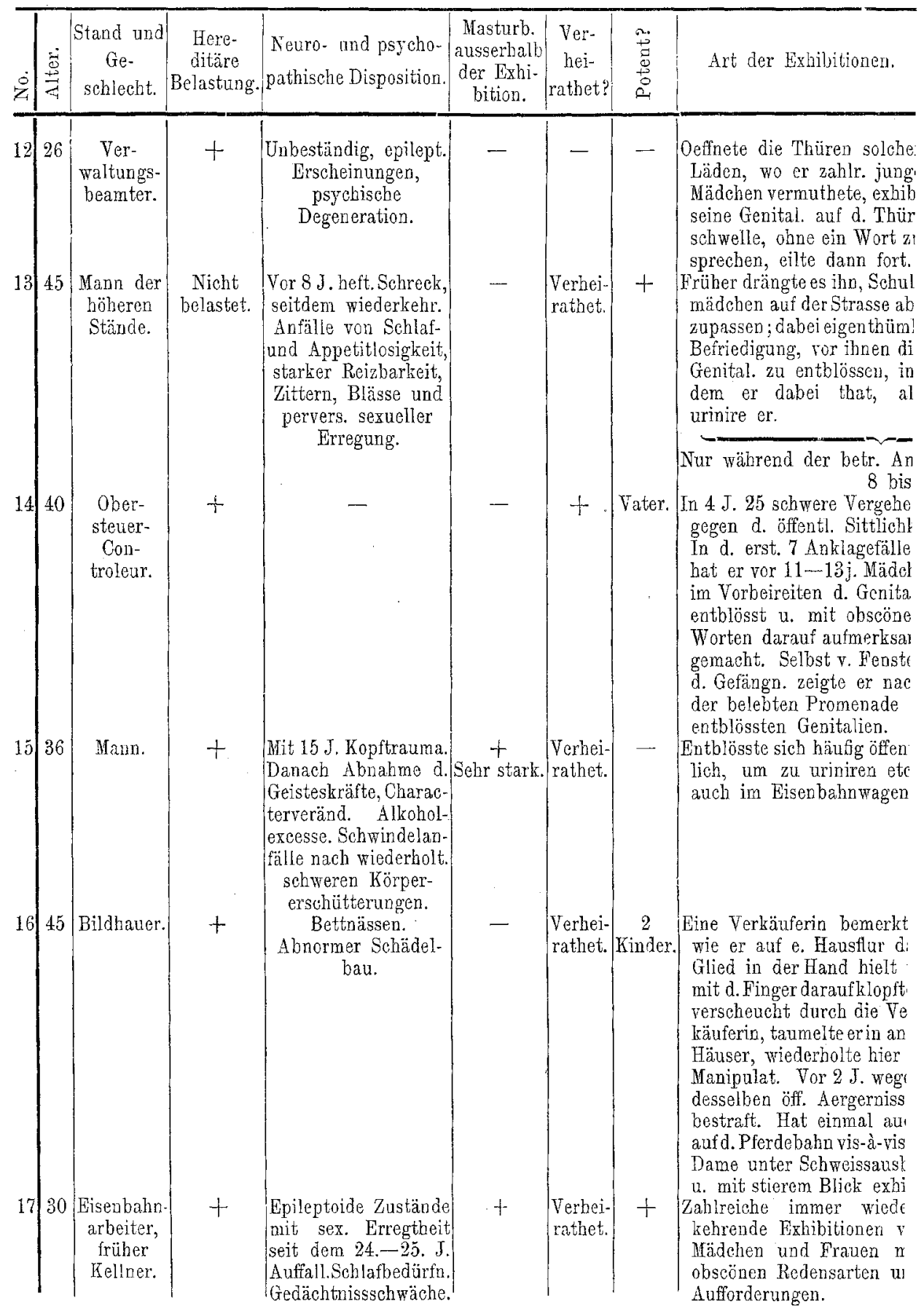




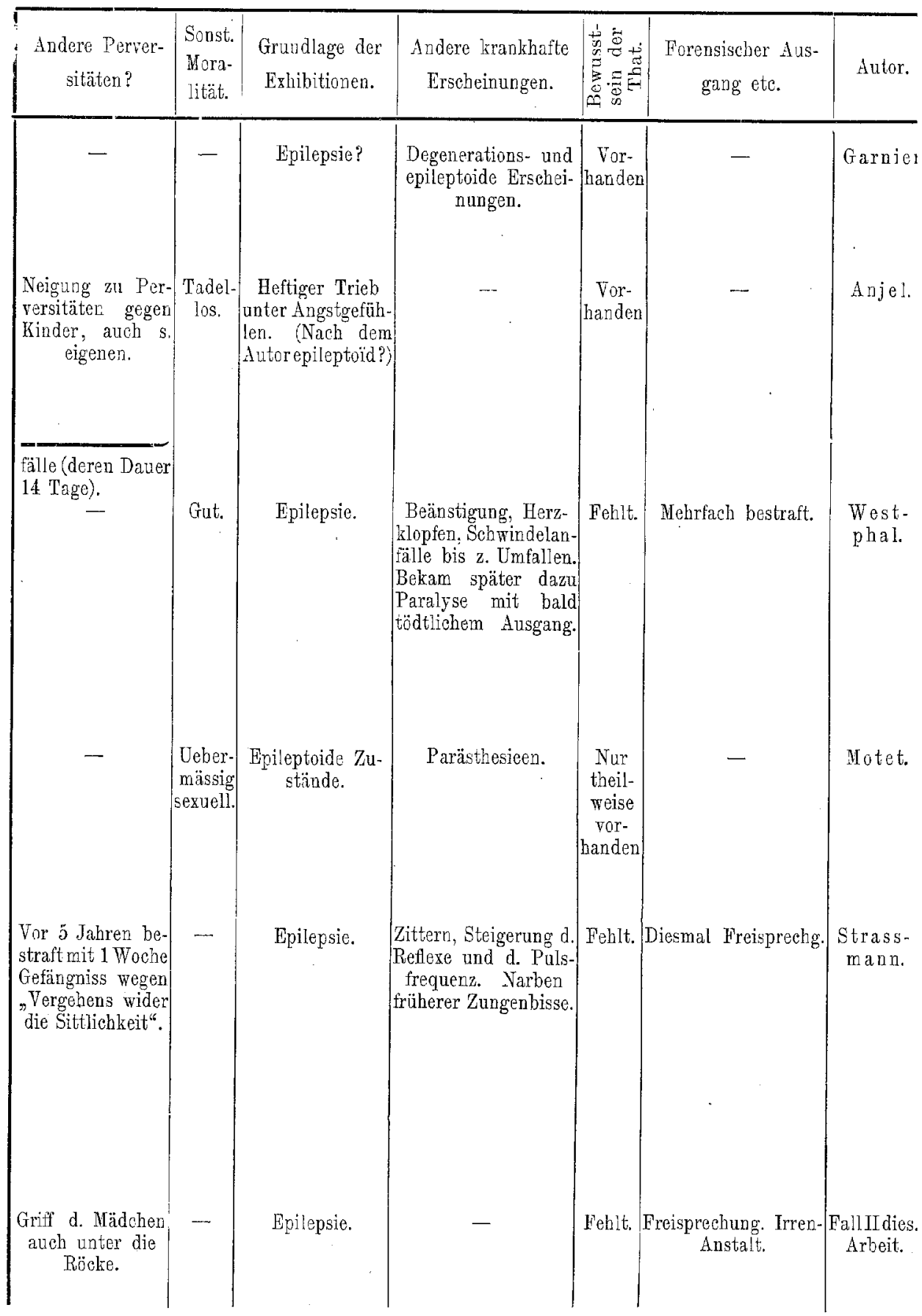


Dr. W. Seiffer;

\begin{tabular}{|c|c|c|c|c|c|c|c|c|}
\hline$\dot{8}$ & ये & $\begin{array}{c}\text { Stand und } \\
\text { Ge- } \\
\text { sehlecht. }\end{array}$ & $\begin{array}{c}\text { Here- } \\
\text { ditäre } \\
\text { Belastung. }\end{array}$ & $\begin{array}{l}\text { Neuro- und psycho- } \\
\text { pathische Disposition. }\end{array}$ & $\begin{array}{c}\text { Masturb. } \\
\text { ausserhalb } \\
\text { der Exhi- } \\
\text { bition. }\end{array}$ & $\begin{array}{c}\text { Ver- } \\
\text { bei- } \\
\text { rathet? }\end{array}$ & 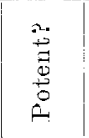 & Art der Exhibitionen. \\
\hline 18 & 26 & $\begin{array}{l}\text { Stud. } \\
\text { theol. }\end{array}$ & + & $\begin{array}{l}\text { War stets kränlilich; } \\
\text { stets nervös, reizbar. } \\
\text { Epiteptoide Zustände. }\end{array}$ & + & Ledig. & + & $\begin{array}{l}\text { Zeigte häufig von sein. Woh- } \\
\text { nufg aus den kl. Mädchen } \\
\text { auf d. Strasse die Genital., } \\
\text { machte diese auf sich auf- } \\
\text { merksam. Nach Verurtheil, } \\
\text { Wiederholung d. Handlung. }\end{array}$ \\
\hline 19 & 60 & Mann. & - & - & - & - & - & $\begin{array}{l}\text { Hatte mit } 58 \mathrm{~J} \text {, begonnen, } \\
\text { ror Frauen und Kindern zu } \\
\text { exhibitioniren. }\end{array}$ \\
\hline 20 & 66 & Mann. & $\mid \begin{array}{l}\text { Schwer be- } \\
\text { lastet, ein } \\
\text { Bruder } \\
\text { ebenfalls } \\
\text { Exhibit. }\end{array}$ & Alter Potator. & 一 & - & - & $\begin{array}{l}\text { Seine Exhibition wurde zum } \\
\text { ersten Male in der Kirche } \\
\text { während des Gottesdienstes } \\
\text { gemerkt. }\end{array}$ \\
\hline 21 & 64 & Mann. & $\begin{array}{c}\text { Sohwer } \\
\text { belastet. }\end{array}$ & - & 一 & Verh. & $\begin{array}{cc}\text { Vat. } \\
14 \\
14 & \mathrm{~K} .\end{array}$ & $\begin{array}{l}\text { Exhibit. seit Jahren trotn } \\
\text { wiederholter Bestrafung. }\end{array}$ \\
\hline 22 & 57 & Kaufmann. & 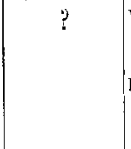 & $\begin{array}{c}\text { Vor } 20 \text { Jabren sehwer } \\
\text { schwer geisteskrank } \\
\text { mit apoplect. Anfall. } \\
\text { Später Potator. }\end{array}$ & - & Ledig. & - & $\begin{array}{l}\text { Hat wiederbolt vor Kindern } \\
\text { exbibit. oder auch urinirt. } \\
\text { einmal dabei auch ein kl } \\
\text { Mädchen abgeküsst. }\end{array}$ \\
\hline 23 & 65 & $\begin{array}{l}\text { Höherer } \\
\text { Officier } \\
\text { a. D. }\end{array}$ & - & - & - & $\begin{array}{l}\text { Witt- } \\
\text { wer. }\end{array}$ & - & $\begin{array}{l}\text { Entblösste periodisch, alle } \\
\text { 2 Tage, stets am selben Ort } \\
\text { seine Genital. vor Mädchen }\end{array}$ \\
\hline 24 & $\begin{array}{c}\text { In } \\
\text { lioh. } \\
\text { Alt }\end{array}$ & Beamter. & - & - & - & - & - & $\begin{array}{l}\text { Periodische Exhibit. der Ge. } \\
\text { nitalien auf dar Strasse. }\end{array}$ \\
\hline 25 & 60 & Beamter. & - & - & - & $\begin{array}{l}\text { Witt- } \\
\text { wer. }\end{array}$ & $\begin{array}{r}\text { Hat } \\
\text { Kind. }\end{array}$ & $\begin{array}{l}\text { Jeden Morg. von s. Fenstel } \\
\text { alls Exhib. d. Genital. vol } \\
\text { einem gegenüberwohnender } \\
\text { kleinen Mädehen. }\end{array}$ \\
\hline 26 & 63 & $\begin{array}{l}\text { Sehrift- } \\
\text { steller. }\end{array}$ & - & - & - & - & - & $\begin{array}{l}\text { Exhib. der Genital. auf eine] } \\
\text { wenig belebten Strasse. }\end{array}$ \\
\hline 27 & 40 & Mann. & - & - & - & Verh. & - & $\begin{array}{l}16 \mathrm{~J} \text {. hindurah Exhibit. ar } \\
\text { off. Orten } u \text {. in der Däm } \\
\text { merung vor Mädch., welch } \\
\text { er durch Pfeiffen auf sich } \\
\text { aufmerksam machte. }\end{array}$ \\
\hline 28 & 78 & Seemann. & - & 一 & - & Vert. & $\begin{array}{c}\text { Vater } \\
\text { ron } 10 \\
\text { Kind. }\end{array}$ & $\begin{array}{l}\text { Exhib. wiederholt an Kinder } \\
\text { spielplätzen } u \text {, beiYädchen } \\
\text { schulen. }\end{array}$ \\
\hline 29 & $?$ & $\begin{array}{l}\text { Refe- } \\
\text { rendar. }\end{array}$ & + & $\begin{array}{l}\text { Defect u. verschroben } \\
\text { in Denzen, Fühlen } \\
\text { und Streben. }\end{array}$ & $\begin{array}{c}\text { Angeblich } \\
\text { nicht. }\end{array}$ & - & $\begin{array}{c}\text { Sonst } \\
\text { keine } \\
\text { Erseh. } \\
\text { von Ge- } \\
\text { schl-- } \\
\text { Trieb. }\end{array}$ & $\begin{array}{l}\text { Zeigte wiederholt Mägden s } \\
\text { Genital. u. oberen Theil d } \\
\text { Körpers aus dem Fenster }\end{array}$ \\
\hline
\end{tabular}




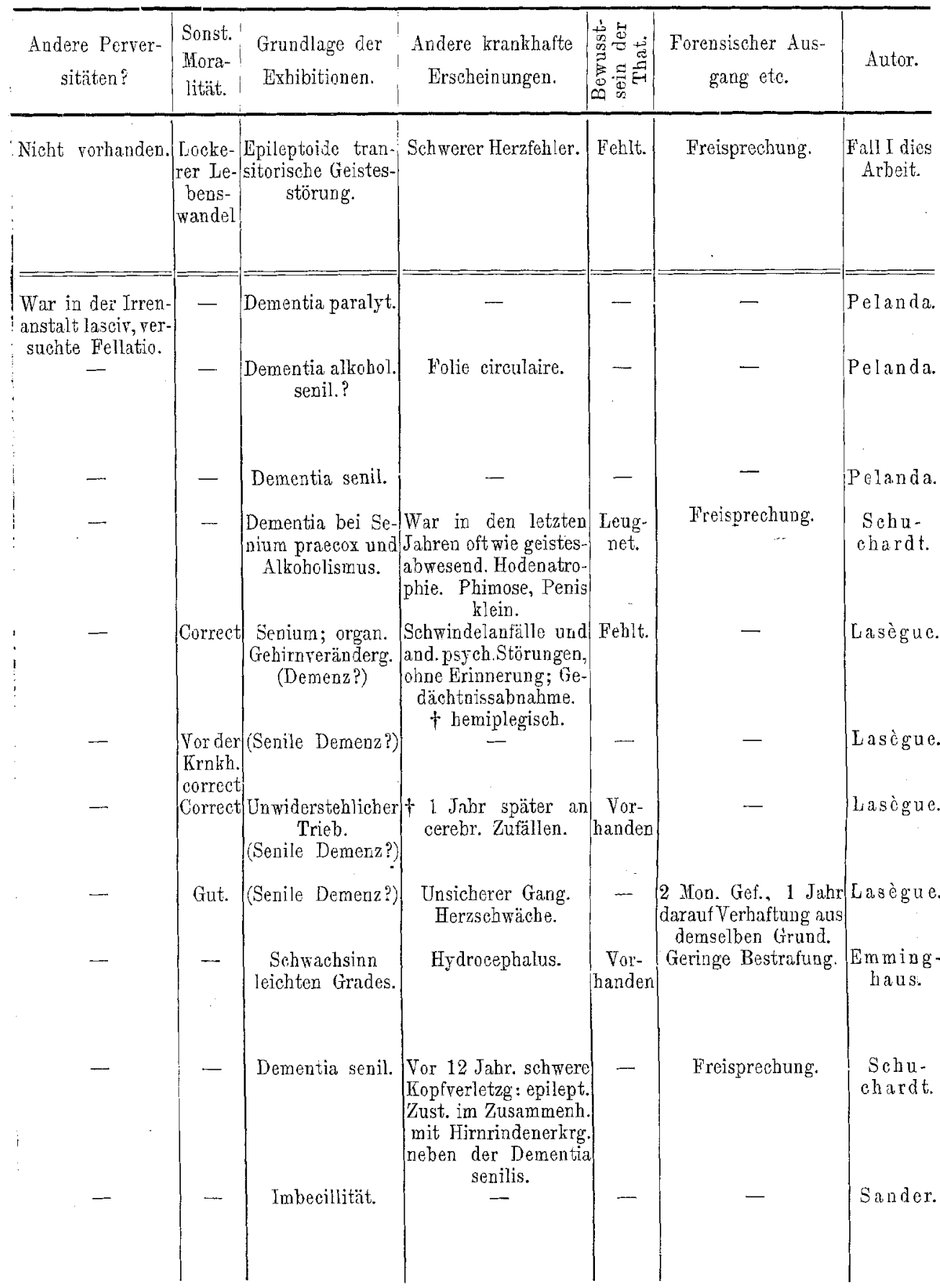




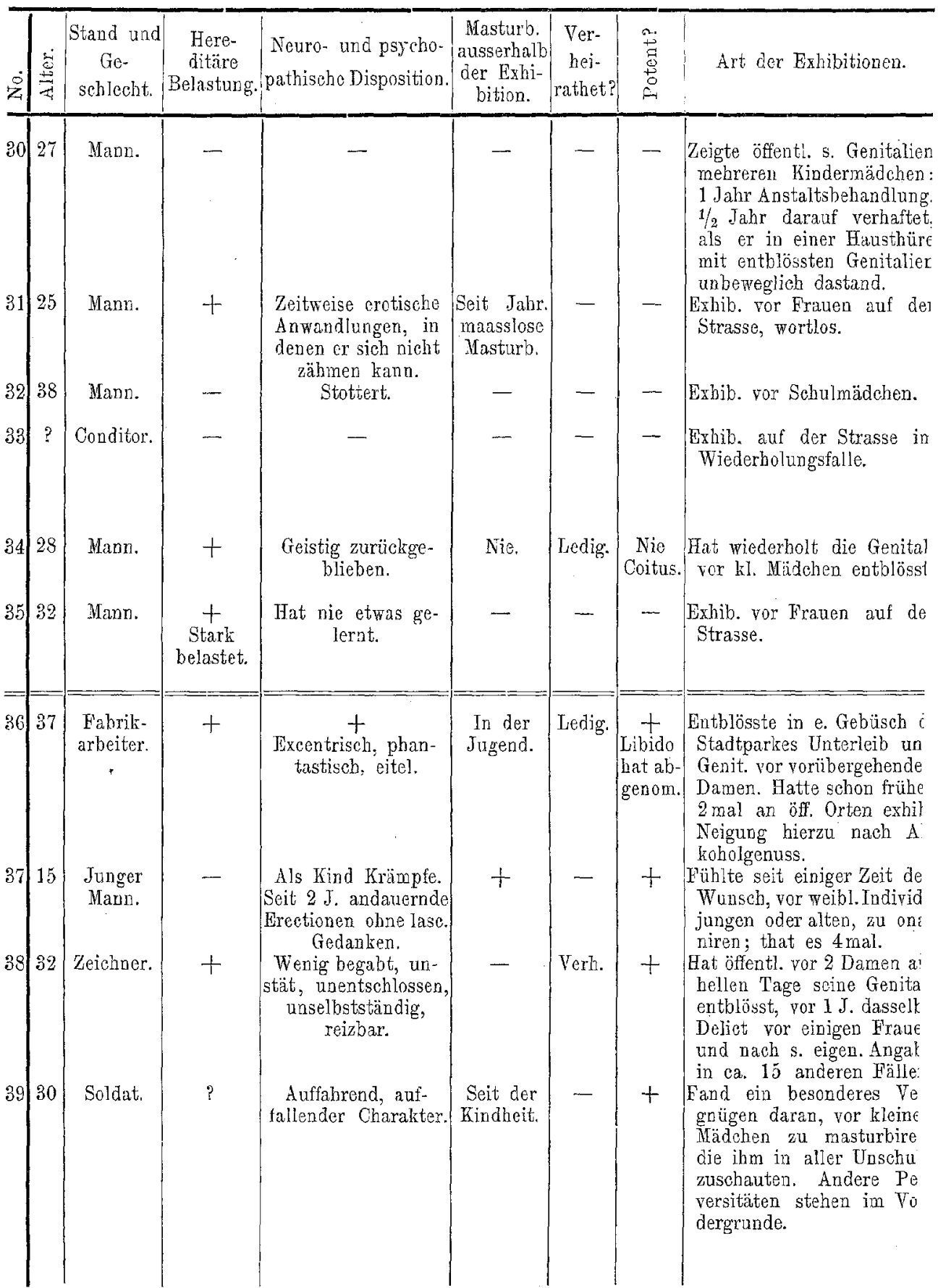




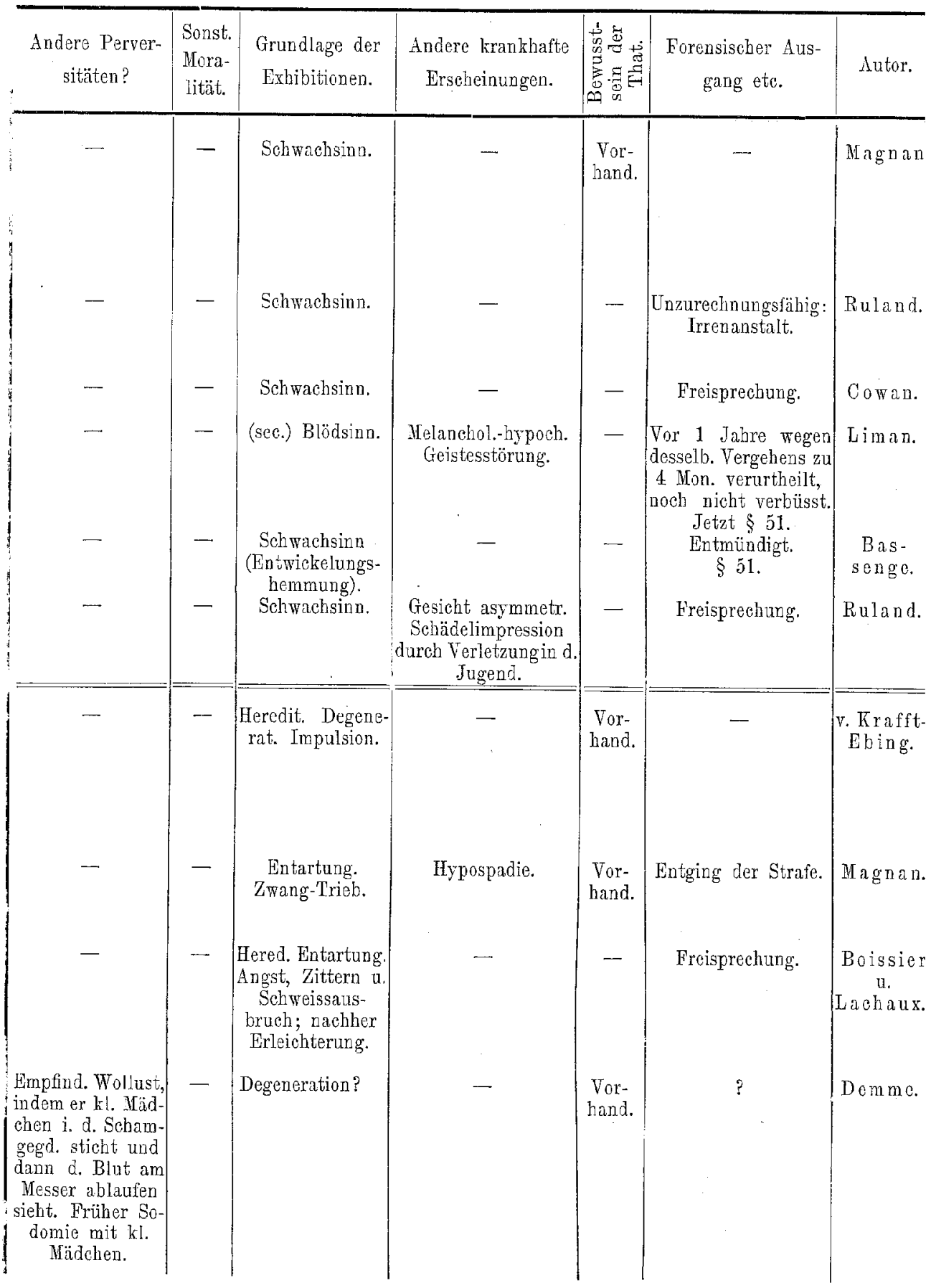




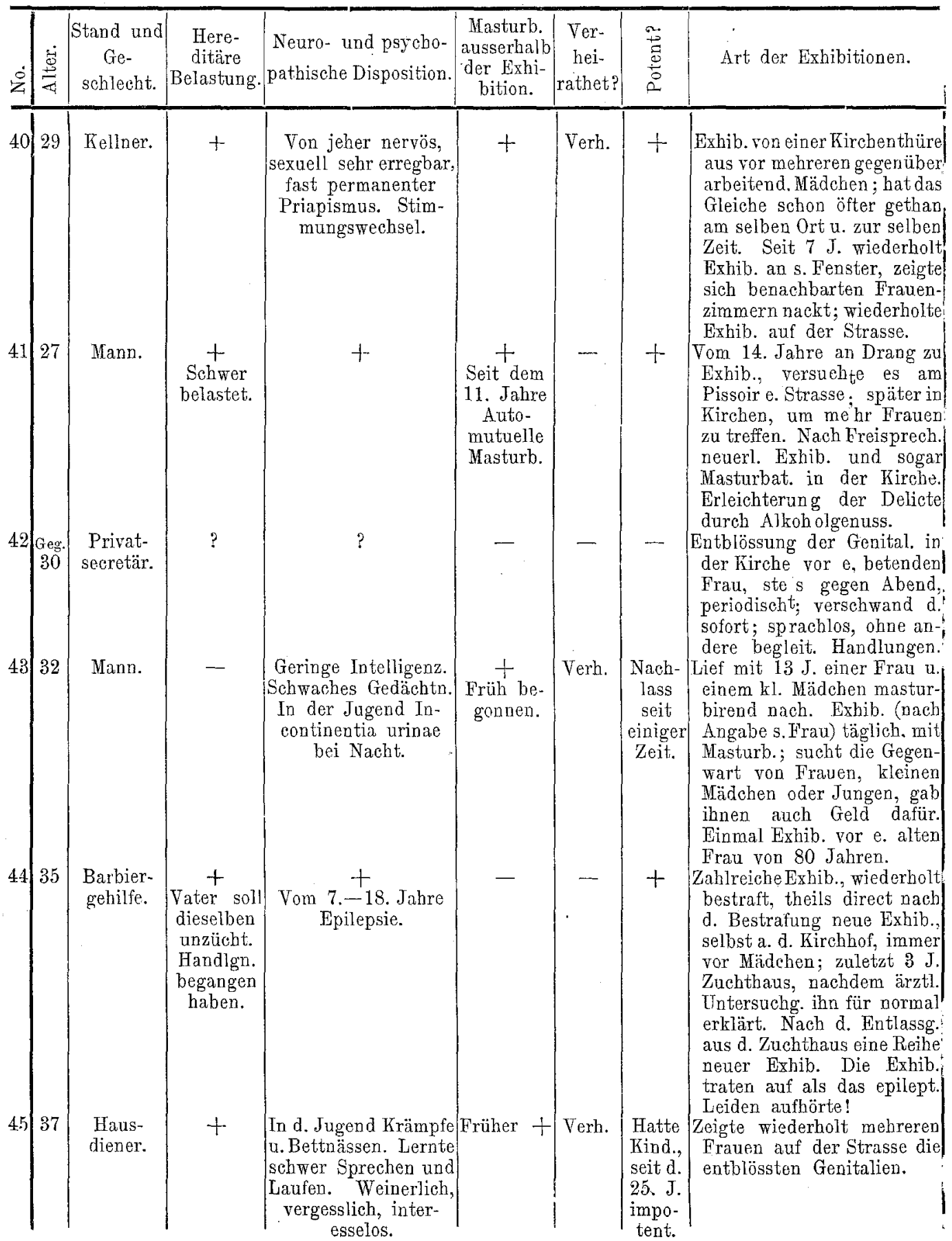




\begin{tabular}{|c|c|c|c|c|c|c|}
\hline $\begin{array}{c}\text { Andere Perver- } \\
\text { sitäten? }\end{array}$ & $\begin{array}{l}\text { Sonst. } \\
\text { Mora- } \\
\text { lität. }\end{array}$ & $\begin{array}{l}\text { Grundlage der } \\
\text { Exhibitionen. }\end{array}$ & $\begin{array}{c}\text { Andere krankhafte } \\
\text { Erscheinungen. }\end{array}$ & 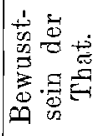 & $\begin{array}{l}\text { Forensischer Aus- } \\
\text { gang etc. }\end{array}$ & Autor. \\
\hline - & Gut. & $\begin{array}{l}\text { Hered. Degen. mit } \\
\text { Zwangsvorstellg. } \\
\text { (er müsse exhib.) } \\
\text { u. unwidersteh- } \\
\text { lichen Antrieben. }\end{array}$ & $\begin{array}{l}\text { Körperl. Entartungs- } \\
\text { zeichen; von jeher } \\
\text { nervöses Zucken im } \\
\text { Gesicht. Lebensüber- } \\
\text { druss. Bei Gemüths- } \\
\text { bewegung Zuckungen } \\
\text { in den Extremitäten. } \\
\text { Allgem. Analgesie. }\end{array}$ & $\begin{array}{l}\text { Vor- } \\
\text { hand. }\end{array}$ & $\begin{array}{c}\text { Vor } 1 \text { Jahr deshaib } \\
1 \text { Mon. Gef. Jetzt } \\
\text { Freisprechung. }\end{array}$ & Magnan \\
\hline $\begin{array}{l}\text { Zeigte auch beim } \\
\text { Militîr den hame- } \\
\text { raden gern sein } \\
\text { Glied. }\end{array}$ & - & $\begin{array}{c}\text { Hered. Degen. } \\
\text { Unwiderstehl. } \\
\text { Drang unter Prä- } \\
\text { cordialangst. }\end{array}$ & - & - & $\begin{array}{l}\text { Freisprechung. Wie- } \\
\text { derholung der That. }\end{array}$ & Magnan \\
\hline- & $\begin{array}{l}\text { Tadel- } \\
\text { los. }\end{array}$ & $\begin{array}{c}\text { Unwiderstehl. } \\
\text { Trieb mit.Angst- } \\
\text { gefühl. }\end{array}$ & $C$ o i b to on & $\begin{array}{l}\text { Vor- } \\
\text { hand. }\end{array}$ & $\begin{array}{l}\text { Autor nach s. eigen. } \\
\text { Angabe damals in } \\
\text { dies. Dingen wenig } \\
\text { erfahren, stellte Un- } \\
\text { zurechnungsfähig- } \\
\text { keit in Abrede. }\end{array}$ & Lasègue \\
\hline - & - & $\begin{array}{l}\text { Unwiderstehl. An- } \\
\text { trieb. Degenerat. } \\
\text { Vor d. That unan- } \\
\text { genehme Sensat., } \\
\text { nachher Erleich- } \\
\text { terung. }\end{array}$ & $\begin{array}{l}\text { Gesichtsasymmetrie } \\
\text { und andere Degene- } \\
\text { rationszeichen. Stru- } \\
\text { ma. Kein Pharynx- } \\
\text { reflex. }\end{array}$ & $\begin{array}{c}\text { Vor- } \\
\text { band. }\end{array}$ & $\begin{array}{l}\text { Ist jetzt weg. desselb. } \\
\text { Delicts zum } 4 \text {. Mal } \\
\text { bestraft. Nach der } \\
\text { Entlassung aus dem } \\
\text { Gef. sofort neue Ex- } \\
\text { hib. u. Verhaftg. }\end{array}$ & $\begin{array}{l}\text { Vigou- } \\
\text { roux. }\end{array}$ \\
\hline $\begin{array}{l}\text { Forderte zuweilen } \\
\text { d. Mäd. auch auf, } \\
\text { s. Glied zu betast. } \\
\text { u. s. w. }\end{array}$ & - & $\begin{array}{c}\text { Erbliche Belastg., } \\
\text { neuropath. Con- } \\
\text { stitution. }\end{array}$ & $\begin{array}{l}\text { Schädelasymmetrie. } \\
\text { Kleiner Penis. Linker } \\
\text { Hoden verkrummt. } \\
\text { Patellarreflex fehlt. } \\
\text { Neurasthen. Sympt. }\end{array}$ & $\begin{array}{c}\text { Vor- } \\
\text { hand. }\end{array}$ & $\begin{array}{l}\text { Nicht verurtheilt, son- } \\
\text { dern Irrenanstalt, } \\
\text { nachder früher: } \\
\text { 1) } 1 \text { Jahr Gef., } \\
\text { 2) } 1 \text { J. } 3 \text { Mon. Gef.. } \\
\text { 3) } 3 \text { Mon. Gef., } \\
\text { 4) } 1 \text { Mon. Gef., } \\
\text { 5) } 6 \text { Mon. Gef., } \\
\text { 6) } 3 \text { J. Zuchthaus. }\end{array}$ & Freyer. \\
\hline - & - & $\begin{array}{c}\text { Hered. Degenerat. } \\
\text { Impulsion unter } \\
\text { Angst u. Hitze- } \\
\text { gefühlen. Leichter } \\
\text { Schwachsinn. }\end{array}$ & $\begin{array}{l}\text { Ohrensausen, Herz- } \\
\text { klopfen u. Schwindel. } \\
\text { Geringe Degenerat.- } \\
\text { zeichen. }\end{array}$ & $\begin{array}{l}\text { Vor- } \\
\text { hand. }\end{array}$ & $\S 51$. Freisprechung. & $\begin{array}{l}\text { Bas- } \\
\text { senge. }\end{array}$ \\
\hline
\end{tabular}




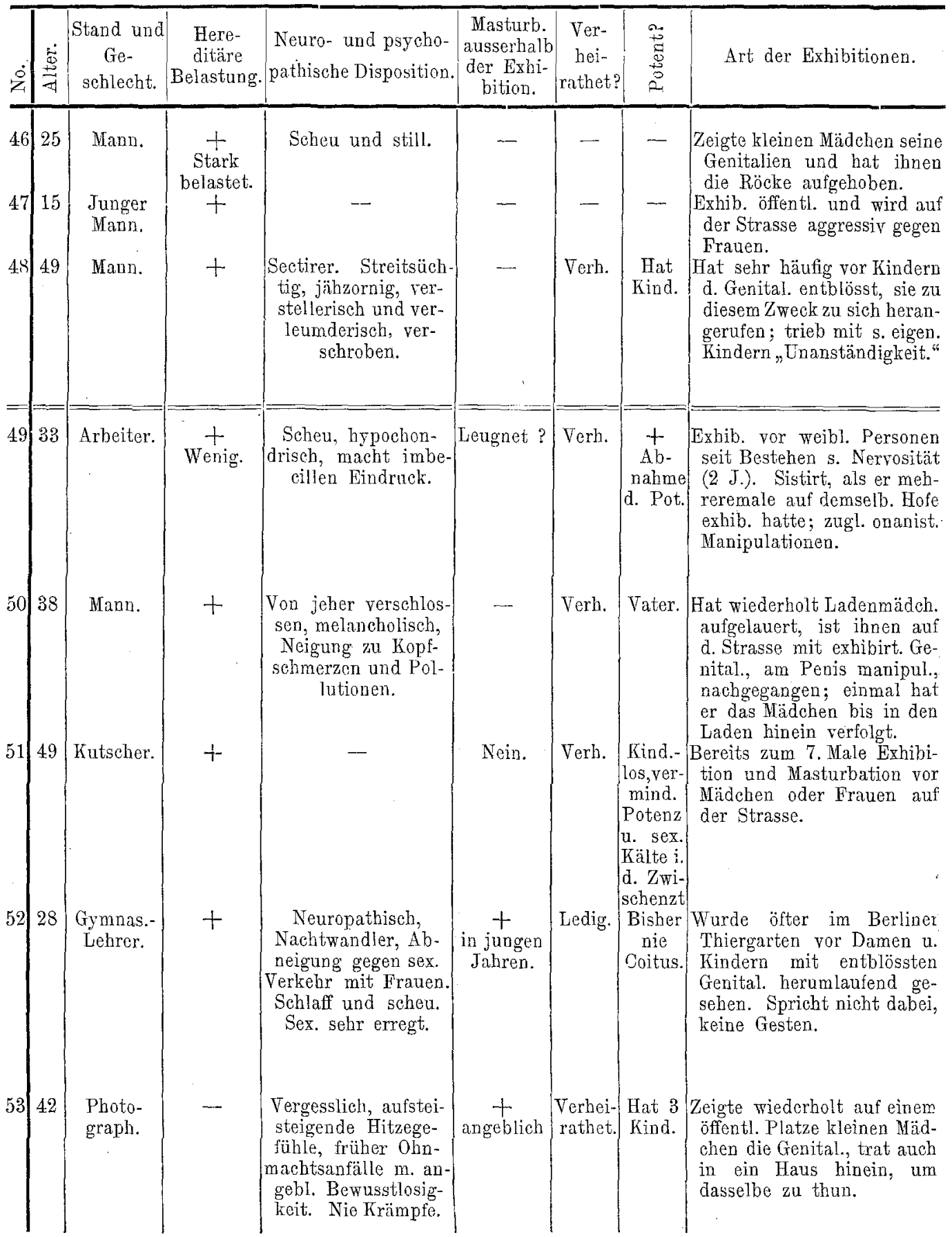




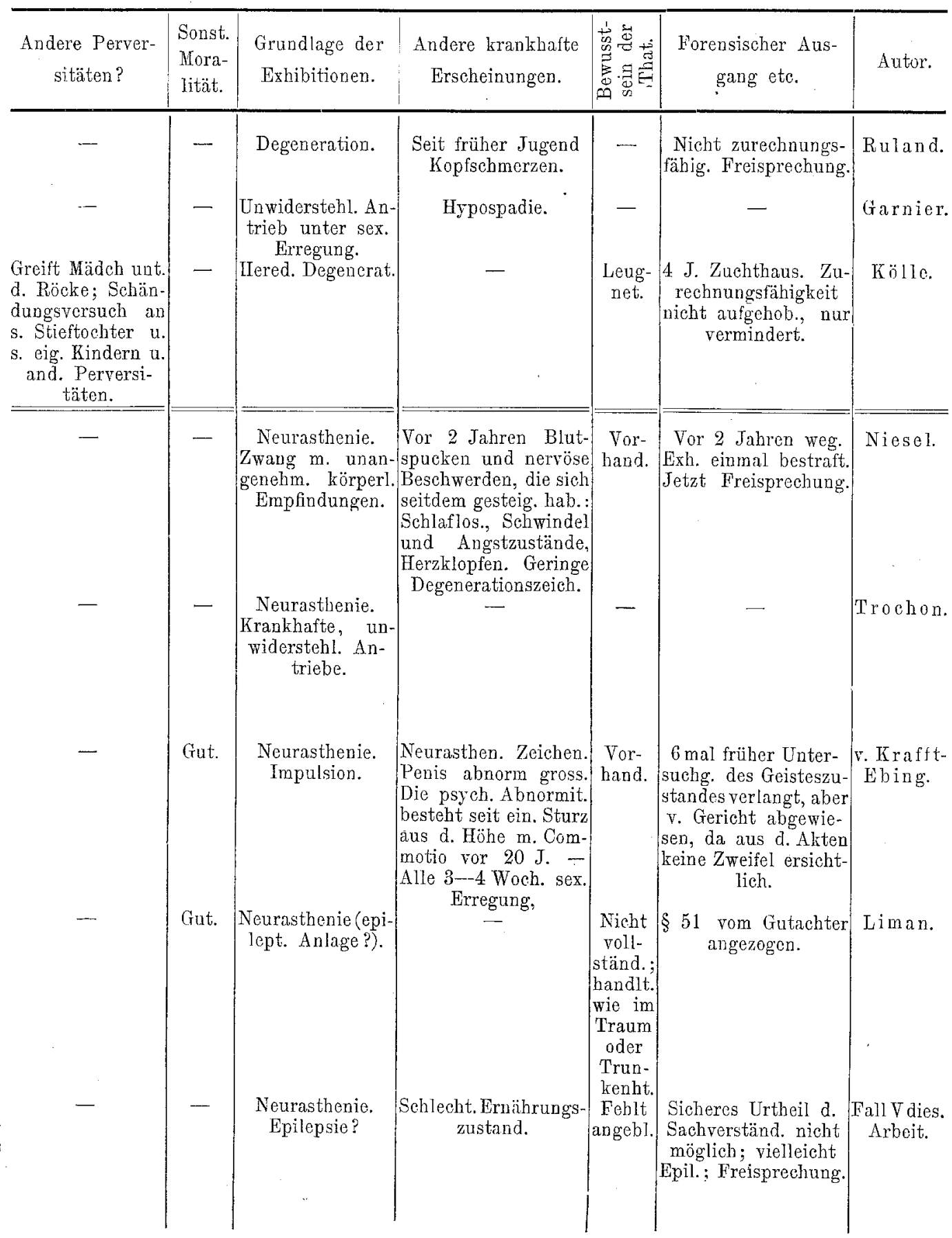




\begin{tabular}{|c|c|c|c|c|c|c|c|c|}
\hline$\dot{\vdots}$ & $\stackrel{s i}{\stackrel{\Perp}{\sharp}}$ & $\begin{array}{c}\text { Stand und } \\
\text { Ge- } \\
\text { schlecht. }\end{array}$ & $\begin{array}{c}\text { Here- } \\
\text { ditäre } \\
\text { Belastung. }\end{array}$ & $\begin{array}{l}\text { Neuro- und psycho- } \\
\text { pathische Disposition. }\end{array}$ & $\begin{array}{c}\text { Masturb. } \\
\text { ausserbalb } \\
\text { der Exbi- } \\
\text { bition. }\end{array}$ & $\begin{array}{c}\text { Ver- } \\
\text { hei- } \\
\text { rathet? }\end{array}$ & $\begin{array}{l}\stackrel{?}{+} \\
\stackrel{0}{0} \\
\stackrel{0}{0} \\
\text { at }\end{array}$ & Art der Exhibitionen. \\
\hline 54 & 44 & Gärtner. & - & $\begin{array}{l}\text { Vergesslich und ge- } \\
\text { dankenschwach seit } \\
\text { einiger Zeit, neur- } \\
\text { asth. Klagen. }\end{array}$ & - & $\begin{array}{l}\text { Verhei- } \\
\text { rathet. }\end{array}$ & + & $\begin{array}{l}\text { Rief kl. Mädchen zu sich ins } \\
\text { Gebüsch, entblösste d. Ge- } \\
\text { nital. vor ihnen u. forderte } \\
\text { sie auf, daran zu greifen. } \\
\text { Er that dies im Wieder- } \\
\text { holungsfalle. }\end{array}$ \\
\hline 55 & $?$ & $\begin{array}{l}\text { Eisen- } \\
\text { bahnsta- } \\
\text { tionsassi- } \\
\text { stent. }\end{array}$ & $\underset{+}{\text { Angebl. }}$ & - & - & - & - & $\begin{array}{l}\text { Wandte sich auf öfentlichen } \\
\text { Wegen, wenn kl. Mädchen } \\
\text { zugegen waren, mit entbl. } \\
\text { Genital. zu denselben hin } \\
\text { u. spielte oder rieb an dem } \\
\text { Gliede bis z. Ejaculation (?). }\end{array}$ \\
\hline 56 & 40 & $\begin{array}{l}\text { Schul- } \\
\text { lehrer. }\end{array}$ & $t$ & $\begin{array}{l}\text { Seit der Jugend ner- } \\
\text { vöses Kopfleiden. } \\
\text { Später verschlossen, } \\
\text { zerstreut. }\end{array}$ & $\begin{array}{l}\text { Seit dem } \\
\text { 12. Jahre. }\end{array}$ & Ledig. & - & $\begin{array}{l}\text { Wxbib. seiner Genitalien vor } \\
\text { Schulmädchen, indem er } \\
\text { dabei d. unfäthigsten Dinge } \\
\text { redete. }\end{array}$ \\
\hline & & & & & & & & $=$ \\
\hline 57 & 49 & Mann. & + & $\begin{array}{l}\text { Von jeher sex. sehr } \\
\text { erregbar. Potator. }\end{array}$ & - & - & - & $\begin{array}{l}\text { Exhibirt jeweils, wenn er } \\
\text { ein weibliches Wesen sieht. }\end{array}$ \\
\hline 58 & 37 & Kaufmann. & + & $\begin{array}{l}\text { Verminderte Resi- } \\
\text { stenz gegen Alkohol, } \\
\text { geschlechtl. erregt. }\end{array}$ & - & Ledig. & - & $\begin{array}{l}\text { Zeigte Abends auf d. Strasse } \\
\text { einer Frau den erig. Penis } \\
\text { u. fordere sie zum Coit. auf. } \\
\text { Vor } 2 \text { J. wegen ders. Hand- } \\
\text { lung (mit } 50 \text { M.) bestraft. }\end{array}$ \\
\hline 59 & 32 & Maler. & $t$ & $\begin{array}{l}\text { Seit einem Fall in } \\
\text { der Jugend Krampf- } \\
\text { anfälle. In den letzten } \\
\text { Jahren keine Krämpfe } \\
\text { mehr, dag. nach Potus } \\
\text { Absencen. Bettnässen } \\
\text { bis zum 17. Jahre. }\end{array}$ & - & $\begin{array}{l}\text { Verhei- } \\
\text { rathet. }\end{array}$ & + & $\begin{array}{l}\text { Hat wiederholt auf d. Strasse } \\
\text { in Gegenwart weibl. Per- } \\
\text { sonen seine Genital. ent- } \\
\text { blösst, war angeblich dabei } \\
\text { stets angetrunken. I mal } \\
\text { Exhibition vor Kindern in } \\
\text { nüchternem Zustande. }\end{array}$ \\
\hline 60 & 51 & $\begin{array}{l}\text { Post- } \\
\text { schaffner. }\end{array}$ & $\begin{array}{c}\text { nicht yor- } \\
\text { handen. }\end{array}$ & $\begin{array}{l}\text { Geist. Entwickl, zu- } \\
\text { rückgeblieb. Krämpfe } \\
\text { als Kind, sowie vom } \\
\text { 28. bis in d. } 30 \text { ger } \\
\text { Jahre. Näss. Potator, } \\
\text { verminderte Alkohol- } \\
\text { Resistenz. }\end{array}$ & $\begin{array}{l}\text { Seit der } \\
\text { Kindheit } \\
\text { bis jetzt. }\end{array}$ & $\begin{array}{l}\text { Zum } \\
\text { 2. Mal } \\
\text { verhei- } \\
\text { rathet. }\end{array}$ & Hat & $\begin{array}{l}\text { Stand im Hemde am Fenster } \\
\text { seiner Wohnung, nabm die } \\
\text { Genitalien heraus u. spielte } \\
\text { daran angesichts der gegen- } \\
\text { über wohnenden Zeugen. } \\
\text { Einmal winkte er diesen, } \\
\text { zu ihm zu bommon. }\end{array}$ \\
\hline 61 & 42 & Journalist. & $t$ & $\begin{array}{l}\text { Hered. Stigmata. } \\
\text { War stets Potator. }\end{array}$ & - & Ledig. & - & $\begin{array}{l}\text { Zeigte Frauen den erigirten } \\
\text { Penis, um sie zu verführen, } \\
\text { wurde auch aggressiv. Ex- } \\
\text { hibition der Genital. auch } \\
\text { in der Irrenzelle. }\end{array}$ \\
\hline 62 & 39 & $\begin{array}{l}\text { Kranken- } \\
\text { wärter. }\end{array}$ & + & $\begin{array}{l}\text { Degenerirt. Von jeher } \\
\text { geistesschwach. }\end{array}$ & - & Ledig. & + & $\begin{array}{l}\text { Gliabte, die Wärterinnen } \\
\text { wollten s. Genit, die sich } \\
\text { nach s. Meinung wie d. übr. } \\
\text { Körper durch Schönheitaus-* } \\
\text { zeichneten, sehen, u. exhi- } \\
\text { birte deshalb vor ihnen. }\end{array}$ \\
\hline
\end{tabular}




\begin{tabular}{|c|c|c|c|c|c|c|}
\hline $\begin{array}{c}\text { Andero Perver- } \\
\text { sitäton? }\end{array}$ & $\begin{array}{l}\text { Sonst. } \\
\text { Mora- } \\
\text { lität. }\end{array}$ & $\begin{array}{l}\text { Grund lage der } \\
\text { Exhibitionen. }\end{array}$ & $\begin{array}{c}\text { Andere krankhafte } \\
\text { Erscheinumgen. }\end{array}$ & 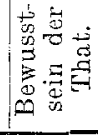 & $\begin{array}{l}\text { Forensischer Aus- } \\
\text { gang ete. }\end{array}$ & Autor. \\
\hline $\begin{array}{l}\text { Wied durch d. An- } \\
\text { jlicz v. Mädehen } \\
\text {,der weibl. Nudi- } \\
\text { äten sexuell er- } \\
\text { regt. }\end{array}$ & - & $\begin{array}{l}\text { Reizbar. Schwäche } \\
\text { auf körp. u. geist. } \\
\text { Gebiet. Krankhaft } \\
\text { gesteigert. Ge- } \\
\text { schlechtstrieb. }\end{array}$ & Tabes dorsalis. & $\begin{array}{c}\text { Vor- } \\
\text { handen } \\
\text { aber } \\
\text { angebl. } \\
\text { nur } \\
\text { theil- } \\
\text { weise. } \\
\text { Vor- } \\
\text { hand. }\end{array}$ & $\begin{array}{l}\text { Ebenso wie in } \\
\text { Fall } 53 . \\
\\
\\
\text { Gutacht.: freie Wil- } \\
\text { lensbestimmung nur } \\
\text { beschränkt, nicht } 51 . \\
\text { Unter Annahme mild. } \\
\text { Jmst. } 1 \mathrm{~J} \text {. Gejänguiss. }\end{array}$ & Seläjer. \\
\hline $\begin{array}{l}\text { rriff den Mädchen } \\
\text { auch unter d. } \\
\text { Zöcke, wollte sie } \\
\text { zu unsittlichen } \\
\text { Jaudlungen ver- } \\
\text { leiten. }\end{array}$ & $一$ & $\begin{array}{c}\text { Neurasthenie und } \\
\text { nerv. Belastung, } \\
\text { aber obne Zwangs- } \\
\text { vorstellungen, } \\
\text { Angstgefühle. }\end{array}$ & $\begin{array}{l}\text { Neurasthenisebe Be- } \\
\text { schwerden. }\end{array}$ & $\begin{array}{l}\text { Angeb- } \\
\text { lichnur } \\
\text { theil- } \\
\text { weise } \\
\text { vor- } \\
\text { hand. }\end{array}$ & $\begin{array}{l}\text { Unter Beruicksichtig. } \\
\text { s. Zustandes: } 3 \mathrm{~J} \text {. } \\
\text { Gefängniss. }\end{array}$ & $\begin{array}{l}\text { Pollitz. } \\
\text {. }\end{array}$ \\
\hline $\begin{array}{l}\text { - } \\
\text { Iriff bald darauf } \\
\text { ung. Mädch. auf } \\
\text { d. Strasse unter } \\
\text { d. Röcke. }\end{array}$ & - & $\begin{array}{c}\text { Alkoholismus } \\
\text { chronic. } \\
\text { Pathologischer } \\
\text { Rauschzustand. }\end{array}$ & - & Fehlt. & $?$ & $\left\{\begin{array}{l}\text { Pelanda. } \\
\text { Fall VI } \\
\text { dieser Arb. }\end{array}\right.$ \\
\hline- & - & $\begin{array}{l}\text { (Frühere Epil.). } \\
\text { Betrunhenheit. }\end{array}$ & $\begin{array}{c}\text { Bedroht seine Frau m. } \\
\text { dem Messer. }\end{array}$ & $\begin{array}{l}\text { Fehlt } \\
\text { in fast } \\
\text { allen } \\
\text { Fällen. }\end{array}$ & Wehrfach verurtheilt. & $\left\{\begin{array}{c}\text { Fall IV } \\
\text { dieser Arb. }\end{array}\right.$ \\
\hline $\begin{array}{l}\text { Nird sex. stark } \\
\text { rregt dureh den } \\
\text { tublick weiblich. } \\
\text { Naden u. Brüste, } \\
\text { iebtd. Berünung } \\
\text { reibl. Genit. mit } \\
\text { d. Munde. } \\
\text { Vurde auch geg. } \\
\text { länner erotisch. } \\
\text { Vünschte „suc- } \\
\text { cion buccale". }\end{array}$ & 一 & $\begin{array}{l}\text { Geistig.Schwäche- } \\
\text { zustund. Epilepti- } \\
\text { sche Anlage. De- } \\
\text { lict i. patholog. } \\
\text { Rauschzustand. } \\
\text { Alkoh. Erregungs- } \\
\text { zustand (nmania- } \\
\text { cal. Anfall"). }\end{array}$ & $\begin{array}{l}\text { Hat verschied. körp. } \\
\text { Erkrankungen durch- } \\
\text { gemacht. }\end{array}$ & - $\begin{array}{c}\text { Sehr } \\
\text { man- } \\
\text { gelhaft }\end{array}$ & F'reisprechung. & $\begin{array}{l}\text { Siemer- } \\
\text { ling. } \\
\\
\text { Lalanne. }\end{array}$ \\
\hline- & -- & $\begin{array}{c}\text { Verfolgungsideen } \\
\text { u. Hallucinationen } \\
\text { Paranoia? }\end{array}$ & $\begin{array}{c}\text { Körperliche Degene- } \\
\text { rationszeichen. } \\
\text { Schwachsinn. }\end{array}$ & $\leftarrow$ & - & Lalanne. \\
\hline
\end{tabular}




\begin{tabular}{|c|c|c|c|c|c|c|c|c|}
\hline$\dot{8}$ & 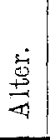 & $\left|\begin{array}{c}\text { Stand und } \\
\text { Ge- } \\
\text { schlecht. }\end{array}\right|$ & $\begin{array}{c}\text { Here- } \\
\text { ditäre } \\
\text { Belastung. }\end{array}$ & $\begin{array}{l}\text { Neuro- und psycho- } \\
\text { pathische Disposition. }\end{array}$ & $\mid \begin{array}{c}\text { Masturb. } \\
\text { ausserhalb } \\
\text { der Exhi- } \\
\text { bition. }\end{array}$ & $\left|\begin{array}{c}\text { Ver- } \\
\text { hei- } \\
\text { rathet? }\end{array}\right|$ & 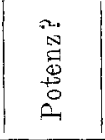 & Art der Exhibitionen. \\
\hline 64 & 56 & $\begin{array}{l}\text { Privatier } \\
\text { (Kauf- } \\
\text { mann). } \\
\end{array}$ & - & $\begin{array}{c}\text { Von jeher hypochon- } \\
\text { drisch und nervös. }\end{array}$ & - & Ledig. & - & $\begin{array}{l}\text { Entblösste s. Genit. täglich } \\
\text { um } 5 \text { Uhr an der Thüreclie } \\
\text { e. Mäddhenpensionats, went } \\
\text { die Mädchen herauskamen } \\
\text { Entblösste an einem öffent } \\
\text { lichen Platze vor kl. Mäd } \\
\text { chen seine Genitalien. }\end{array}$ \\
\hline 65 & $\begin{array}{l}\text { ca. } \\
32\end{array}$ & Bergmann. & $\begin{array}{l}\text { Angeblich } \\
\text { nicht. }\end{array}$ & $\begin{array}{l}\text { Früherer Alkohol- } \\
\text { missbrauch. }\end{array}$ & $\begin{array}{c}\text { Seit dem } \\
7 . \text { Jahre } \\
\text { sehr viel, } \\
\text { auch in d. } \\
\text { Ehe. }\end{array}$ & Verh. & 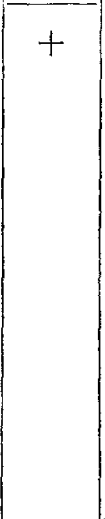 & $\begin{array}{l}\text { 1885: Hat vor jung. Frauens. } \\
\text { persenen s. erigirt. Penis } \\
\text { demonstrirt. } 1890: \text { Dieselb. } \\
\text { Handlungen i. } 9 \text { naebgewie- } \\
\text { senen Fällen vor Häusern } \\
\text { i. denen er eine weibl. Per. } \\
\text { son bemerkte, oder wenn er } \\
\text { solehen begegnete. } 1895: \text { Ir } \\
\text { d. letzt. } 3 \text { J. . } 23 \text { Fällen } \\
\text { dieselbe That am hellen Tą } \\
\text { vor Fenstern, hinter dener } \\
\text { er Mädch. sah; hat zuweiler } \\
\text { auch ans Fenster geklopit } \\
\text { oder ist d. weibl. Pers. au } \\
\text { der Strasse nachgelaufer } \\
\text { u. suchte sie anzubalten. }\end{array}$ \\
\hline 66 & ca. & Studios. & $\underset{\text { Stark }}{+}+\underset{\text { belastet. }}{c}$ & $\begin{array}{c}\text { Auffallende Charak- } \\
\text { terentwickl., verbum- } \\
\text { melt, willenssehwach, } \\
\text { erregbar. }\end{array}$ & $\begin{array}{l}\text { Seit dem } \\
\text { 12. Jahre. }\end{array}$ & - & - & $\begin{array}{l}\text { Entblösste s. Gesäss u. d } \\
\text { Genital. i. Gegenwart vor } \\
\text { Frauen u. Mädchen. Lie } \\
\text { viel auf d. Strasse mit ganz } \\
\text { oder halbentblössten Ge- } \\
\text { schlechtstheil. herum. Theil } \\
\text { weise dabei Onanie. }\end{array}$ \\
\hline 67 & 42 & Schlosser. & + & $\begin{array}{l}\text { Stets sehr sinnlich } \\
\text { veranlagt und sex. } \\
\text { perverse Neigungen. }\end{array}$ & + & Verh. & 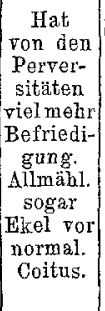 & $\begin{array}{l}\text { Schon vor } 12 \mathrm{~J} \text {. in } 15 \text { Häller } \\
\text { Entblössung s. Genit. vo } \\
\text { kl. Mädch. Jetzt dieselb. } \\
\text { Handlg. unter obscönen Re } \\
\text { densarten, kurz naebhe } \\
\text { Wiederbolung vor eineman an } \\
\text { deren Mädchen. Befriedigt, } \\
\text { seit Jahren seinen starl } \\
\text { sex. Drang so gut wie aus } \\
\text { schliesslich in Exhib. }\end{array}$ \\
\hline 68 & 30 & $\begin{array}{l}\text { Wein- } \\
\text { händler. }\end{array}$ & - & \begin{tabular}{|c|} 
Krankhafte Schlaf- \\
attaquen während d. \\
Arbeit, sonst nichts \\
epil.
\end{tabular} & - & Ledig. & - & $\begin{array}{l}\text { Zeigt sich fast tägl. halb } \\
\text { nackt z. selben Zeit an } \\
\text { Fenster einer Nachbarii } \\
\text { Monirt flieht er, auf de } \\
\text { Flucht exhib. er s. Geni- } \\
\text { einem Kinde, sprachlos. }\end{array}$ \\
\hline 69 & 23 & Stud. med. & t & $\begin{array}{l}\text { Von Jugend auf ner- } \\
\text { rös, zu Krämpfen u. } \\
\text { Ohnm. gen., moment. } \\
\text { "Erstarrung bei Ta- } \\
\text { del. Schlaff, weich- } \\
\text { lich, reizbar. }\end{array}$ & + & - & $\begin{array}{l}\text { Nie } \\
\text { Coit. }\end{array}$ & $\begin{array}{l}\text { Wiederholtes u. offentl. Zei } \\
\text { gen d. Genit. vor Mädd } \\
\text { am hell. Tage, ohne ei } \\
\text { Wort zu reden. }\end{array}$ \\
\hline
\end{tabular}




\begin{tabular}{|c|c|c|c|c|c|c|}
\hline $\begin{array}{c}\text { Andere Perver- } \\
\text { sitäten? }\end{array}$ & $\begin{array}{l}\text { Sonst. } \\
\text { Moral- } \\
\text { lität. }\end{array}$ & $\begin{array}{l}\text { Grundlage der } \\
\text { Exhibitionen. }\end{array}$ & $\begin{array}{c}\text { Andere krankhafte } \\
\text { Erscheinungen. }\end{array}$ & 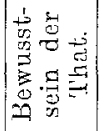 & $\begin{array}{l}\text { Forensischer Aus- } \\
\text { gang ete. }\end{array}$ & Autor. \\
\hline- & $\begin{array}{l}\text { Cor- } \\
\text { rest. }\end{array}$ & $\begin{array}{c}\text { Wurde bald darauf } \\
\text { unbeilbar geistes- } \\
\text { krank. } \\
\text { Senium? }\end{array}$ & $\begin{array}{l}- \\
\text { Hypochondr. - molan- } \\
\text { chol. Geistesstörg. }\end{array}$ & $\begin{array}{c}\text { Fehlt } \\
\text { angebl. }\end{array}$ & $\begin{array}{c}\text { Einige Wochen Get. } \\
\text { Unbekannt. }\end{array}$ & $\begin{array}{l}\text { Fall VII } \\
\text { dieser } A r b .\end{array}$ \\
\hline - & Gut. & $\begin{array}{l}\text { Keine besondere } \\
\text { brankhafte Ur- } \\
\text { sache. Tmpulsion. }\end{array}$ & $\begin{array}{l}\text { Geringe neurasthen. } \\
\text { Syrmptome. }\end{array}$ & $\begin{array}{l}\text { Vor- } \\
\text { hand. } \\
\text {. }\end{array}$ & $\begin{array}{c}\text { 1885: } 1 \mathrm{~J} \text {. Gef. } \\
\text { 1890: } 1 \mathrm{~J} \mathrm{~J} \text {. Gef. } \\
\text { 1895:? } \\
\text { Autor plaidirt für ver- } \\
\text { minderte Zurech- } \\
\text { nungsfähigkeit. }\end{array}$ & Schäfer. \\
\hline $\begin{array}{l}\text { Geschlechtl. Reiz } \\
\text { durch Stich ins } \\
\text { Gesäss u. ähnl. }\end{array}$ & Defect. & $\begin{array}{c}\text { Schwäche des Cen- } \\
\text { tralnerven- } \\
\text { systems. Nicht } \\
\text { geisteskrank. }\end{array}$ & - & $\begin{array}{c}\text { Vor- } \\
\text { hand. }\end{array}$ & $\begin{array}{l}\text { Gutachten: Freie Wil- } \\
\text { lensbest. nur be- } \\
\text { schränt, nicht auf- } \\
\text { gehoben (nicht } \$ 51 \text { ). } \\
\text { Annahme mild. Umst. } \\
1 \text { J. Gef. }\end{array}$ & Schäfer. \\
\hline $\begin{array}{l}\text { Berübrung d. Ge- } \\
\text { nit. ron Mädchen. }\end{array}$ & - & $\begin{array}{c}\text { Perverser Ge- } \\
\text { schlechtstrieb, } \\
\text { vielleicht auf he- } \\
\text { redit. Grundlage. } \\
\text { Nicht geistes- } \\
\text { brant. }\end{array}$ & $\begin{array}{c}\text { Nur neurasthenische } \\
\text { Zeichen. }\end{array}$ & $\begin{array}{c}\text { Vor- } \\
\text { hand. }\end{array}$ & $\begin{array}{c}\text { Vor } 12 \mathrm{~J} \text {. auf d. } \\
\text { Gnadenweg theilweis. } \\
\text { Erlass d. Strafe. dies- } \\
\text { mal Verurtheilg. unt. } \\
\text { Annahme mild. Um- } \\
\text { stände. }\end{array}$ & $\begin{array}{l}\text { Siemer- } \\
\text { ling. }\end{array}$ \\
\hline- & Gut. & $\begin{array}{l}\text { Unwiderstehlicher } \\
\text { Trieb. }\end{array}$ & - & $\begin{array}{l}\text { Vor- } \\
\text { hand. }\end{array}$ & $\begin{array}{c}2 \text { Mon. Gef. nach be- } \\
\text { endet. Strafe dieselb. } \\
\text { Handlg., neue Ver- } \\
\text { haftung. }\end{array}$ & Las ègue. \\
\hline $\begin{array}{l}\text { Zuweilen verfolgte } \\
\text { er die Mädchen, } \\
\text { drängte sich an sie } \\
\text { und beschmutzte } \\
\text { sie mit Urin. }\end{array}$ & $\begin{array}{c}\text { Sehr } \\
\text { decent. }\end{array}$ & $\begin{array}{l}\text { Peinigende und } \\
\text { excessive ge- } \\
\text { schlechti: Erre- } \\
\text { gungen. }\end{array}$ & $\begin{array}{c}\text { Lungenkrank, zeitw. } \\
\text { Verdauungsstörgn., } \\
\text { obstipat., Schwindel, } \\
\text { excess. sex. Erregung, } \\
\text { zeitweise melanchol. } \\
\text { Zwangshandlungen. }\end{array}$ & $\begin{array}{c}\text { Vor- } \\
\text { hand. }\end{array}$ & $\begin{array}{l}\text { Annahme d. Aufhe- } \\
\text { bung d. freien Wil- } \\
\text { lensbestimmung. }\end{array}$ & Arndt. \\
\hline
\end{tabular}




\begin{tabular}{|c|c|c|c|c|c|c|}
\hline $\begin{array}{c}\text { Andere Perver- } \\
\text { sitäten? }\end{array}$ & $\begin{array}{l}\text { Sonst. } \\
\text { Mora- } \\
\text { lität. }\end{array}$ & $\begin{array}{l}\text { Grundlage der } \\
\text { Exhibitionen. }\end{array}$ & $\begin{array}{l}\text { Andere krankhafte } \\
\text { Erscheinungen. }\end{array}$ & 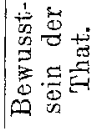 & $\begin{array}{l}\text { Forensischer Aus- } \\
\text { gang etc. }\end{array}$ & Autor. \\
\hline $\begin{array}{l}\text { Taschentuchfeti- } \\
\text { schist. }\end{array}$ & - & $\begin{array}{l}\text { Sexuelle Perver- } \\
\text { sion ohne Geistes- } \\
\text { krankheit. Trieb. }\end{array}$ & $\begin{array}{l}\text { Seit 4-5 J. zunehm. } \\
\text { Impotenz. }\end{array}$ & $\begin{array}{l}\text { Vor- } \\
\text { hand. }\end{array}$ & $\begin{array}{c}\text { Gutachten: Verant- } \\
\text { wortlichkeit nur ver- } \\
\text { ringert, nicht aufge- } \\
\text { hoben. }\end{array}$ & $\begin{array}{l}\text { Ray- } \\
\text { neau. }\end{array}$ \\
\hline- & - & $\begin{array}{l}\text { Gesteigert. Trieb } \\
\text { mit perverser } \\
\text { Richtung. }\end{array}$ & $\begin{array}{l}\text { Epileptoide Sympt., } \\
\text { aber keine r. Epil. }\end{array}$ & $\begin{array}{l}\text { Vor- } \\
\text { hand. }\end{array}$ & $\begin{array}{c}? \\
\$ 51 \text { richt anwend- } \\
\text { bar. }\end{array}$ & $\begin{array}{l}\text { Thom - } \\
\text { sen. }\end{array}$ \\
\hline- & - & $\begin{array}{c}\text { Gesteigert. Trieb } \\
\text { mit perverser } \\
\text { Richtung. }\end{array}$ & $\begin{array}{l}\text { Nach d. letzt. That } \\
\text { starke Depression und } \\
\text { Verfolgungswahnsinn. } \\
\text { Bitdige Besserung. }\end{array}$ & $\begin{array}{l}\text { Vor- } \\
\text { hand. }\end{array}$ & $?$ & $\begin{array}{l}\text { Thom- } \\
\text { sen. }\end{array}$ \\
\hline Mutuelle Masturb. & - & $\begin{array}{l}\text { Unwidersteblicher } \\
\text { Drang. Epil. An- } \\
\text { lage. }\end{array}$ & $\begin{array}{l}\text { Heruntergekommener } \\
\text { Ernährungszustand. }\end{array}$ & $\begin{array}{l}\text { Vor- } \\
\text { hand. }\end{array}$ & $\begin{array}{l}\text { Diesmal Freisprechg. } \\
\text { u. Verbringung in } \\
\text { eine Anstalt. }\end{array}$ & Nötel. \\
\hline $\begin{array}{c}\text { Früher mutuelle } \\
\text { Onanie. }\end{array}$ & Gut. & $\begin{array}{l}\text { Unwiderstehlicher } \\
\text { Drang unter Angst } \\
\text { u. Schmerzen in } \\
\text { den Hoden. } \\
\text { („Unwiderstehl. } \\
\text { Trieb"). Nicht } \\
\text { geisteskrank. }\end{array}$ & $\begin{array}{l}\text { Zur Zeit der ersten } \\
\text { Exhib.Selbstmordged, } \\
\text { pach unglückl. Erieb- } \\
\text { nissen und schlechter } \\
\text { Ernährung. } \\
-\end{array}$ & $\begin{array}{l}\text { For- } \\
\text { hand. } \\
\text { Vor- } \\
\text { hand. }\end{array}$ & $\begin{array}{l}\text { Wurde jedesmal ver- } \\
\text { urtheilt. } \\
\S 51 \text { nieht anwend- } \\
\text { bar. }\end{array}$ & Lalanne. \\
\hline $\begin{array}{l}\text { Unzucht mit ihrem } \\
18 \text { jahr. Bruder. }\end{array}$ & - & $\begin{array}{c}\text { "Folie raison- } \\
\text { nante. }\end{array}$ & - & - & - & $\underset{d u}{\operatorname{Leg} r a n d}$ \\
\hline- & 一 & Epilepsie. & - & Fehlt. & $\begin{array}{c}\text { Arretirt; freigelassen; } \\
\text { Anstalt: dort nooh } \\
\text { ofter Wiederhlg. dies. } \\
\text { Exhib. }\end{array}$ & A.Vois \\
\hline - & - & Epilepsie? & - & - & - & Garnier. \\
\hline - & - & Paranoia. & - & - & - & $\begin{array}{l}\text { v. Krafft- } \\
\text { Ebing. }\end{array}$ \\
\hline
\end{tabular}




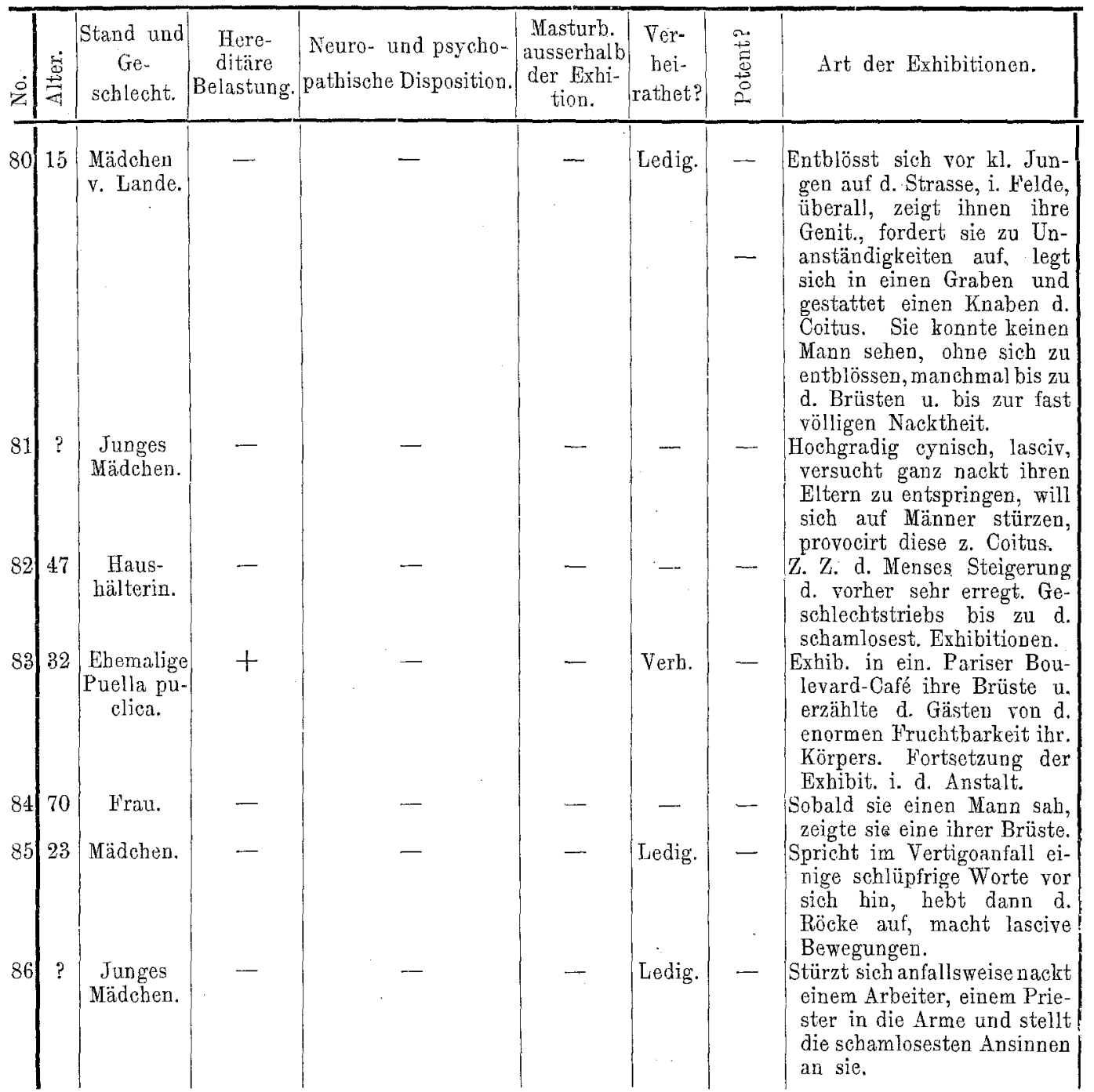

Es sind also im Ganzen 75 Fälle von Exhibitionismus beim Manne, wovon 18 auf die Epileptiker entfallen, 17 auf die Dementen, 13 auf die Degenerirten, 8 anf die Neurasthenischen, 8 auf die Alkoholiker etc. und 11 anf die Gewohnheitsmässigen.

Die in den Rubriken gemachten Angaben über die Epileptiker genügen gerade zu einer oberflächlichen Orientirung; Genaueres über die Erscheinungsweise der Krankheit und die Beziehungen der Exhibi- 
Ueber Exhibitionismus.

\begin{tabular}{|c|c|c|c|c|c|c|}
\hline $\begin{array}{c}\text { Andere Perver- } \\
\text { sitäten? }\end{array}$ & $\begin{array}{l}\text { Sonst. } \\
\text { Mora- } \\
\text { lität. }\end{array}$ & $\begin{array}{l}\text { Grundlage der } \\
\text { Exhibitionen. }\end{array}$ & $\begin{array}{c}\text { Andere krankhafte } \\
\text { Erscheinungen. }\end{array}$ & 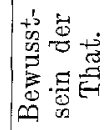 & $\begin{array}{l}\text { Forensischer Aus- } \\
\text { gang ete. }\end{array}$ & Autor. \\
\hline - & - & $\begin{array}{c}\text { "Nymphomanie" } \\
\text { (nach d. Krkg. } \\
\text { Imbecillität?) }\end{array}$ & - & $\begin{array}{l}\text { Vor- } \\
\text { hand. }\end{array}$ & $\begin{array}{l}\text { Wurde in ein Correc- } \\
\text { tionshaus gebracht! }\end{array}$ & Tardieu \\
\hline- & - & - & - & - & - & Moreau. \\
\hline- & - & $\begin{array}{l}\text { Melancholie mit } \\
\text { Stupor" ? }\end{array}$ & - & - & - & Lalanne \\
\hline- & - & $\begin{array}{c}\text { Progressive Para- } \\
\text { lyse. }\end{array}$ & - & - & - & $\begin{array}{l}\text { Maran- } \\
\text { donde } \\
\text { Montyel }\end{array}$ \\
\hline- & - & Demenz. & - & - & - & Lalanne \\
\hline - & $\begin{array}{l}\text { Streng } \\
\text { sitt- } \\
\text { lich. }\end{array}$ & Epilepsie. & - & - & - & Simon. \\
\hline- & -- & Hysterie. & - & - & - & $\begin{array}{l}\text { Louyer- } \\
\text { Viller- } \\
\text { may. }\end{array}$ \\
\hline
\end{tabular}

tionen zu dieser war oft nicht zu eruiren. Es wäre daher zwecklos, vergleichende Betrachtungen über die einzelnen Fäle anzustellen; die klinische Seite der epileptischen Geistesstörungen ist sebr ausführlich in Specialwerken abgehandelt und bezüglich des Exhibitionismus bei Epilepsie verweise ich auf die Arbeit von Pribat'1). Nur soviel möchte ich hervorheben, dass die Epileptiker fast den 4. Theil aller

1) Pribat, De l'exhibition chez les épileptiques. Thèse de Paris 1894. 
Delinquenten bilden, von denen ich in der Literatur berichtet fand. In dieser Ueberzahl zeigt sich ungefähr ihre forensische Wichtigkeit. Sie hatten fast alle gar keine oder eine mehr weniger partielle Erinnerung ihrer Thaten, wemn man den vorhandenen Angaben Glauben schenkt; nur bei zweien, deren Epilepsie zweifelhaft war, war das Bewusstsein vorhanden; bei 3 derselben fand ich darüber keinen Vermerk. Man sieht ferner, wie häufig epileptoide Zustände, Aequivalente als hauptsächliche Aeusserung der Epilepsie zur Erklärung der Exhibitionen herangezogen werden mussten, wie gerade die geschlechtlichen Verirrungen in diesen Zuständen mit "photographischer Treue"* immer wiederkehrten. Von Interesse ist es auch, dass sich unter den 18 epileptischen Exhibitionisten 2 fanden, die beim Militär desertirten. Anf dieses Zusammenvorkommen von Entweichungstrieb (automatisme ambulatoire, attaques procursives) mit perversen Instincten hat auch Féré in seinen "Epilepsies" hingewiesen. - Es bedarf keiner besonderen Betonung, dass die Exhibitionen der Epileptiker nach der eigentlichen Bedeutung des Wortes als solche sehr oft nicht rein sind, sie können sich, wie man sieht, mit öffentlicher Masturbation, Urinentleerung und anderen Unsittlichkeiten verbinden; dies erklärt sich durch den besonderen Bewusstseinszustand der Kranken. Die That ist häufig nul eine ganz zufällige, es ist ihr auf die Stirn geschrieben, dass eine Absicht, gesehen zu werden, nicht vorgelegen hat, sie entsteht automatisch bei Menschen, die in der normalen $Z$ wischenzeit sexuell ganz indifferent und oft streng moralisch veranlagt sind. Sie kann aber in anderen Fällen auch den wahren Kern eines Menschen ans Tageslicht fördern, indem ein von Jugend auf gesteigerter oder perverser Geschlechtstrieb durch irgend eine Störung des Bewusstseins sich zügellos bethätigt.

Für die Dementen bedarf es keiner besonderen Besprechung. Zum grösseren Theil lag bei ihnen erworbener, zum kleineren Theil angeborener Schwachsinn vor.

Zu den entarteten Exhibitionisten im Sinne Magnan's habe ich einige Fälle gerechnet, die von den betreffenden Autoren nicht ausdrücklich als solche bezeichnet wurden, die aber doch nach allem, was man von ihnen weiss, hier besser als in einer anderen Gruppe untergebracht sind. Ein ernsterer Zweifel hierüber existirt nur in Betreff des zuletzt aufgeführten Falles No. 48 von Kölle: derselbe bot zwar reichliche Zeichen psychischer Degeneration, aber das Magnan'sche Kriterium, ein unüberwindlicher $Z_{w}$ ang zu den Exhibitionen, verbunden mit Angst und unangenehmen körperlichen Empfindungen und nachheriger Erleichterung, war bei ihm - wie übrigens auch bei einigen anderen sicher Degenerirten nicht nachweisbar. Mlan könnte ihn daher auch zu den zweekbewussten 
und gewohnheitsmässigen Exhibitionisten rechnen. Der schwierigen Frage der Zurechntungsfähigkeit ist hiermit natürlich nicht vorgegriffen. Jedenfalls aber ist daraus wieder zu ersehen, dass zwischen den einzelnen Formen ein fliessender Vebergang besteht. Der Sachverständige führte aus, dass bei dem Delinquenten die Fähigkeit der Selbstbestimmung vermindert aber nicht aufgehoben sei; dementsprechend urtheilte das Gericht. Ans anderen Gründen war bei Fall 42 und 43 Verurtheilung: erfolgt; im letzteren sind sie aus der betreffenden Mittheilung nicht ersichtlich; im ersteren von Lasègue beschriebenen giebt der Autor an, dass er damals noch zu wenig Erfahrung in diesen Dingen gehabt habe, um die Unverantwortlichkeit zu exkennen. In 3 Fällen fehlt eine Notiz über den forensischen Ausgang, in den 7 anderen wurde der Angeklagte freigesprochen, resp. in einem (Fall 44) in die Irrenanstalt verbracht. Dieser letztere Fall zeichnet sich auch noch dadurch aus, dass der Betreffende bereits 6 mal aus demselben Grunde, unter anderem zu sehr schwerer Strafe verurtheilt worden war, dass er vor seiner letzten Bestrafung rom Arzt für ganz normal erklärt wurde und immer wieder von Neuem exhibitionirte. Er war stark neuropathisch veranlagt, degenerirt, in der Jugend lange epileptisch, belastet und stammte von einem Vater, der dieselben unzüchtigen Handlungen begangen haben soll wie er. Mehrfachen Exhibitionismus bei verschiedenen Mitgliedern derselben Familie finden wir übrigens auch in Fall 20. Hier in Fall 44 war noch das Zusammentreffen zweier Umstände merkw ürdig, welche für die Entstehung der perversen Geschlechtsrichtung von Wichtigkeit waren. Dieselbe manifestirte sich zur gleichen Zeit, wo die epileptischen Krampfanfülle verschwanden, und sie scheint ihren Ausgang genommen zu haben von dem ganz zufälljgen, aber angenehm empfundenen Erlebniss des neugierigen Zuschauens von Kindern, als der Mann urinirte. Während ich zu dem ersteren Punkt (ausser meinem Fall IV) in der Literatur keine Analogien gefunden habe, ist dies bei dem letzteren gelungen und ich werde später noch darauf zurïckkommen. Zum Unterschiede von den Epileptikern ist es für die Degenerirten charakteristisch, dass, soweit Angaben darüber vorhanden sind, in der Mehrzahl der Fälle das Bewusstsein der That vorhanden war, nämlich in 8 von 13 Fällen; in einem wurde geleugnet, in 4 fehlen Angaben daräber. Die neuropathischen Symptome, die Belastung, die Masturbation und der deutliche Zweck, vor weiblichen Personen, besonders vor Kindern zu exhibiren, treten bei dieser Gruppe in den Vordergrund. Auf die sonstige Moralität und auf die Frage nach auderen Perversitäten lassen sich keine besonderen Schlüsse ziehen. Das Alter dieser Exhibitionisten bowegte sich zwischen 15 und 49 Jahren, im Durchschnitt betrug es 30 . 
Während es nach den bisherigen casuistischen Veröffentlichungen nicht schwer war, ungefähr 13 Fälle degenerirter Exhibitionisten zuzusammenzustellen, so liess sich für die von v. Krafft-Ebing eingeführte Gruppe der Neurastheniker wenig reines Material auffinden. Nur indem mas den Verbältnissen Gewalt anthut, bringt man 8 Fälle zusammen, bei denen die Neurasthenie eine grössere Rolle spielt. Daron sind aber allein 3 mit epileptischen Elementen vermischt (Fall 52, 53 und 54), einer wird durch die Combination mit Tabes dorsalis getrïbt (55), zwei könnte man ebenso gut oder vielleicht noch besser zu den Degenerirten rechnen (49 und 50) und der letzte Fall (56) macht sehr den Findruck eines zweckbewussten, gewohnheitsmässigen, wenn auch neuropathischen Liebhabers von Perversitäten. Der einzige reine Fall, den ich gefunden habe, ist der von $\mathrm{v}$. Krafft-E bing selbst mitgetheilte. Dadurch fehlt die Grundlage für eine vergleichende Würdigung dieser Fälle und ilrer Eigenthümlichkeiten. Der demonstrative Zweck der Delinquenten liegt überall klar zu Tage.

Ueber die Exhibitionen der Alkoliolisten und der Psychosen im engeren Sinne bedarf es nur weniger Worte. Die in dieses Gebiet gehörenden Fälle sind wegen ihrer geringen Zahl in der Tabelle zusammen aufgeführt; vielleicht wäre besser von den Psychosen überhaupt Abstand genommen worden; sie sind nur cler Vollständigkeit wegen mit hereingenommen. Selbstverständlich kommen bei Maniakalisehen, Paranoischen und bei Hallucinanten jeder Art Exhibitionen viel häufiger vor, als man hiornach den Eindruck bekommen könnte. Dieselben passiren aber meist innerhalb der Anstaltsmauern oder des Krankenzimmers, sie verletzen nicht die "öfentliche" Siittlichkeit und bieten daher ein viel geringeres Interesse. Was die Melancholie und die Hypochondrie betrifft, so bietet der bei ihnen vorherrschende Geisteszustand für Exhibitionen im Allgemeinen keinen günstigen Boden. Wenn trotzdem Bassenge in seiner Dissertation 4 Fälle von Exhibitionismus bei diesen depressiven Psychosen gefunden zu haben glaubte, so kann ich das zum Theil nur auf eine verschiedene Definition dieser Krankheitsbegriffe zurückführen. Seine Fälle sind die auch in meiner Tabelle unter No. 33, 50, 52 und 63 aufgefülurten. Der Repräsentant des Falles 33 litt an „hypochondrischer Melancholie mit Uebergang in Blödsinn"; ich habe ihn daher unter die Dementen gerechnet; derjenige des Falles 50 musste nach delı vorhandenen Angaben eher als neurasthenisch bezeichnet werden; ebenso verhielt es sich mit Fall 52, bei dem von anderer Seite sogar eine epileptische Basis vermuthet wurde. In Fall 63 endlich entwickelte sich bald nach der That eine unheilbare Geisteskrankheit, deren Art Lasègue nicht näher hezeichnet hat. 
Wir kommen nun zu der wichtigen Gruppe der gewohnheitsmässigen Exhibitionisten. Die Beurtheilung jedes einzelnen Delinquenten macht hier ebenso grosse Schwierigkeiten, wie der Versuch, der ganzen Gruppe eine auch nur annähernde Grenze zu ziehen. Man findet hier nicht nur zahlreiche Uebergänge zu jeder der vorher beschriebenen krankhaften Formen des Exhibitionismus, sondern auch bei ein und demselben Menschen die verschiedensten pathologischen Ingredienzien, die man trotz alledem nicht im Sinne des $\S 51$ verwerthen darf. Das Pathologische kann auch ganz fehlen; der Betreffende handelt dann, indem er einem Triebe folgt, der zwar an sich abnorm aber nicht krankhaft ist. In anderen fällen ist es derselbe Trieb, den man wegen seiner Stärke oder wegen des Mangels genügender Hemmungen, oder aus anderen Gründen bereits als krankhaft bezeichnen müsste, ohne doch von einer krankhaften Störung der Geistesthätigkeit im Sinne des Gesetzes, von einer Aufhebung der freien Willensbestimmung sprechen zu können. Dies beweisen besonders die in den letzten Jahren veröffentlichten Fälle von Schäfer, Siemerling, Thomsen, Rayneau und Hoche (s. Tabelle). - Insere Gruppe umfasst 11 Fälle. Davon könnte man vielleicht die Fälle $69,71,73$ und 74 zur Klasse der Degenerirten rechnen, indem sie wie diese unter lobhafter Impulsion und theilweise unter unangenehmen körperlichen Empfindungen gehandelt haben; es fehlen ihnen aber doch diese oder jene Züge zum vollen Bilde des typischen Entarteten. Es ist also ein Nothbelf, wenn sie unter diese Gruppe gestellt sind. In Fall 71 und 73 sind epileptoide Symptome angegeben, die aber nur untergeordnete Bedeutung haben. Masturbation und neuropathische Veranlagung sind ziemlich stark vertreten, erstere ist in 10, letztere in 8 Fällen notirt. Bei einigen sind auch andere Perversitäten mitgetheilt; mehrfach bestand Abneigung gegen den normalen Gescblechtsverkebr; 4 sind erblich belastet, 2 nicht, bei den 5 übrigen fehlt eine Angabe hierüber. Vier von ihnen waren Studirende. Der Rayneau'sche Delinquent war 70 Jahre alt, ohne jegliche Spur einer Geisteskrankheit; wenn man daher im Allgemeinen geneigt ist, bei exhibitionirenden Greisen eine senile Demenz vorauszusetzen, so lehrt dieser Fall, dass auch hier Vorsicht geboten ist. In 8 Füllen lagen die Verhältnisse so, dass eine Bestrafung des Angeklagten eintreten komnte; bei diesen plaidirte das Gutachten 4 mal für "verminderte Zurechnungsfähigkeit." In 3 der anderen Fälle fehlt einmal eine diesbezügliche Angabe, einmal (73) trat Freisprechung und Verbringung in eine Irrenanstalt ein (olne dass in der mif zur Verfügung stehenden Mittheilung über den Fall eine Geisteskrankheit bewiesen ist), und im letzten Fall (69), der allerdings 
den Degenerirten am nächsten stebt, wurde der Angeklagte ebenfalls freigesprochen. Bei dem interessanten Siemerling'schen Fall (67) ist noch besonders hervorzuheben, dass der 42 jährige Mann mit 24 Jahren beim Uriniren geschlechtlich anfgeregt wurde, als ein Mädchen dabei seine Genitalien anblickte (cf. Fall 44) und dass er seitdem die Gelegenheit suchte, zunächst beim Uriniren, später aber bei jeder denkbaren Gelegenheit seine Geschlechtstheile vor Mädchen zu entblössen. Ausserdem ist es interessant, dass er Nachts im Traum exhibirte und dadurch Pollutionen bekam.

Nun noch einige Worte über den Exhibitionismus bei Frauen. ఛ. Krafft-Ebing sagt in der letzten Auflage seiner "Psychopathia sexualis", die bisherige Casuistik weise ausschliesslich Männer auf, obwohl er an anderer Stelle von den schamlosen Exhibitionen mancher geisteskranken Frauen spricht. Wie man aus der Tabelle ersieht, lassen sich allerdings in der Literatur einige Falle auffinden. Dieselben sind freilich nur spärlich, beweisen aber doch, was von vornherein zu erwarten war, dass die geisteskranke Frau die öffentliche Sittlichkeit ebenso verletzen kann wie der geisteskranke Mann. Ich habe 11 Fälle zusammengestellt, bin aber im Zweifel, ob nicht Fall 77 und 78 , obwohl von 2 verschiedenen Autoren erwähnt, identisch sind. Es bestand überall eine manifeste Geisteskrankheit (das Mädchen in Fall 80 war höchstwahrscheinlich schwachsinnig, Fall 81 ist obne Angabe), wobei ich selbstverständlich Epilepsie und Hysterie auch als solche bezeichne. In 6 Fällen handelt es sich um Exhibition der Brüste, in 2 Fällen sucht sich das Individuum nackt auf sein Opfer zu stürzen, und nur in Fall 80 und 85 findet eine Exhibition in jenem engeren Sinne statt, wie sie beim Manne das gewöbnliche ist. Die zweckbewusste, gewohnheitsmässige Form scheint also beim Weibe nie beschrieben worden zu sein und auch nicht vorzukommen. Aber auch auf Grund wirklicher Geistesstörungen scheint der Exhibitionismus bei Frauen relativ selten zur Beobachtung zu kommen. Man führt dies zurïck anf die eigenartige Stellung, welche die Frau bei der heutigen Kultur in der Gesellschaft einnimmt und welche im Laufe der Generationen einen bestimmten Einfluss auf die Erregharkeit gewisser Centren und die Hemmungsfähigkeit gewisser Triebe ausgeübt haben soll. Immerhin werden bei maniakalischen, hysterischen und epileptischen Frauen, sowie bei manchen menstruellen Erregungszuständen Exhibitionen oft genug vorkommen, nur dass sie fast nie eine forensische Bedeutung erlangen. 
Ueberblicken wir die bisherigen Mittheilungen kurz noch einmal, so finden wir bei den Exhibitionisten eine auffallende Gleichartigkeit ihrer Handlungen. Fast immer sind es die Genitalien oder deren Gegend, welche entblösst werden, höchst selten sind es andere für obscön geltende Theile. Dehnt man auch auf letztere Fälle den Begriff des Exhibitionismus ans, so hat man sich zu erinnern, dass sie fast nie zu einer praktisch-forensisehen Bedeutung gelangen und dass es daher schon aus diesem Grunde unnöthig ist, den Exhibitionismus nach Körpergegenden einzutheilen, wie es von Lalanne vorgeschlagen wurde. Man könnte dann ebenso gut den Diebstahl nach den gestuhlenen Gegenständen classificiren. Es ist aber oft genug und von den meisten Autoren betont worden, dass es für uns nicht auf die Qualität des Delicts, sondern auf den Geisteszustand des Delinquenten ankommt. Je nach dem Boden, auf dem die Perversität entstanden ist, verbinden sich mit der Exhibition noch andere unsittliche Akte (öfentliches Uriniren, Masturbation u. a.). Dies ist indessen seltener. Von den sog. "Frotteurs" habe ich hier abgesehen, da nur wenige Fälle bekannt sind und es ihnen offenbar weniger auf eine Exhibition als auf die Befriedigung masturbatorischer oder fetischistischer Triebe ankommt.

Wir finden den Exhibitionismus in allen Gesellschaftsklassen, bei jeder Altersstufe von der Pubertät bis zum Greisenalter, bei Frauen aber, wenigstens vor dem Forum des Gerichts, sehr selten.

Was die neuerdings von Pelanda wieder betonten Anomalien der Geschlechtsorgane bei Exhibitionisten betrifft, so habe ich Angaben hierüber bei 2 Epileptikern, 3 Degenerirten, 1 Dementen und 1 Neurastheniker gefunden. Ich glaube aber nur insoweit an einen Zusammenhang dieser Erscheinungen, als sie eben beide der Ausdruck einer gowissen Degeneration sind.

In den meisten Fiallen wird vor Kindern, kleinen Mädehen, etwas weniger, aber fast ebenso häufig vor Frauen und erwachsenen Mädchen exhibirt; dadurch bekommt das "offentliche" Aergerniss noch einen specielleren Charakter. Warum gerade Kinder mit besonderer Vorliebe ansgesucht werden, ist noch nicht ganz aufgeklärt. v. Krafft-Ebing sagt bei den Sittlichkeitsdelicten der senil Dementen im Allgemeinen, dass die leichtere Gelegenheit, an Kinder zu gerathen, und das Gefühl mangelhafter Potenz es erkläre, dass die Kinder das nächste Angriffsgebiet für die sexuelle Libido der Greise darstellen. Diese Erklärung ist für unsere Fälle nicht ganz zureichend, insofern ja anch jugendliche und im besten Mannesalter stehende, sonst völlig potente Männer mit grosser Regelmässigkeit vor kleinen Mädchen exhibirt haben. Vielmehr muss man, wio mir scheint, Folgendes in Betracht ziehen: bei der 
sexuellen Befriedigung spielen bekauntlich psychische Momente vor allem die Wahrnehmung einer gesehlechtlichen Erregung bei dem andern Theil eine grosse Rolle, und so findet der Exhibitionist, was auch Hoche hervorhebt, einen ganz besouderen Reiz mit eventueller Befriedigung darin, bei weiblichen Personen die Wirkung seiner Entblössung zu beobachten; eine noch gesteigerte Befriedigung hofft er vielleicht darin zu finden, wenn er auf seine Manier versucht, bei unentwickelten, reinen Individuen geschlechtliche Gedanken anzuregen und deren Effect zu beobachten. Die Annahme einer derartigen Berechnung bei einem grossen Theil der nicht bewusstlosen Exhibitionisten scheint mir eine Stütze zu finden in gewissen Angaben über die Entstehungsart dieser Perversität. Schon oben habe ich bei Fall 44 und 67 hervorgehoben, dass hier das zufällige Beobachtetwerden während des Urinirens durch Kinder resp. durch ein Mädchen angenehme Empfindungen hervorgerufen hat und so der Ausgangspunkt immer häufiger sich wiederbolender Exhibitionen geworden ist. Ganz ähnliche Verhältnisse kehren in dem Thomsen'schen Fall (71) wieder: Der Betreffende wurde angeblich als halbwüchsiger Mensch eines Tages von einem Dienstmädchen beim Onaniren beobachtet, welches lachte und er selbst vermuthete einen $\mathrm{Zu}$ sammenhang seines Exhibitionismus mit diesem Vorfall; es war nach seiner eigenen Ansicht wohl möglich, dass eine unklare Vorstellung, das Zuschauen Anderer beim Onaniren könnte ihm einen Genuss bereiten, ihn zu seinen letzten Delicten veranlasst habe. Thomsen ist von dieser Erklärung überzeugt und sie ist in der That sehr wahrscheinlich. In allen 3 Fällen trieb also das Wiederauftauchen einer früheren Association, die von Lustgefühlen begleitet war, zu dem perversen Acte, und zwar war das Lustgefübl durch das bei dem anderen Theile beobachtete Interesse bezw. den heiteren Affect hervorgerufen. Dies giebt mir Veranlassung, die interessante Frage der Aetiologie der sexuellen Perversitäten und damit des Exhibitionismus ganz kurz zu berühren. Diese 3 Fälle sind nämlich geeignet, die ätiologische Wichtigkeit zufälliger Ereignisse bei prädisponirten Individuen darzuthun und die von Binet für die conträre Sexualempfindung aufgestellte, von Anderen aber angefochtene Theorie der Entstehung durch Ideenassociationen zu stützen, wenigstens soweit man sie für die anderen sexuellen Perversitäten heranzieht. Nach dieser Theorie können letztere dadurch entstehen, dass durch irgend ein zufälliges, an sich unschuldiges oder geringfügiges sexuelles Erlebniss in früherem Lebensalter eine Association geschaffen wird, welche sich später wiederholt und festigt, selbständig zur Herbeiführung der ursprünglichen situation drängt und dadurch dem Vorstellungsleben eine unter Umständen perrerse Richtung giebt. 
Bekannt sind die Beispiele (v. Krafft-Ebing, Charcot und Magnan u. A.), in denen durch zufällige erstmalige geschlechtliche Erregung beim Anblick einer weissen Schürze oder eines weiblichen Unterrocks, oder bei derBerührung eines Pelzes die als „Fetischismus" bekannte Geschlechtsperversität entstand. Aber auch im reiferen Lebensalter können, wie $\mathrm{R} u$ tge ers ausführt, Erinnerungsbilder aus der Jugendzeit einen maassgebenden Einfluss auf das gesteigerte Reizbedürniss' (Reizhunger" Hoche's) gewinnen, wenn die gewölnlichen Reize nicht mehr genügen. Je nach der Art and Empfindung, welche jener ursprünglichen Association zukam, wird dann das Resultat der Associationsneubildung sein. $Z \pi$ einem derartigen Haften eines zufälligen Eindrucks ist aber eine degenerative Veranlagung, eine neuro- oder psychopathische Disposition des betreffenden Individuums nothwendig. Diese Vorbedingung traf anch in den drei kritischen Fällen zu. Thomsen hat übrigens in seinem Vortrag an diese Theorie ebenfalls erinnert und hauptsächlich der Onanie bei der Entstehung des Exhibitionismus wie anderer Perversitäten eine wichtige Rolle zugeschrieben. Er sagt von seinem Delinquenten sehr treffend: "Der N. zeigt eine frühzeitig beginnende Sexualität, er wird Onanist, ohne dass sich damit sexuelle Vorstellnngen specieller Natur rerbinden, es wird der körperliche Drang rein körperlich befriedigt. Erst durch das Lachen. des Dienstmädchens wird der psycbische Factor nebenher hineingetragen. Die Beziehung zum weiblichen Geschlecht stellt sich her, aber in läppischer Weise: nicht die Vorstellung des Geschlechtsactes, sondern die Vorstellung, beim Onaniren beobachtet zu werden, gewährt eine Steigermug der Befriedigung.".

Kommen wir nun zu unserem Ausgangspunkt wieder zurück, zur Frage nach der Verantwortlichkeit der Exhibitionisten, so müssen wir constatiren, dass thatsächlich der weitaus grösste Theil derselben in einem geistesgestörten Zustande gehandelt hat, welcher die Bestrafung ansschloss, dass es aber auch Exhibitionisten giebt, auf welche der Wortlant des $\S 51$ des R.-Str.-G. keine Anwendung finden kann. Die letzteren sind theils völlig gesund, theils fallen. sie in das Grenzgebiet zwischen geistiger Gesundheit und Krankheit, für welches das Gesetz keine Ausnahmestellung kennt. Diese Grenzfälle bilden eine Scala, welche allmälig vom Normalen zum Pathologischen hinüberleitet. Sic von den anderen zu erkennen und sie zu beurtheilen, erfordert die strengste Individualisirung und die schärfste Beobachtung.

Am Schlusse gestatte ich mir, meinem hochverehrten Chef, Herrn Geheimrath Hitzig, für gütige Ueberlassung des Materials zu dieser 
Arbeit, sowie Hern Professor Wollenberg für freundliche Unterstützung meinen ganz ergebenen Dank auszusprechen.

\section{Liter a t $\mathrm{cr}$.}

Anjel, Dieses Archiv. XV.

Arndt, Vierteljahrsschr. für gerichtliche Medicin. 1872.

Ball, La folio érotique. 1888.

Bassenge, Der Exhibitionismus und seine forensische Bedeutung. Dissert. Berlin 1895 .

Boissier et Lachaux, Archives do Neurologie. 1893.

Charcot et Magnan, Archives de Neurol. 1882.

Cramer, A., Die conträre Sexualempfindung in ihren Beziehungen zum $\S 175$

Str.-G.-B. Berliner klin. Wochenschr. 1897.

Garnier, P., La folie à Paris. 1890.

Garnior, P., Les fétichistes pervertis et invertis. Annales d'hyg. publ. 1895.

(Allgem. Zeitschr. f. Psych. Literaturber. 1895.)

Garnier, P., Un cas d'exhib. Annales méd. psychol, 1894.

Hoche, Zur Frage der forensischen Beurtheilung sexueller Vergehen. Neurol. Centralbl. 1896.

Kölle, Gerichtlich-psychiatr. Gutachten aus etc. 1896.

v. Krafft-Ebing, Psychopathia sexualis. IX. Aufl.

Derselbe, Lebrbuch der Psychiatrie. VI. Aufl. 1897.

Derselbe, Lehrbach der gerichtlichen Psychopathologie. III. Aufl. 1892.

Derselbe, Zur Erklärung der contr. Sexualempfindung. Jahrb. f. Psych. etc.

XIII. Band.

Lalanne, Les exhibitionnistes. Thèse de Paris. 1896.

Lasègue, Union médicale (Mai 1877).

Langier, Annales d'hygiène publique. 1878. No. 106. (Virchow-Hirsch's

Jahresbericht.)

Legrand du Saulle, Les hystériques etc. 1883.

Lemesle, Les irrésponsables devant la loi. Paris. 1896. (Lit.-Ber. 1896 der

Allgem. Zeitschr. f. Psych.)

L iman, Vierteljahrsschr. f. gerichtl. Med. N. F. Bd. 38.

M a gnan, Recherches sur les centres nerveux. 1893.

Moreau, La folie chez les enfants. 1888.

Morselli, Esposizione accessuale degli org. genit. come equivalente epilettoide.

Bollet. delle R. Acad, med. di Genova. 1894.

Motet, Outrage publ. à la pudeur. Ann. d'hyg. 1886. (Virch.-Hirsch).

Niesel, Sitzung des wissenschaftlichen Vereins der Aerzte zu Stettin rom

6. April 1897. (Berl. kl. W.)

Nötel, Allgem. Zeitschr. für Psychiatrie. 53. Bd. 1897.

Pelanda, Ueber Pornopathiker. Virchow-Hirsch's Jahresber. 1889. Derselbe, Ermie ed anomalie sessuali. (Neurol. Centralbl. 1896: Referat.) 
Pollitz, Vierteljahrsschr. f. gerichtl. Med. 1897.

Pribat, De l'exhibition chez les épileptiques. Thèse do Paris 1894.

Rayneau, Annales médico-psychol. Mai 1895.

Rutgers, Die Aetiologie des perversen Geschlechtstriebs. Psychiatr. Bladen.

Bd. 12. (Ref. Lit.-Ber. 1896 d. Allgem. Zeitschr. f. Psych.)

S chäfer, Vierteljahrsschr. f. gerichtl. Med. 1895.

Siemerling, Casuist. Beitr. zur forens. Psyehiatrie, Sittlichkeitsvergehen und

Geistesstörung. Nietleb. Festschr. 1897.

Strassmann, Vierteljahrsschr. f. gerichtl. Med. 1895.

T ardieu, Etude médico-légale sur les attentats aux moeurs. 1878.

Tarnowsky, Die krankhaften Erscheinungen des Geschlechissinnes. 1886.

Thomsen, Allgem. Zeitschr. f. Psych. 53. Bd. 1897.

Vallon, Rapport méd.-légal sur un attentat à la pudeur etc. Annal. méd.psych. Sér. VII. Bd. 20.

Vigouroux, Exhibitionniste condamné par les tribunaux. Annales med.psych. 1896.

Westphal, Dieses Archiv Bd. VII. 